\title{
Iron redox cycling in surface waters: effects of humic substances and light
}

\author{
A dissertation submitted to the \\ SWISS FEDERAL INSTITUTE OF TECHNOLOGY ZURICH \\ for the degree of \\ Doctor of Natural Sciences
}

\author{
presented by \\ Bettina Margrit Voelker-Bartschat \\ M.S. Civil Engineering, MIT, Cambridge (USA) \\ born May 21, 1967 \\ citizen of the Federal Republic of Germany
}

accepted on the recommendation of

Prof. Dr. René Schwarzenbach, examiner

Dr. Barbara Sulzberger, co-examiner

Prof. Dr. François Morel, co-examiner 
Wie ist das klein, womit wir ringen,

Was mit uns ringt, wie ist das groß...

Rainer Maria Rilke 


\section{Abstract}

In this work, we examine the effects of humic substances and light on the kinetics of oxidation of $\mathrm{Fe}(\mathrm{II})$, reduction of $\mathrm{Fe}(\mathrm{III})$, and reductive dissolution of an $\mathrm{Fe}$ (III) oxide.

In the dark reaction of $\mathrm{Fe}$ (II) with hydrogen peroxide (Fenton's reaction) at pH 3 and 5, several effects are observed in the presence of fulvic acid. (1) At $\mathrm{pH} 5$, the rate of $\mathrm{Fe}(\mathrm{II})$ oxidation increases with increasing fulvic acid concentration, indicating formation of $\mathrm{Fe}$ (II)-fulvate complexes that react more rapidly with hydrogen peroxide than $\mathrm{Fe}$ (II)-aquo complexes do. This effect is not observed at $\mathrm{pH} 3$. (2) In the presence of oxygen, the reaction of the $\mathrm{OH}$ radicals formed in Fenton's reaction with fulvic acid results in production of $\mathrm{HO}_{2} / \mathrm{O}_{2}^{-}$radicals, which oxidize $\mathrm{Fe}(\mathrm{II})$ and thereby regenerate hydrogen peroxide. (3) $\mathrm{Fe}(\mathrm{III})$ is reduced by a dark reaction with fulvic acid, consisting of an initial fast reduction step followed by a slower process. The fraction of total Fe(III) that is reduced by the initial fast step does not depend on the Fe(III)-to-ligand ratio. The behavior of $\mathrm{Fe}(\mathrm{II})$ and hydrogen peroxide over time in the presence of fulvic acid can be modeled if all of these processes are taken into account.

In the presence of light, fulvic acid, and lepidocrocite $(\gamma-\mathrm{FeOOH})$ particles, $\mathrm{Fe}$ (II) is formed on the surface of the iron oxide by ligand-to-metal chargetransfer reactions of surface $\mathrm{Fe}$ (III)-fulvate complexes. Detachment of the surface $\mathrm{Fe}$ (II) results in photo-reductive dissolution of the solid phase. Due to a decrease in the concentration of surface Fe(III)-fulvate complexes with increasing $\mathrm{pH}$, a smaller rate of photo-reductive dissolution is observed in de-aerated systems at $\mathrm{pH} 5$ than at $\mathrm{pH} 3$. In the presence of oxygen, a further decrease in the rate of photo-reductive dissolution at both $\mathrm{pH}$ values is observed, probably because some of the surface Fe(II) is reoxidized before detachment can take place. A fast redox cycling of dissolved $\mathrm{Fe}$ (II) and $\mathrm{Fe}$ (III) is observed in the aerated solutions. A kinetic model of the aerated systems at $\mathrm{pH} 3$ and 5 indicates that, at both $\mathrm{pH}$ 
values, the dark reduction of $\mathrm{Fe}$ (III) by fulvic acid and photochemical ligand-to-metal charge transfer reactions of dissolved $\mathrm{Fe}(\mathrm{III})$-fulvate complexes play almost equally significant roles in the reduction of dissolved Fe(III). The oxidants of dissolved Fe(II) in these systems are $\mathrm{HO}_{2} / \mathrm{O}_{2}{ }^{-}$(produced mainly via reduction of $\mathrm{O}_{2}$ by photo-excited fulvic acid) and hydrogen peroxide (the product of the reaction of $\mathrm{HO}_{2} / \mathrm{O}_{2}{ }^{-}$with $\mathrm{Fe}(\mathrm{II})$ ). Oxidation of dissolved $\mathrm{Fe}(\mathrm{II})$ by $\mathrm{O}_{2}$ is insignificant in the $\mathrm{pH}$ range of this study. Ligand-to-metal charge transfer reactions of Fe(III)fulvate complexes at the lepidocrocite surface act mainly as a source of dissolved Fe(II); surface reactions do not appear to be either a major source or sink of hydrogen peroxide or $\mathrm{HO}_{2} / \mathrm{O}_{2}^{-}$.

$\mathrm{HO}_{2} / \mathrm{O}_{2}{ }^{-}$is not only an oxidant of Fe(II) but also a reductant of $\mathrm{Fe}(\mathrm{III})$. In sunlit seawater, reaction of inorganic Fe(III) species with photo-produced $\mathrm{HO}_{2} / \mathrm{O}_{2}{ }^{-}$could be an important source of $\mathrm{Fe}(\mathrm{II})$. Experiments in $0.7 \mathrm{M}$ chloride show that in the presence of high $\mathrm{HO}_{2} / \mathrm{O}_{2}{ }^{-}$concentrations, up to $75 \%$ of the total dissolved iron is present as $\mathrm{Fe}(\mathrm{II})$ at $\mathrm{pH}$ values greater than 5.5. Using this result and previously published $\mathrm{HO}_{2} / \mathrm{O}_{2}^{-}$flux measurements in sunlit open-ocean surface waters, we calculate that, despite possible competition for $\mathrm{HO}_{2} / \mathrm{O}_{2}^{-}$by copper, the steady-state concentration of $\mathrm{HO}_{2} / \mathrm{O}_{2}^{-}$is high enough to result in significant concentrations of $\mathrm{Fe}$ (II) in these waters. Our calculations predict that, in the absence of organic complexation of Fe(III), 30-75\% of dissolved iron in the photic zone will be present as $\mathrm{Fe}$ (II) during daytime. Consistent with this hypothesis, illumination by simulated sunlight of open-ocean water samples (acidified to $\mathrm{pH} 7.3$ ), to which $5 \mathrm{nM}$ iron had been added, resulted in the conversion of approximately $60 \%$ of the dissolved iron into $\mathrm{Fe}(\mathrm{II})$ after steady state was achieved. 


\section{Zusammenfassung}

In dieser Arbeit untersuchen wir die Kinetik der Oxidation von Fe(II), der Reduktion von Fe(III) und der reduktiven Auflösung von Eisenoxiden in Gegenwart von Huminstoffen und Licht.

Bei der Reaktion von Fe(II) mit Wasserstoffperoxid im Dunkeln (Fenton Reaktion) können in Gegenwart von Fulvinsäure mehrere Effekte beobachtet werden. (1) Bei pH 5 steigt die Rate der Fe(II) Oxidation mit zunehmender Konzentration an Fulvinsäure. Dieser Effekt weist darauf hin, dass sich Fe(II)-Fulvat Komplexe bilden, die schneller mit Wasserstoffperoxid reagieren als die Fe(II)-Aquokomplexe. Bei pH 3 wird dieser Effekt nicht beobachtet. (2) In Gegenwart von Sauerstoff entsteht $\mathrm{HO}_{2} / \mathrm{O}_{2}^{-}$aus der Reaktion von $\mathrm{OH}$ Radikalen (erzeugt durch die Fenton Reaktion) mit Fulvinsäure. Die $\mathrm{HO}_{2} / \mathrm{O}_{2}{ }^{-}$Radikale oxidieren $\mathrm{Fe}(\mathrm{II})$, was zu einer Rückbildung von Wasserstoffperoxid führt. (3) Fe(III) wird durch Fulvinsäure im Dunkeln reduziert. Einer anfangs sehr schnellen Reduktion folgt eine langsamere Reaktion. Der Anteil des totalen Fe(III), der im schnellen Reduktionsschritt reduziert wird, bleibt konstant, auch wenn das Fe(III) Ligand-Verhältnis variiert wird. Mit einem kinetischen Modell, welches diese drei Effekte der Fulvinsäure auf die Fenton-Reaktion berücksichtigt, können die Konzentrationen von $\mathrm{Fe}(\mathrm{II})$ und Wasserstoffperoxid als Funktion der Zeit in Gegenwart von Fulvinsäure berechnet werden.

In Gegenwart von Licht, Fulvinsäure und Lepidokrokit ( $\gamma$-FeOOH)Partikeln, entsteht $\mathrm{Fe}$ (II) an der Oberfläche des Eisenoxids durch lichtinduzierte Ligand-zu-Metall Ladungstransfer-Reaktionen innerhalb der Oberflächen Fe(III)-Fulvat-Komplexe. Ablösung des Oberflächen$\mathrm{Fe}$ (II) aus dem Gitterverband führt dann zur reduktiven Auflösung der Festphase. Da die Oberflächenkonzentration an Fe(III)-Fulvat-Komplexen mit zunehmendem $\mathrm{pH}$ abnimmt, beobachtet man in entlüfteten Systemen eine kleinere Rate der reduktiven Auflösung bei pH 5 als bei pH 3. In Gegenwart von Sauerstoff nimmt die Rate der reduktiven Auflösung noch weiter ab, vermutlich weil ein Teil des Oberflächen-Fe(II) wieder oxidiert 
wird, bevor es sich ablösen kann. Ein schneller Redox-Zyklus zwischen gelöstem Fe(II) und Fe(III) kann in den belüfteten Systemen beobachtet werden. Eine kinetische Modellierung dieser Systeme bei $\mathrm{pH} 3$ und $\mathrm{pH} 5$ ergibt, dass die thermische Reduktion von gelöstem Fe(III) durch Fulvinsäure und licht-induzierte Ladungstransfer-Reaktionen gelöster $\mathrm{Fe}$ (III)-Fulvat-Komplexe bei beiden $\mathrm{pH}-\mathrm{Werten}$ fast gleichwertige Rollen für die Bildung von $\mathrm{Fe}$ (II) spielen. $\mathrm{Fe}$ (II) wird sowohl durch $\mathrm{HO}_{2} / \mathrm{O}_{2}{ }^{-}$ (hauptsächlich gebildet durch Reaktion von Sauerstoff mit elektronisch angeregter Fulvinsäure) als auch durch Wasserstoffperoxid (dem Produkt der Reaktion von $\mathrm{HO}_{2} / \mathrm{O}_{2}{ }^{-}$mit $\mathrm{Fe}$ [II]) oxidiert. Die Oxidation von $\mathrm{Fe}$ (II) durch Sauerstoff ist unbedeutend bei den pH-Werten unserer Systeme. Ladungstransfer-Reaktionen von Fe(III)-Fulvat-Komplexen an der Lepidokrokit Oberfläche fungieren hauptsächlich als Quelle von gelöstem Fe(II); die Oberflächenreaktionen scheinen keine wichtige Quelle oder Senke von Wasserstoffperoxid oder $\mathrm{HO}_{2} / \mathrm{O}_{2}^{-}$zu sein.

$\mathrm{HO}_{2} / \mathrm{O}_{2}{ }^{-}$kann nicht nur $\mathrm{Fe}$ (II) oxidieren, sondern auch $\mathrm{Fe}$ (III) reduzieren. In sonnenbestrahltem Meerwasser kann die Reaktion von anorganischen $\mathrm{Fe}$ (III) Spezien mit $\mathrm{HO}_{2} / \mathrm{O}_{2}^{-}$eine bedeutende Quelle von $\mathrm{Fe}(\mathrm{II})$ sein. Experimente in 0.7 M Chlorid-Lösungen zeigen, dass in Gegenwart relativ hoher Konzentrationen an $\mathrm{HO}_{2} / \mathrm{O}_{2}{ }^{-}$und bei pH-Werten oberhalb von 5.5 bis zu 75\% des total gelösten Eisens als Fe(II) vorhanden ist. Basierend auf diesem Resultat und auf veröffentlichten Messungen des $\mathrm{HO}_{2} / \mathrm{O}_{2}{ }^{-}$ Fluxes im sonnenbestrahlten offenen Meer berechnen wir, dass trotz der möglichen Konkurrenzreaktionen von $\mathrm{HO}_{2} / \mathrm{O}_{2}^{-}$mit Kupfer die Stationärkonzentrationen von $\mathrm{HO}_{2} / \mathrm{O}_{2}{ }^{-}$in diesen Gewässern hoch genug sind, um signifikante Mengen an $\mathrm{Fe}(\mathrm{II})$ zu produzieren. Unsere Rechnungen sagen voraus, dass in Abwesenheit von organischen Komplexbildnern von Fe(III) 30 bis $75 \%$ des gelösten Eisens in der photischen Zone bei Tageslicht als Fe(II) vorhanden ist. In Uebereinstimmung mit dieser Rechnung beobachteten wir bei Belichtung mit simuliertem Sonnenlicht von Meerwasserproben, die leicht angesäuert (pH 7.3) und mit $5 \mathrm{nM}$ Eisen versetzt waren, eine Umwandlung von 60\% des total gelösten Eisens zu Fe(II) nach Erreichen des Stationärzustands. 


\section{Acknowledgements}

Barbara Sulzberger took on the (sometimes difficult) task of being my "Doktormutter" with heartening enthusiasm. I thank her for her guidance, support, and friendship, and for leaving me the freedom I needed to do this work while at the same time reminding me to stay focused.

François Morel always managed to find some time to discuss all aspects of science with me, from the details of iron redox chemistry to the business of being a scientist. His friendship, encouragement, sage advice, and infectious joie de vivre often boosted my spirits and were much appreciated.

René Schwarzenbach fulfilled the most important task assigned to the thesis advisor: that of convincing me to start writing (and just in time...). His sensible counsel, critical comments, and good humor have been very helpful as well.

The work presented in Chapter 6 was really a collaborative effort with David Sedlak, the result of long hours we shared in the basement of the chemistry building of the ETHZ. David Sedlak and Meg David were also crucial sources of scientific and personal advice, moral support, and (when all else failed) beer. I am very grateful for their friendship and frequent hospitality, which made Kunklerstrasse 4 seem like a second home.

Jürg Hoigné's expertise in humic acid photochemistry and the continuous radiolysis technique were a valuable help. I thank him for our discussions and for allowing me to use some of the resources of his research group, especially for the work in Chapter 6. I also thank Rolf Bühler for allowing us to use the radiation source at the Laboratory for Physical Chemistry at the ETHZ.

I thank Werner Stumm for convincing me to come to EAWAG, for helpful discussions and advice, and for teaching me that chemical intuition and mathematical models should complement, and not contradict, each other. 
Stephan Hug had the idea of using Matlab and a simplex routine in the kinetic modeling work, and did much of the programming necessary for putting the idea into practice.

I am grateful to Whitney King and Heather Lounsbury for providing me with the chemiluminescence system for $\mathrm{Fe}(\mathrm{II})$ analysis and with a seawater sample, and to Jerry Leenheer for sending me a sample of fulvic acid.

Hans-Ueli Laubscher was a great help and a calming influence in the lab. He also did some of the experiments shown in Figures 4.1, 4.2, and 5.1.

I thank Silvio Canonica, Carrick Eggleston, FG Kari, Urs Von Gunten, David Waite, Ollie Zafiriou, Richard Zepp, and Yuegang Zuo for helpful discussions.

Thanks to the doctoral students, postdocs and visitors for creating a cordial and international atmosphere at EAWAG, and to all the support personnel who make sure that this institute keeps running smoothly.

I thank the women of the Frauenlunch and the book discussion group. These two groups were a kind of breathing space for me, and a place for exploring new perspectives.

I am grateful to the Ammanns for providing me with a warm home and Swiss hospitality for almost four years, and Christine for sharing her apartment with me during the final phases of this work.

To my old and new friends, who shared the joys and frustrations of the last four years -- thanks for everything, especially the trips to the mountains and the chocolate. There isn't enough space here to thank so many individuals (some are already named above) -- you know who you are.

I thank my family for always being there, and the Völkers for welcoming me into their family. Lastly, of course, my gratitude to Martin, who understands me better than anybody else does, tolerates my moods and obsessions patiently, reminds me of all the important things, and always finds a way to make me laugh. 


\section{Table of contents}

Abstract
Zusammenfassung
Acknowledgements

Table of contents

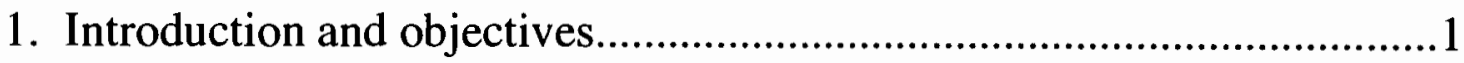

2. Iron speciation and reactivity in surface waters...................................

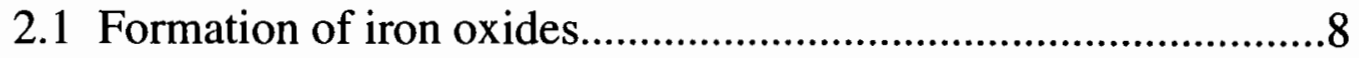

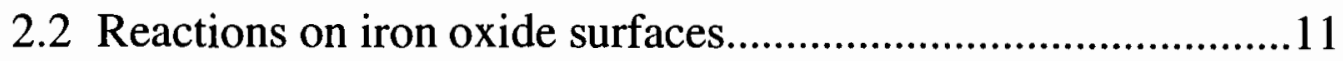

2.3 Dissolution of iron oxides......................................................... 11

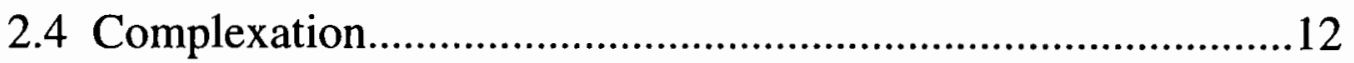

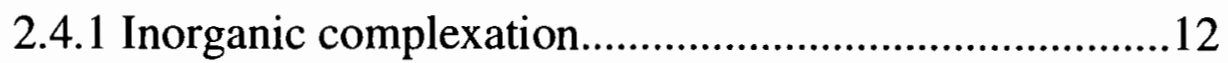

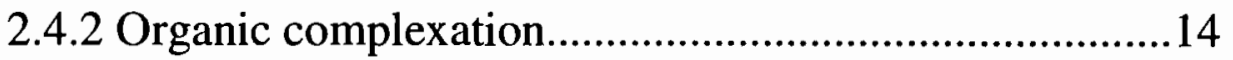

2.5 Reduction-oxidation processes...............................................16

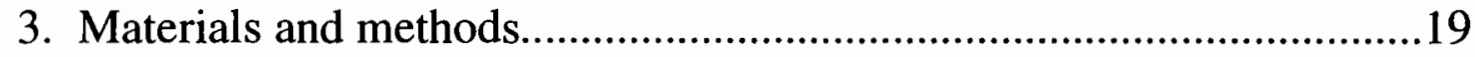

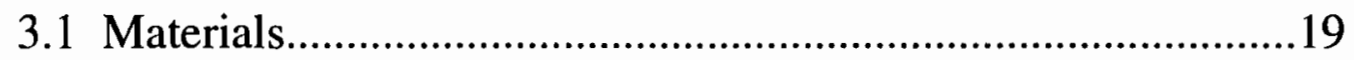

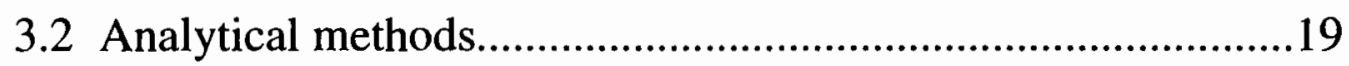

3.2.1 Hydrogen peroxide analysis with simultaneous

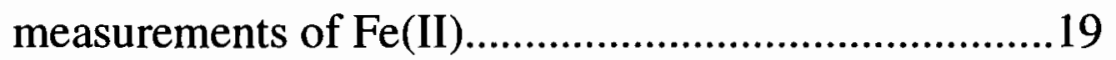

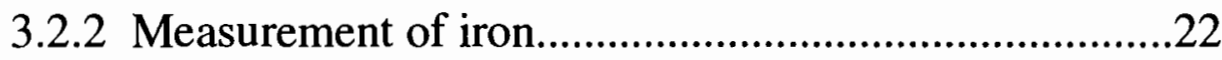

3.2.2.1 Colorimetry ................................................22

3.2.2.2 Chemiluminescence........................................23

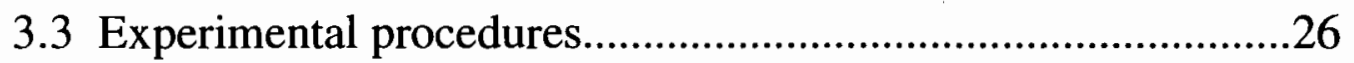

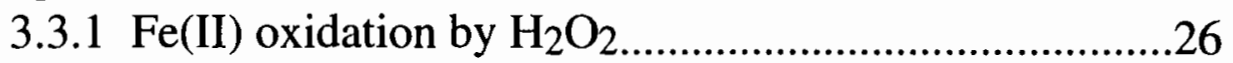

3.3.2 $\mathrm{Fe}(\mathrm{III})$ dark reduction experiments............................27

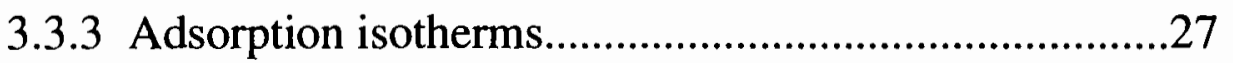

3.3.4 Experiments in lepidocrocite suspensions...................28

3.3.5 $\gamma$-radiolysis experiments............................................29

3.3.6 Seawater experiments................................................30

3.4 Characterization of light conditions in the irradiated systems...31

3.4.1 Actinometry............................................................. 31

3.4.2 Comparison of the average light intensity in different

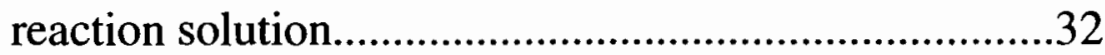

3.5 Optimization of unknown kinetic parameters...........................35 
4. An iron redox cycle in the dark -- Fenton's reaction in the presence of fulvic acid.

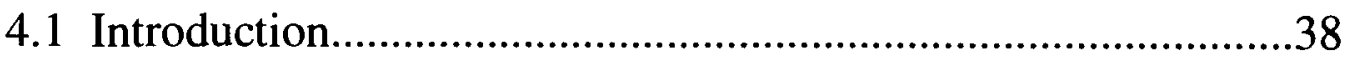

4.2 Fulvic acid as a ligand and its effect on the rate of Fenton's reaction.

4.2.1 Background

4.2.2 Results

4.3 Fulvic acid as a scavenger of $\mathrm{OH}$ radicals -- production of $\mathrm{HO}_{2} / \mathrm{O}_{2}$ - radical.

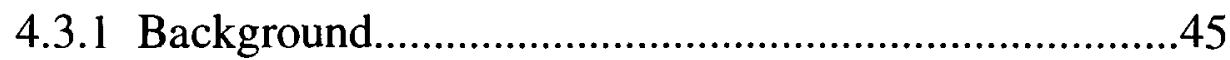

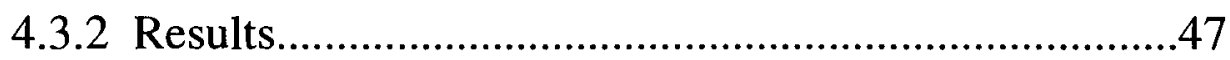

4.4 Fulvic acid as a reductant of Fe(III) .....................................50

4.5 A kinetic model of the reactions in the Fe(II)-SRFA- $\mathrm{H}_{2} \mathrm{O}_{2}$ system

5. Photochemical iron cycling in the presence of fulvic acid and $\gamma-\mathrm{FeOOH}$

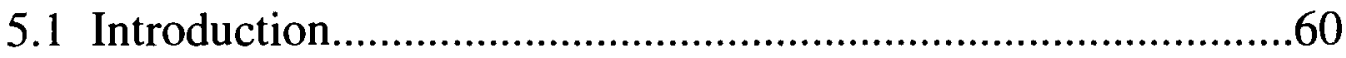

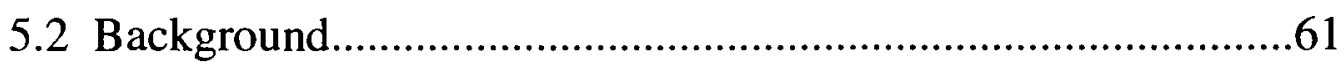

5.2.1 Photo-reduction of dissolved Fe(III) ..........................61

5.2.2 Photo-reductive dissolution of iron oxides...................63

5.2.3 Photo-formation of $\mathrm{Fe}(\mathrm{II})$ oxidants.............................65

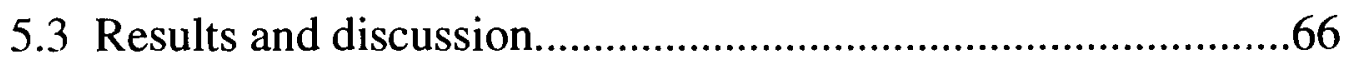

5.3.1 Adsorption of fulvic acid on the $\gamma$-FeOOH surface......66

5.3.2 Photo-reductive dissolution of $\gamma$-FeOOH by fulvic acid .68

5.3.3 Redox cycling of dissolved iron in the presence of light.

5.4 A kinetic model of iron cycling in the irradiated

lepidocrocite-SRFA system. .79

5.4.1 Model set-up. .82

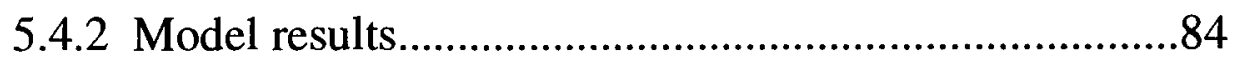

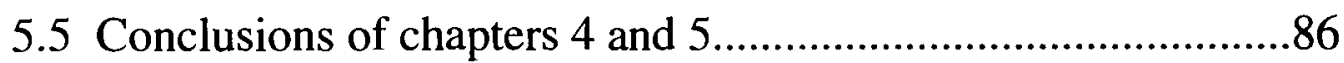

6. Iron redox cycling by superoxide in seawater.....................................91

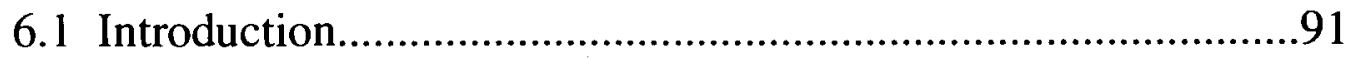

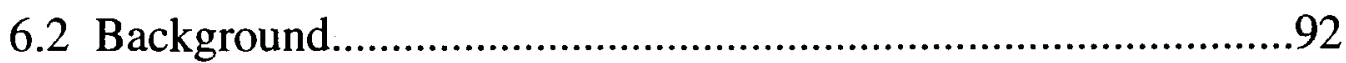

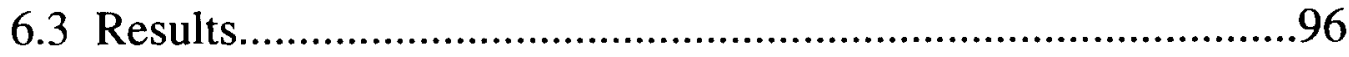

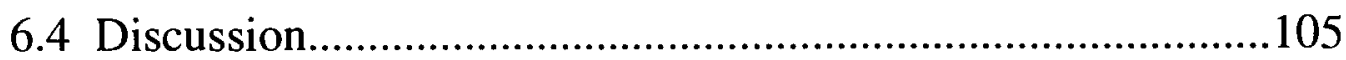

References. 


\section{Chapter 1: Introduction and objectives}

Iron plays a central role in numerous chemical and biological processes occurring in the environment. For example, adsorption on iron oxide particles is a factor in the biogeochemical cycling of many substances, including heavy metals, phosphate, and other pollutants (Stumm, 1992). When the particles aggregate and settle, the substances are transported from the water column to the sediment of a water body. In addition to being adsorbents, the surfaces of iron oxides can also participate in chemical reactions. Acting either as catalysts or as reactants, iron oxide particles have been shown to accelerate the rates of oxidation of organic pollutants (Cunningham et al., 1988a), natural organic matter (Miles and Brezonik, 1981; Waite and Morel, 1984c), metals (Davies and Morgan, 1989), and inorganic ligands (Dos Santos Afonso and Stumm, 1992). Dissolved iron species also participate in the redox transformations of organic and inorganic substances. Some ligands are oxidized by ligandto-metal charge-transfer reactions with $\mathrm{Fe}(\mathrm{III})$, especially in the presence of light (Zuo and Hoigné, 1992; Faust and Zepp, 1993). Another role of dissolved iron species is that of an electron transfer mediator, or catalyst, in the reduction of organic pollutants (Schwarzenbach et al., 1990). Finally, reactions involving iron can be major sources or sinks of reactive transient species (usually oxidants), including $\mathrm{H}_{2} \mathrm{O}_{2}$ (Zuo and Hoigné, 1992; Weinstein-Lloyd and Schwartz, 1991; King et al., submitted), $\mathrm{OH}^{*}$ radicals (Sigleo et al., 1988; Faust and Hoigné, 1990; Zepp et al., 1992), $\mathrm{HO}_{2} / \mathrm{O}_{2}{ }^{-}$radicals (Sedlak and Hoigné, 1993) and ozone (Sedlak and Hoigné, 1993). In biological systems, iron is a common transition metal in enzymes, and therefore an important nutrient. In some parts of the ocean, iron can even be a limiting nutrient to phytoplankton, with consequences not just for the local ecology but also for the global cycling of carbon (Martin et al., 1994). 
If one considers iron's importance in aquatic environments, one may be surprised to learn that fundamental questions concerning its speciation and behavior in natural waters remain unanswered. Looking at iron more closely, one comes to the realization that those aspects of iron's chemistry that make it an interesting element in environmental and biological processes also make it an extremely difficult element to study:

1) Iron is ubiquitous -- Iron is the fourth most common element in the earth's crust and abundant on the earth's surface. One can expect to find iron participating in chemical reactions everywhere: in the atmosphere, on mountain tops, in soils, lakes, rivers, and oceans, and in biochemical processes. Unfortunately, iron's abundancy also presents the analytical chemist with a significant problem. In a typical laboratory (including ours) one can expect iron to be falling from the ceiling -- literally -- and samples are easily contaminated. For this reason, measuring field samples from those few parts of the world where iron is scarce, such as in remote regions of the ocean, is a great challenge.

2) Iron chemistry is heterogeneous chemistry. -- Because of the low solubility of $\mathrm{Fe}(\mathrm{III})$ at neutral or higher $\mathrm{pH}$, much of the chemistry involving iron takes place on iron oxide surfaces. A common way to arrive at conclusions about what happens at surfaces is to look for the effect of surface reactions on solution composition, but often it is not easy to distinguish among different processes by this indirect method of observation. For example, accelerated removal of Fe(II) from solution in the presence of an iron oxide surface could be due either to adsorption or surface-catalyzed oxidation. Furthermore, even measuring solution composition is often a major task: a simple, non-intrusive analytical method sensitive enough to measure iron at concentrations below its solubility limit at $\mathrm{pH} 8$ (the $\mathrm{pH}$ of seawater) has not yet been developed (and may be impossible to develop; see next point). 
3) Iron chemistry is dynamic. -- Competing reactions, for example iron reduction or oxidation and complexation, can occur within the time span of preparing a sample for analysis. Many of these reactions proceed at increasing rate with increasing $\mathrm{pH}$. When attempting to take a "snapshot" picture of iron speciation in a given sample at a given time, the possible effects of sample preparation on the speciation must therefore always be considered.

Despite the difficulties described above, we have enough information to outline a general picture of iron's speciation and reactivity in surface waters. In an oxygenated system in the presence of light, iron is converted back and forth between its reduced and oxidized forms, and between surface and solution species. Figure 1.1 shows a schematic summary of the possible reactions in such a system. Fe(III) is (photo-)reduced at the surface of the iron oxide, forming surface Fe(II) (1). The Fe(II) may be re-oxidized on the surface of the oxide (2), or detach (3). Dissolved $\mathrm{Fe}(\mathrm{II})$ is oxidized by oxygen (4), by $\mathrm{HO}_{2} / \mathrm{O}_{2}^{-}$(5), and by $\mathrm{H}_{2} \mathrm{O}_{2}(6)$, or removed from the solution by adsorption on the iron oxide surface (7). Dissolved Fe(III) can be reduced by reaction with $\mathrm{HO}_{2} / \mathrm{O}_{2}^{-}(8)$, and by thermal or photochemical processes involving oxidation of a ligand (9). When the concentration of dissolved Fe(III) exceeds its solubility limit, it may be quickly removed from solution by precipitation (10). Finally, some iron oxide phases are reactive enough to dissolve even in the absence of (photo-)reductive processes (11).

To understand the biogeochemistry of iron, and the significance of iron reactions in various environmental processes, more detailed information is needed on the roles that organic ligands can play in the various reactions of the iron cycle shown in Figure 1.1. Numerous studies of the interactions of iron with organic ligands have been carried out, but most of these have (understandably) concerned themselves with small compounds of known structure (Waite and Morel, 1984b; Cunningham et al., 1988b; Siffert and Sulzberger, 1991; Zuo and Hoigné, 1992; 
Figure 1.1. Summary of possible iron reactions in surface waters:

1. (Photo-)reduction of surface Fe(III) (oxidation of ligand not shown)

2. Re-oxidation of surface $\mathrm{Fe}(\mathrm{II})$ (probably by $\mathrm{O}_{2}$ )

3. Detachment of surface Fe(II)

4. $\mathrm{Fe}(\mathrm{II})$ oxidation by $\mathrm{O}_{2}$

5. $\mathrm{Fe}(\mathrm{II})$ oxidation by $\mathrm{O}_{2}$

6. $\mathrm{Fe}(\mathrm{II})$ oxidation by $\mathrm{H}_{2} \mathrm{O}_{2}$

7. $\mathrm{Fe}(\mathrm{II})$ adsorption

8. $\mathrm{Fe}(\mathrm{III})$ reduction by $\mathrm{O}_{2}^{-}$

9. $\mathrm{Fe}(\mathrm{III})$ (photo-)reduction (oxidation of ligand not shown)

10. $\mathrm{Fe}$ (III) adsorption/precipitation

11. Non-reductive dissolution of Fe(III) oxide 


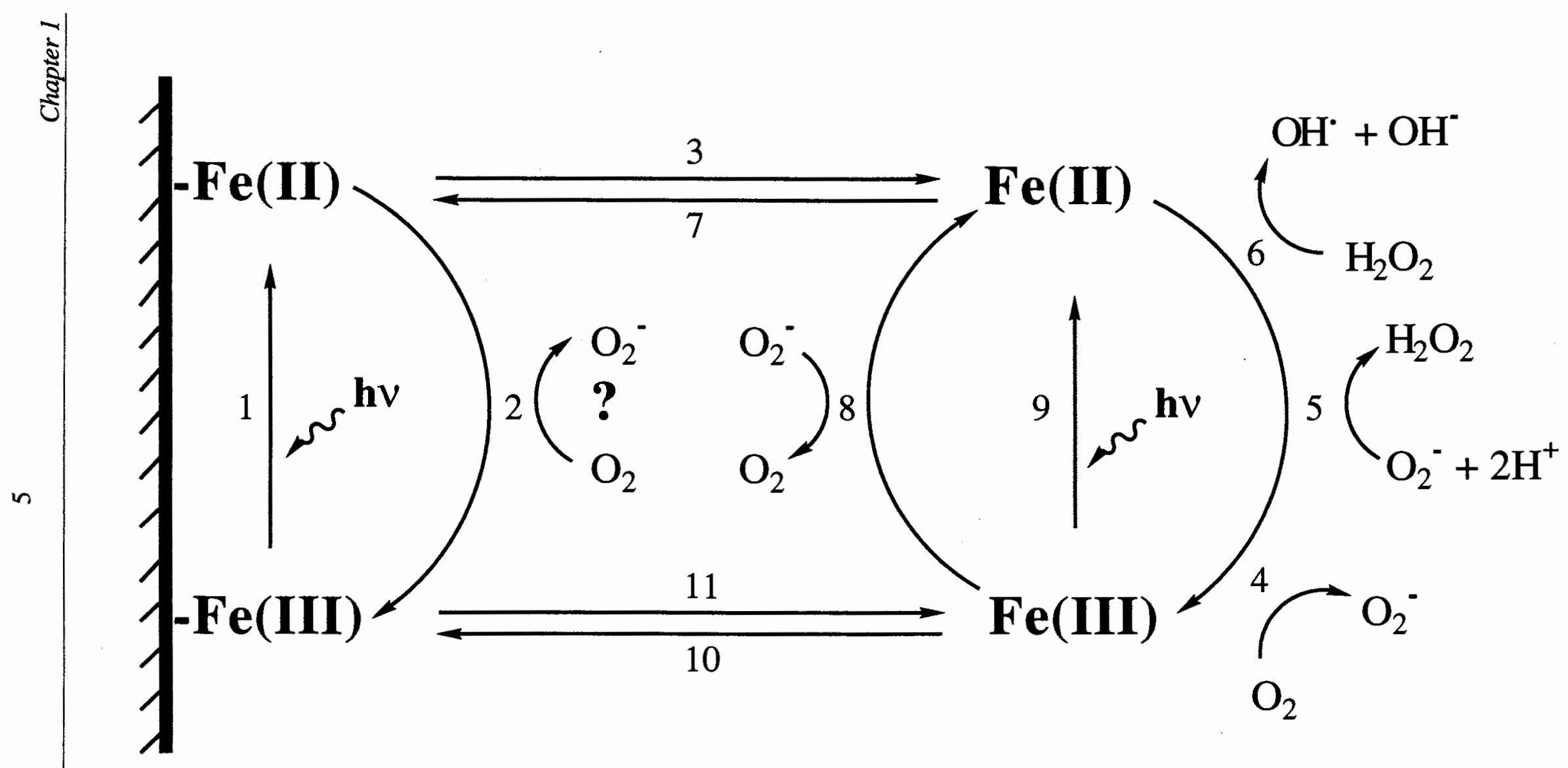


Pehkonen et al., 1993; Faust and Zepp, 1993; etc.). However, in many natural waters, humic substances are likely to be the most important organic ligand influencing iron chemistry. Humic substances differ from most model ligands in that they consist of a mixture of functional groups, including hydrophobic components as well as acidic (carboxylic and phenolic) sites, which can participate in a variety of reactions. In the light, Fe(III)-humate complexes, either in solution or on the surface, undergo ligand-to-metal charge transfer reactions, similar to those observed for other Fe(III)-carboxylate complexes (Waite and Morel, 1984c) . Unlike most simple carboxylic acids, however, humic substances can also reduce $\mathrm{Fe}(\mathrm{III})$ in the absence of light (Szilàgi, 1971; Langford et al., 1977; Skogerboe and Wilson, 1981; Deng and Stumm, 1994). Furthermore, ligand-to-metal charge transfer reactions are not the only photochemical reactions that humic substances can undergo. Photoexcited humic substances can reduce oxygen and are therefore a significant source of $\mathrm{HO}_{2} / \mathrm{O}_{2}{ }^{-}$and $\mathrm{H}_{2} \mathrm{O}_{2}$ (Cooper et al., 1989; Hoigné et al., 1989). Humic substances are also a sink of radicals, especially of $\mathrm{OH}^{\cdot}$ radicals (Hoigné et al., 1989). Finally, complexation of Fe(II) and Fe(III) by organic ligands changes the rates of their reactions with the reactive oxygen species (Theis and Singer,1974; Miles and Brezonik, 1981; Liang et al., 1993).

While interactions of humic substances and iron in the dark and in the light have been studied before (see references above), a systematic account of all the reactions taking place in an illuminated, oxygenated iron oxide suspension in the presence of humic substances has not been attempted. This work is mainly a laboratory study of these reactions, using a well-defined crystalline iron oxide phase (lepidocrocite or $\gamma$-FeOOH), and a standard humic substance (Suwannee River Fulvic Acid or "SRFA"), in solutions at $\mathrm{pH} 3$ and 5, as a model system. We chose to work in acidic solutions because the relatively slow oxidation of Fe(II) and higher solubility of $\mathrm{Fe}$ (III) in this $\mathrm{pH}$ range reduced the analytical difficulties. Lepidocrocite was chosen because it is the most reactive of 
the crystalline iron oxides, SRFA because it is one of the most thoroughly studied humic substances.

Our general approach was to examine the kinetics of individual reactions separately (as far as this was possible), and then to test whether the reactions we examined can account for the observed behavior of iron in systems simulating natural water conditions. In chapter 2 , our present knowledge of the speciation and reactivity of iron in natural waters is discussed in more detail. Experimental materials and methods are described in chapter 3 . In chapter 4 , a study of iron redox cycling in the dark is presented, specifically the effect of fulvic acid on the rate of the reaction of $\mathrm{Fe}(\mathrm{II})$ with hydrogen peroxide (known as "Fenton's reaction") and the dark reduction of $\mathrm{Fe}$ (III) by fulvic acid. In chapter 5, the photoreductive dissolution of lepidocrocite, and photochemical reactions of dissolved iron and fulvic acid are examined. Using the reaction rates determined in chapters 4 and 5, an overall kinetic model of the photochemical iron cycle in the presence of humic substances is then constructed and used to assess the relative significance of the different reactions taking place in our model systems.

Because of the role of iron as a limiting nutrient in some parts of the ocean, marine iron chemistry has been of increasing interest. Marine waters differ from our model system in two important ways: the total amounts of dissolved organic carbon and iron are much smaller and the $\mathrm{pH}$ is higher. In such a system, we might expect reactions of $\mathrm{Fe}$ (III) complexes on surfaces or in solution to be less significant, and indirect photochemistry to be more important. In chapter 6, photochemical iron redox cycling by $\mathrm{HO}_{2} / \mathrm{O}_{2}{ }^{-}$radical is examined and the significance of these reactions in marine systems is discussed. 


\section{Chapter 2: Iron speciation and reactivity in natural waters}

To understand the chemistry of iron in a certain natural water system, one must know which iron species are present and which reactions each species can undergo. Speciation also affects the "bioavailability" of iron. "Bioavailability" is a term reflecting the ability of the organisms in the water to take up the iron that is present, and is really the sum of the availability of each iron species to each organism.

The thermodynamically stable form of dissolved iron in aerated natural waters is Fe(III). Significant concentrations of reduced iron, Fe(II), can be maintained by a number of chemical, photochemical, and biological processes, especially at low $\mathrm{pH}$, where $\mathrm{Fe}(\mathrm{II})$ oxidation is slow. Both $\mathrm{Fe}$ (II) and $\mathrm{Fe}$ (III) may form complexes with organic and inorganic ligands. In the absence of complexation, Fe(III) is rather insoluble and forms various kinds of iron oxide solids. In contrast, Fe(II) solid species are much more soluble and, accordingly, form more rarely. (In the presence of sulfide, for example in anoxic bottom waters, $\mathrm{FeS}$ is a common Fe(II) solid.)

Iron chemistry, then, is the chemistry of a large number of possible species. In this chapter, we briefly summarize our current understanding of iron speciation in natural water systems (restricting ourselves mostly to the consideration of aerated surface waters), and discuss what is known about the dynamics of change in speciation.

\subsection{Formation of iron oxides}

Aqueous Fe(III) (in the absence of all ligands other than water) is present as various hydrolysis products, the relative concentrations of which are $\mathrm{pH}$ dependent. As a result, the solubility of $\mathrm{Fe}(\mathrm{III})$ is also $\mathrm{pH}$ dependent, 


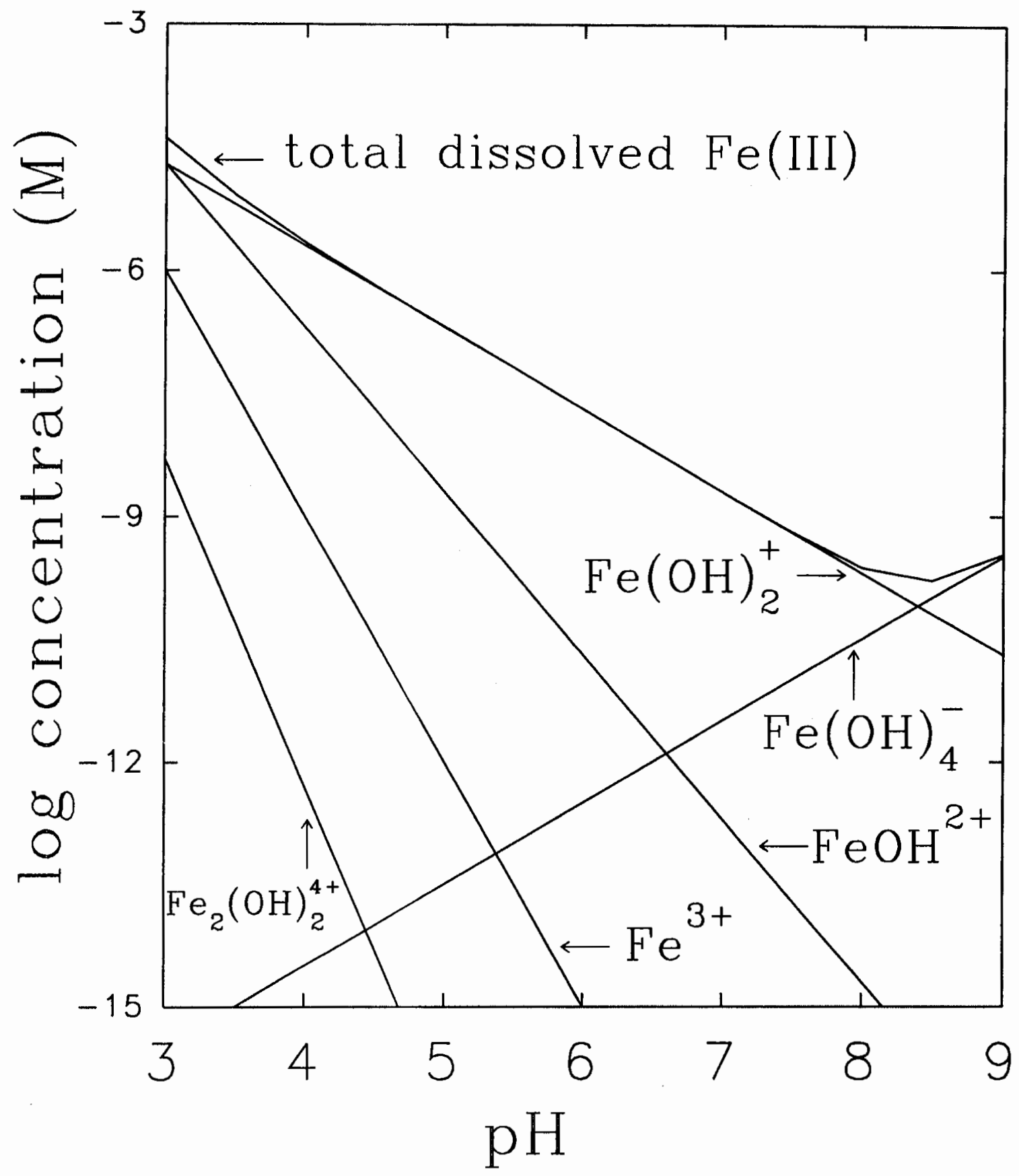

Figure 2.1. Major Fe(III) species and total dissolved Fe(III) as a function of $\mathrm{pH}$ in an aqueous solution in equilibrium with amorphous Fe(III) oxyhydroxide. Equilibrium constants for the hydrolysis of $\mathrm{Fe}(\mathrm{III})$ and solubility of $\mathrm{Fe}(I I)$ oxyhydroxide are from Westall et al. (1976). 
and is lowest near neutral $\mathrm{pH}$ values (Figure 2.1).

Oversaturation of $\mathrm{Fe}(\mathrm{III})$, followed by precipitation of iron oxide solids, is a common occurence in natural water systems. Oversaturation can be brought about by a sudden change in iron concentration, such as when acidic atmospheric water rich in iron enters a lake or ocean (Duce, 1986), or when a river enters an esturary (Sholkovitz, 1976). Another example is the upwelling of oxygen poor, $\mathrm{Fe}$ (II)-rich water (for example from the anoxic zone of a lake) into oxygenated waters: as the Fe(II) is oxidized, $\mathrm{Fe}$ (III) concentrations increase past its solubility limit (Davison et al., 1980). Weathering of minerals, such as pyrite $\left(\mathrm{FeS}_{2}\right)$ or $\mathrm{Fe}(\mathrm{II})$ silicates, and subsequent oxidation of the $\mathrm{Fe}$ (II), also results in formation of $\mathrm{Fe}$ (III) solids (Schwertmann and Cornell, 1991).

Precipitation of $\mathrm{Fe}(\mathrm{III})$ proceeds by the formation of small polynuclear Fe(III) species or colloids, which, depending on solution conditions, may coagulate and age to form a variety of more or less crystalline end products (Schneider and Schwyn, 1987; Dzombak and Morel, 1990; Schwertmann and Cornell, 1991). A product of low crystallinity, ferrihydrite (also called hydrous ferric oxide, amorphous ferric hydroxide, or amorphous iron oxyhydroxide), is formed when Fe(III) concentrations are increased suddenly, such as during the fast oxidation of $\mathrm{Fe}$ (II) or after addition of an acidic Fe(III) stock solution to a solution of higher $\mathrm{pH}$. Ferrihydrite may slowly age to form crystalline hematite ( $\alpha$ $\mathrm{Fe}_{2} \mathrm{O}_{3}$ ), but in natural waters is frequently prevented from doing so by crystallization inhibitors (for example organic substances, phosphates and silicate), which co-precipitate with the ferrihydrite. Other crystalline iron oxides common in nature are goethite $(\alpha-\mathrm{FeOOH})$ and lepidocrocite $(\gamma-\mathrm{FeOOH})$, both of which can precipitate directly from solution.

Colloidal Fe(III) is small enough to pass through commonly used filters (Wu and Luther, 1994) and therefore almost impossible to distinguish from dissolved Fe(III) species. As a result, even the solubility of Fe(III) 
at seawater $\mathrm{pH}$ is still an open question -- and how one interprets the behavior of iron at this $\mathrm{pH}$ depends on whose hydrolysis constants one chooses to use.

\subsection{Reactions on iron oxide surfaces}

Iron oxide surfaces are important reactants in natural water systems. Both metals and ligands form complexes on iron oxide surfaces, the former binding to an oxygen site and the latter binding to a surface iron site (Dzombak and Morel, 1990; Stumm, 1992). Adsorbed cations or anions are removed from the water column when the iron oxide particles settle (Sigg and Stumm, 1980; Sigg, 1985). Adsorbed substances may also participate in further chemical reactions, which often proceed more quickly than corresponding reactions in solution. For example, the rate of oxidation by oxygen of $\mathrm{Fe}$ (II) adsorbed to the surface of goethite is much faster than that of dissolved Fe(II) (Tamura et al., 1976). Oxidation of organic or inorganic ligands (either by photochemical or thermal reactions), where $\mathrm{Fe}$ (III) acts as the electron acceptor, also takes place at the surfaces of iron oxides (examples: sulfide, DosSantos Afonso and Stumm, 1992; oxalate, Cunningham et al., 1988b; Siffert and Sulzberger, 1991; fulvic acid, Waite and Morel, 1984c; Deng and Stumm, 1994; this work). These surface reactions are not necessarily faster than those of the corresponding solution complexes, but they are important in systems where little dissolved $\mathrm{Fe}(\mathrm{III})$ is present.

\subsection{Dissolution of iron oxides}

Dissolution of iron oxides is often slow, especially that of crystalline phases. The rate of dissolution of iron oxides is a crucial factor in the bioavailability of the iron present in these phases. Phytoplankton are unable to absorb particulate iron (Rich and Morel, 1990). If an iron 
oxide particle in a body of water sinks much more quickly than it dissolves, this particle is therefore irrelevant for the iron nutrition of phytoplankton (except for those species that can "catch" the particles as they sink and actively dissolve them on their own surfaces; Rueter, 1988). Dissolution rates of iron oxides are also of interest in natural waters because dissolution can result in the mobilization of adsorbed or coprecipitated substances, such as phosphate (Francko and Heath, 1982).

The dissolution rate of iron oxides is increased by surface protonation (Wieland et al., 1988) and specific adsorption of some Fe(III) ligands (Hering and Stumm, 1991). In the presence of reductants and/or light, surface $\mathrm{Fe}$ (III) is reduced to surface-bound $\mathrm{Fe}$ (II). If the $\mathrm{Fe}$ (II) then detaches from the surface, iron oxide is dissolved by reductive dissolution (Hering and Stumm, 1990). Fe(II) may also re-oxidize on the surface before detachment can occur (Sulzberger and Laubscher, submitted); it is possible that the surface reactivity of the iron oxide is changed by such a process (Wells and Mayer, 1991), even if no dissolution takes place.

\subsection{Complexation}

Complexation has a large effect on the reactivity of dissolved Fe(II) and $\mathrm{Fe}(\mathrm{III})$. The total solubility of Fe(III) is increased by the formation of complexes. Complexation affects the rates of reactions of iron with other solutes, especially the rates of redox reactions (see below). The ligands themselves may also participate in redox reactions, usually by acting as electron donors.

\subsubsection{Inorganic complexation}

In natural waters, the speciation of inorganic $\mathrm{Fe}(\mathrm{II})$ or $\mathrm{Fe}$ (III) is generally dominated by their aquo-complexes (Figure 2.2). In some cases, chloride can be an important ligand. $\mathrm{FeCl}^{+}$is a major $\mathrm{Fe}(\mathrm{II})$ species in seawater, and $\mathrm{Fe}(\mathrm{III})$-chloride complexes may dominate $\mathrm{Fe}$ (III) 


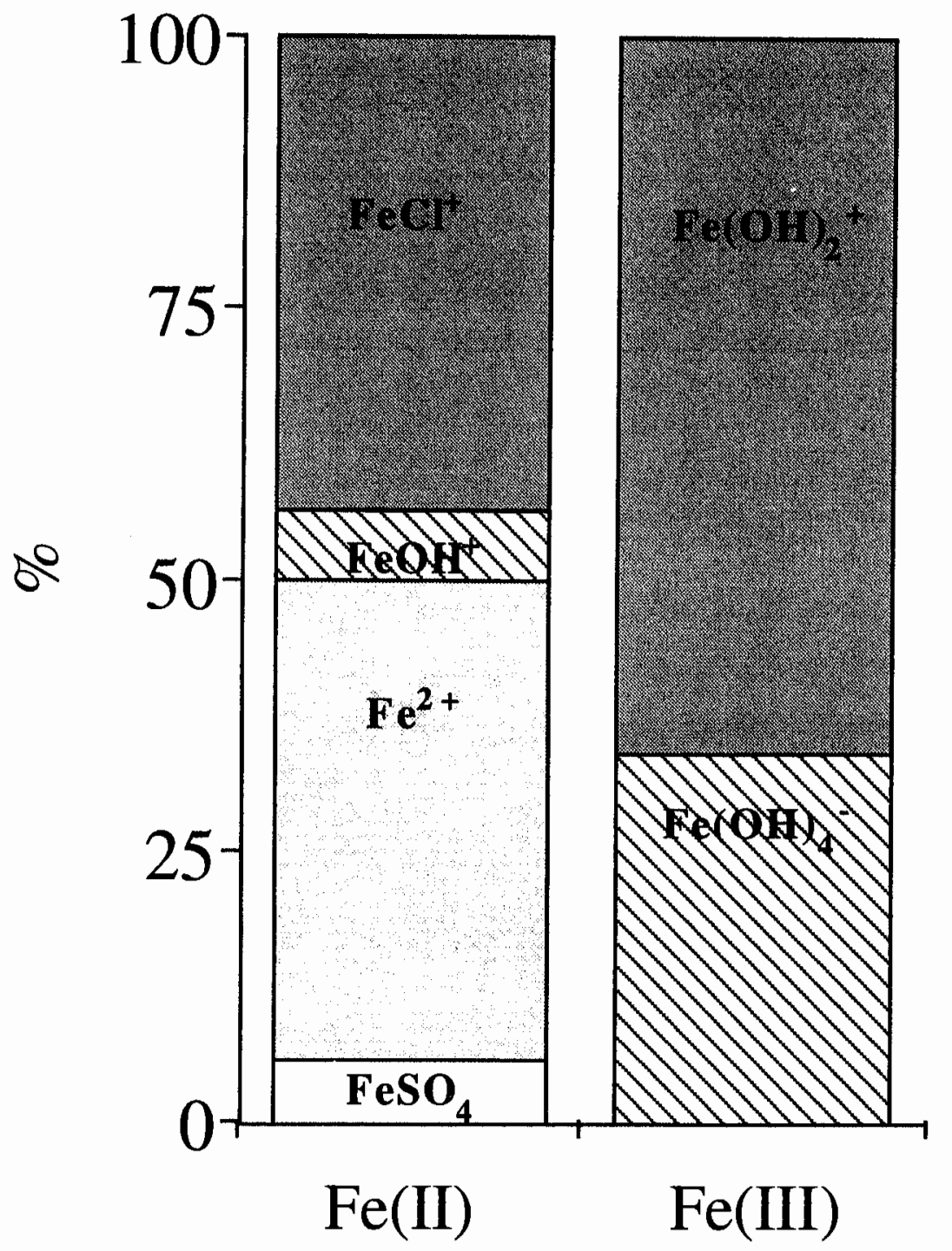

Figure 2.2. Inorganic speciation of $F e(I I)$ and $F e(I I I)$ in seawater ( $p H$ 8.2) calculated using MINEQL (Westall et al., 1976) and the composition of major ions in seawater (Morel and Hering, 1993). In acidic fresh waters, inorganic $\mathrm{Fe}(\mathrm{II})$ and $\mathrm{Fe}(\mathrm{III})$ are present predominantly as aquocomplexes (Turner et al., 1981). 
speciation in acidic, high chloride systems. The rates of $\mathrm{Fe}(\mathrm{II})$ oxidation by oxygen and hydrogen peroxide are affected when $\mathrm{Fe}$ (II) is complexed by inorganic anions. Fe(II) oxidation rates were found to be slowed by chloride and sulfate, and increased by bicarbonate (Millero et al., 1991; Millero and Izaguirre, 1989). Complexation by $\mathrm{OH}^{-}$is also an important factor: the effect of $\mathrm{pH}$ on the rate of oxidation of $\mathrm{Fe}$ (II) by oxygen and hydrogen peroxide (see section 2.5) is attributable to the difference in reaction rate constants of $\mathrm{Fe}^{2+}, \mathrm{FeOH}^{+}$, and $\mathrm{Fe}(\mathrm{OH})_{2}$ with these oxidants.

\subsubsection{Organic complexation}

In atmospheric waters, $\mathrm{Fe}$ (III) may be mostly complexed by small organic acids such as oxalate or formate (Zuo and Hoigné, 1992). In acidic surface waters, it is likely that humic substances are a major complexing agent of Fe(III) (Schnitzer and Khan, 1972). Humic substances, a dominant component of dissolved organic carbon in surface waters, are colored molecules of high molecular weight, resistant to degradation by organisms. Their structure is not well-defined, but includes hydrophobic components as well as acidic (carboxylic and phenolic) functional groups.

At neutral or higher $\mathrm{pH}$, an organic ligand would have to be very strong to outcompete $\mathrm{Fe}$ (III) hydrolysis. The binding constants of most small carboxylic acids are not high enough to complex significant amounts of $\mathrm{Fe}$ (III) at $\mathrm{pH} 8$ (Figure 2.3). The carboxylate binding sites which dominate the ligand properties of humic substances are therefore also not likely to be able to do so. However, some substances, such as EDTA, and siderophores, (synthesized by humans, and plants, respectively, for the purpose of complexing iron) can affect iron speciation even at alkaline $\mathrm{pH}$ (Figure 2.3). EDTA and similar ligands may be important in waters with high anthropogenic inputs (Kari, 1994). Siderophores have been found in soils (Powell et al., 1980) and recent evidence (Gledhill and van den Berg, in press; Rue and Bruland, 1994) suggests that they may play a role 


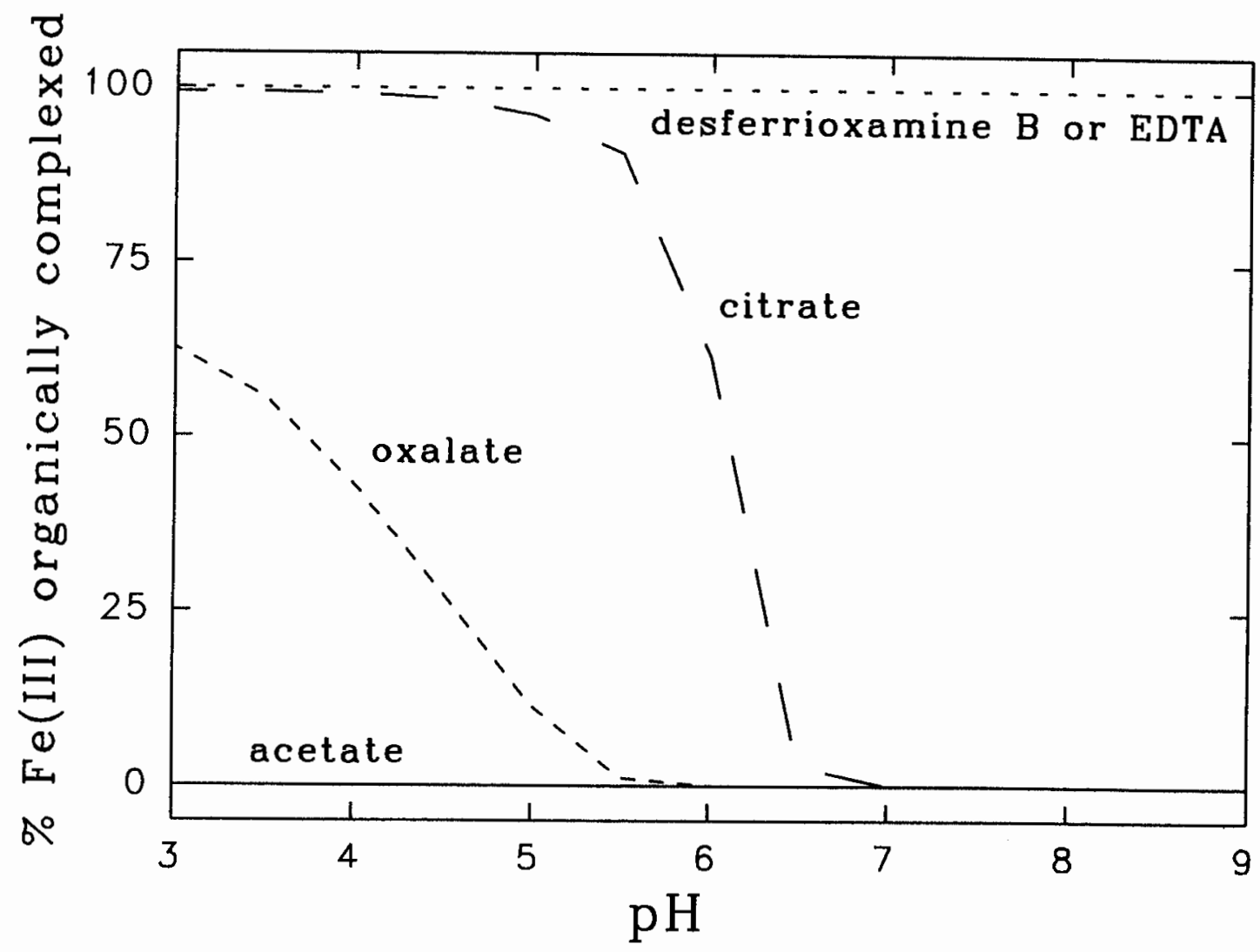

Figure 2.3. The effect of $\mathrm{pH}$ on the \% of total $\mathrm{Fe}(\mathrm{III})$ complexed by various organic ligands.

Total concentrations of $\mathrm{Fe}(\mathrm{III})$ and ligand are both $1 \mu \mathrm{M}$ in all cases. Precipitation of $\mathrm{Fe}(\mathrm{III})$ oxyhydroxide is included in the calculations. For desferrioxamine $B$ (a siderophore), acidity constants and stability constants of the $\mathrm{Fe}(\mathrm{III})$ complex were taken from Morel and Hering (1993). All other constants are from Westall et al. (1976). In the presence of high concentrations of calcium, such as in seawater, competition of $\mathrm{Ca}^{2+}$ and $\mathrm{Fe}(\mathrm{III})$ for binding sites results in a decrease of complexation of $\mathrm{Fe}(I I I)$. The ability of EDTA and the siderophore to complex $\mathrm{Fe}(\mathrm{III})$ is therefore smaller in seawater than is shown in this figure. 
in the speciation of iron in seawater as well.

\subsection{Reduction-oxidation processes}

Although $\mathrm{Fe}$ (III) is the redox state of iron at thermodynamic equilibrium in oxygenated waters, significant amounts of Fe(II) have been detected in atmospheric waters (Behra and Sigg, 1990; Zhuang et al., 1992; Zhu et al., 1993; Erel et al., 1993 ), acidic surface waters (Collienne, 1983; McKnight et al., 1988; Sulzberger et al., 1990) and even in seawater (Hong and Kester, 1986; O'Sullivan et al., 1991; Johnson et al., 1994). The latter is especially surprising, because at seawater $\mathrm{pH}, \mathrm{Fe}$ (II) is oxidized quite rapidly by hydrogen peroxide and oxygen.

Reduction of $\mathrm{Fe}(\mathrm{III})$ in oxygenated natural waters can occur in the absence of light through microbial processes (Jones and Morel, 1988; Price and Maldonado, 1994) or via chemical reductants such as humic substances (Szilagi, 1971; Langford et al., 1977; Skogerboe and Wilson, 1981; Deng and Stumm, 1994). In sunlight, Fe(III) reduction can be greatly accelerated by primary (direct ligand-to-metal charge transfer) or secondary (via intermediates) photo-processes. Many Fe(III)-organic complexes (for example carboxylic acids) undergo photochemical ligandto-metal charge transfer reactions, either on an iron oxide surface or in solution, much more readily than inorganic Fe(III) species (Waite and Morel, 1984a and 1984b; Faust and Zepp, 1993; etc.). As a result, Fe(II) concentrations in natural waters containing organic carbon are observed to be greatly dependent on light intensity (Collienne, 1983; McKnight et al., 1988; Sulzberger et al., 1990). The reduction of Fe(III) by secondary processes, such as by reaction with photoproduced superoxide radical $\left(\mathrm{HO}_{2} / \mathrm{O}_{2}^{-}\right)$(which can either reduce $\mathrm{Fe}(\mathrm{III})$ or oxidize $\mathrm{Fe}(\mathrm{II})$ depending on solution conditions), has not been given much attention but can be significant, especially in systems where $\mathrm{Fe}$ (III)-organic complexes are 


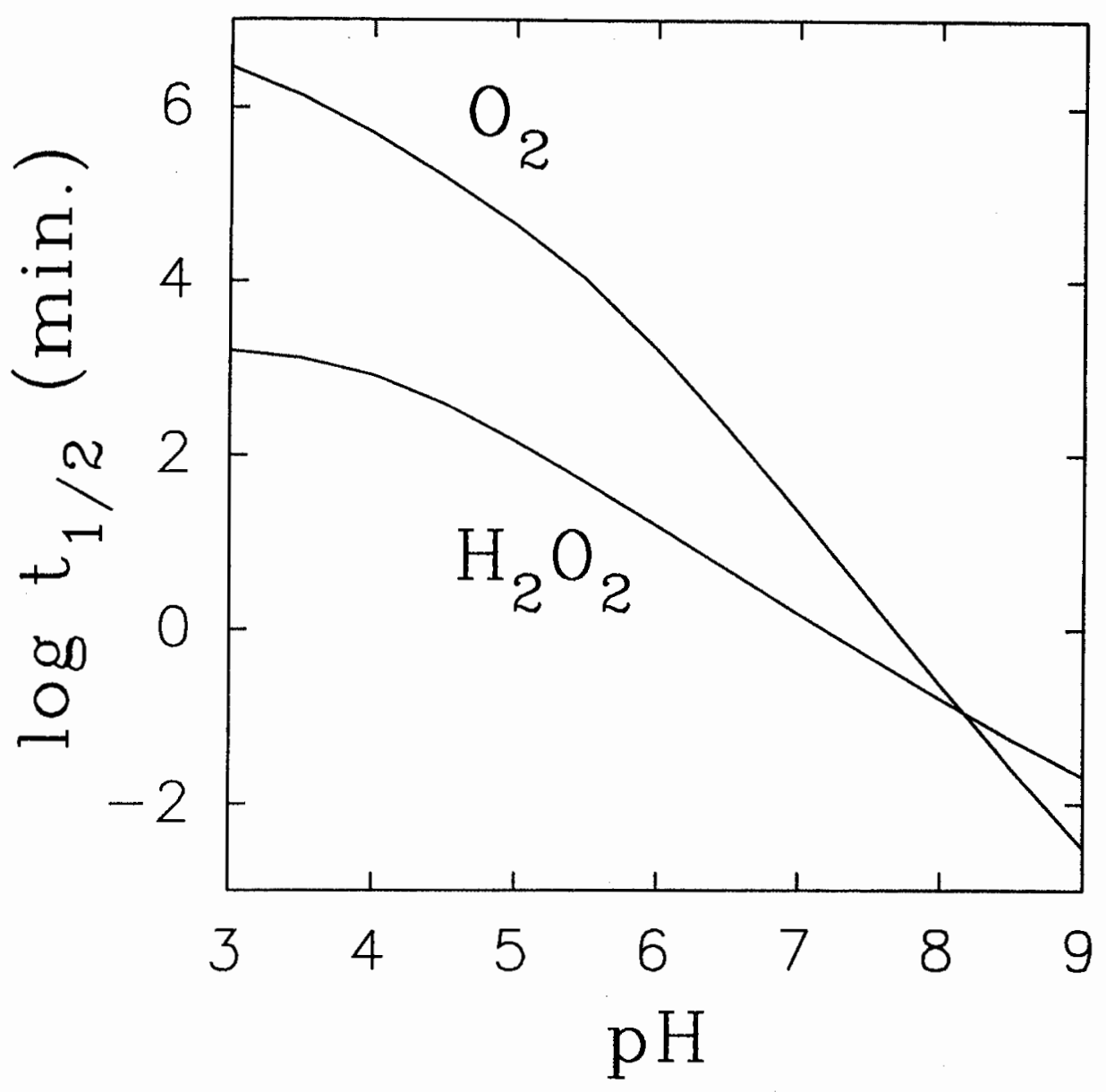

Figure 2.4. Effect of $\mathrm{pH}$ on the half-life of $\mathrm{Fe}(\mathrm{II})$ with respect to oxidation by oxygen $\left(\mathrm{PO}_{2} \mathrm{O} .2 \mathrm{~atm}\right)$ and hydrogen peroxide $\left(\left[\mathrm{H}_{2} \mathrm{O}_{2}\right]=0.1\right.$ $\mu M)$ at $25^{\circ} \mathrm{C}$. Half-lives were calculated for an ionic strength of 0 using rate constants from Wehrli (1990) for oxygen and Millero and Sotolongo (1989) for hydrogen peroxide. In seawater the half-life of $\mathrm{Fe}(I I)$ is greater than shown in this figure, because complexation of $\mathrm{Fe}(\mathrm{II})$ by chloride slows its oxidation by both oxygen and hydrogen peroxide (Millero et al., 1987; Moffett and Zika; 1987b; Millero and Sotolongo, 1989). 
absent (see chapter 6). Once Fe(II) is formed, it is primarily re-oxidized by oxygen or hydrogen peroxide. The expected half-life of aqueous $\mathrm{Fe}(\mathrm{II})$ in the presence of concentrations of oxygen and hydrogen peroxide typical for surface waters (in the absence of complexation by organic or inorganic ligands) is strongly affected by $\mathrm{pH}$ (Figure 2.4). In acidic waters, $\mathrm{Fe}(\mathrm{II})$ remains stable to oxidation for long periods of time. However, at alkaline $\mathrm{pH}$, measurable amounts of $\mathrm{Fe}$ (II) will be found only if iron-reducing processes are fast enough to generate $\mathrm{Fe}(\mathrm{II})$ as quickly as it disappears again by oxidation. (The analytical method also has to be fast enough to "catch" this $\mathrm{Fe}$ (II) without in itself causing further $\mathrm{Fe}$ (II) reduction; $\mathrm{Fe}$ (II)-complexing ligands such as ferrozine, used for colorimetric detection of $\mathrm{Fe}(\mathrm{II})$, are somewhat problematic in this aspect.)

Light can have an effect not only on the rate of Fe(III) reduction but also on the rate of $\mathrm{Fe}$ (II) oxidation. In the presence of light and dissolved organic matter, superoxide radical $\left(\mathrm{HO}_{2} / \mathrm{O}_{2}{ }^{-}\right)$is formed through reduction of oxygen by photo-excited organic compounds. The end product of superoxide dismutation is hydrogen peroxide. An effect of light on hydrogen peroxide concentration can therefore be observed in fresh (Cooper and Zika, 1983; Cooper and Lean, 1989; Sturzenegger, 1989) and marine (Szymczak and Waite, 1988; Moore et al., 1993) surface waters. The rate of $\mathrm{Fe}$ (II) oxidation is faster when hydrogen peroxide concentrations are higher, and superoxide radical $\left(\mathrm{HO}_{2} / \mathrm{O}_{2}^{-}\right)$can also oxidize $\mathrm{Fe}(\mathrm{II})$.

Organic complexation of $\mathrm{Fe}(\mathrm{II})$ can change the rates of its oxidation by oxygen or hydrogen peroxide. In general, it is observed that complexation of $\mathrm{Fe}$ (II) by a ligand which binds Fe(III) more strongly than Fe(II) (such as a carboxylate-type ligand) will increase the rate of oxidation while a ligand which binds $\mathrm{Fe}(\mathrm{II})$ more strongly than $\mathrm{Fe}$ (III) (such as ferrozine) stabilizes Fe(II) against oxidation. 


\section{Chapter 3: Experimental Materials and Methods}

\subsection{Materials}

Suwannee River Fulvic Acid was isolated by J. Leenheer according to the method described in Leenheer (1981). Fresh SRFA stock solutions were prepared every month and stored in the refrigerator.

Lepidocrocite was synthesized by slow oxidation of $\mathrm{Fe}$ (II) near neutral $\mathrm{pH}$, as described in Schwertmann and Cornell (1991). The identity of the product was verified using FTIR spectroscopy. The synthesis was carried out in a polypropylene vessel at room temperature, and lepidocrocite was stored in suspension in a polypropylene bottle kept in the dark at $4{ }^{\circ} \mathrm{C}$. The same batch of lepidocrocite was used in all of the experiments.

All reagents used were reagent grade unless otherwise mentioned. All glassware and other vessels were soaked in $0.1 \mathrm{~N} \mathrm{HCl}$ for at least 12 hours before use.

\subsection{Analytical methods}

3.2.1 Hydrogen peroxide analysis with simultaneous measurement of $\mathrm{Fe}(\mathrm{II})$

Hydrogen peroxide was analyzed using a modified version of the DPD method developed by Bader et al. (1988). In this method, the peroxidase-catalyzed oxidation of DPD (N,N-diethyl-p-phenylenediamine) by hydrogen peroxide results in a colored product $\left(\varepsilon_{\max }=21000 \pm 500 \mathrm{M}^{-1} \mathrm{~cm}^{-1}\right.$ at $551 \mathrm{~nm}$, Bader et al., 1988). The DPD method of Bader et al. (1988) had to be modified, because both Fe(II) and $\mathrm{Fe}(\mathrm{III})$ in micromolar concentrations were found to interfere with the 


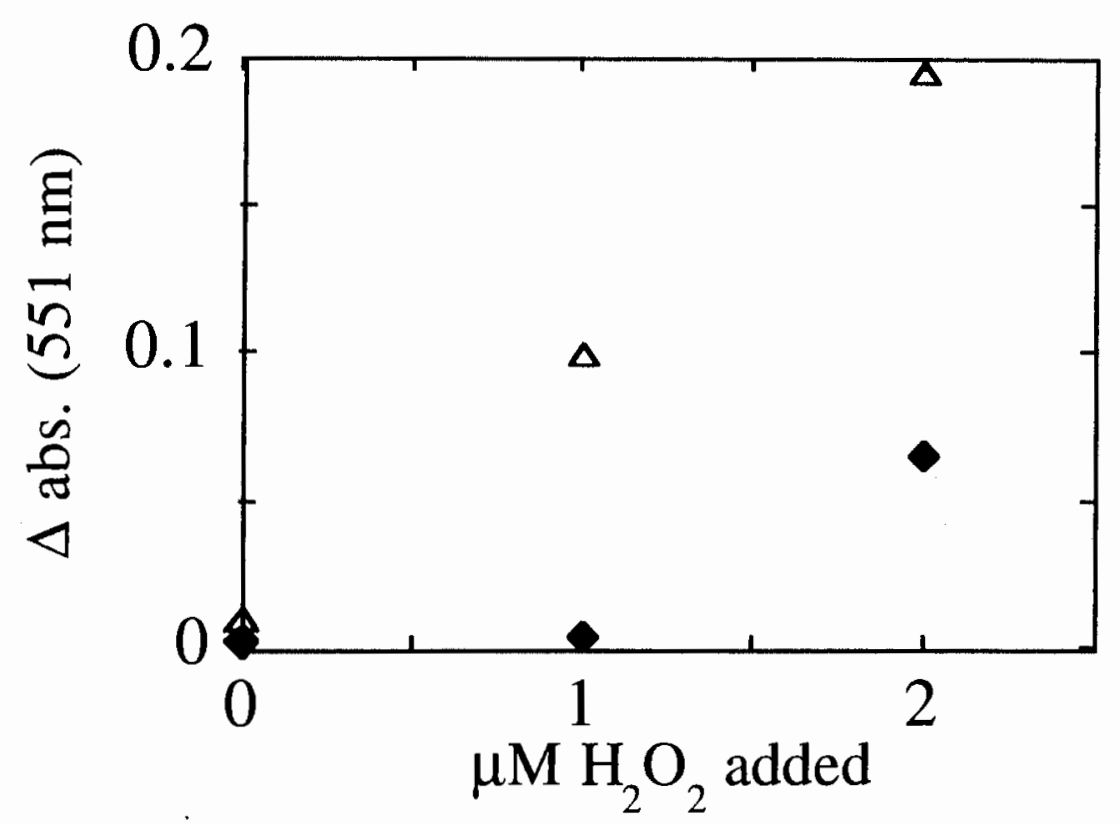

Figure 3.1. Effect of $F e(I I)$ on hydrogen peroxide measurement using the DPD method. Triangles represent absorbance measurement at 551 $\mathrm{nm}$ as a function of added hydrogen peroxide concentration in the absence of added Fe(II), diamonds show measurements in the presence of $5 \mu \mathrm{M}$ added $\mathrm{Fe}(I I)$.

measurements: Fe(II) decreased the observed signal, possibly by rereduction of the colored product (Sedlak and Hoigné, 1993 and Figure 3.1), while Fe(III) had a slight effect on the blank measurements. To minimize this interference, bipyridine was added to complex $\mathrm{Fe}(\mathrm{II})$, and EDTA to complex Fe(III). Because bipyridine forms a colored complex with $\mathrm{Fe}$ (II) ( $\varepsilon=8650$ at $522 \mathrm{~nm}$, Moss and Mellon, 1942), this method also provided a convenient simultaneous $\mathrm{Fe}(\mathrm{II})$ measurement.

The modified procedure consisted of the following steps: $0.5 \mathrm{ml}$ of bipyridine stock $\left(0.01 \mathrm{M}\right.$ bipyridine in approx. $\left.10^{-3} \mathrm{M} \mathrm{HClO}_{4}\right)$ and $2 \mathrm{ml}$ of a $\mathrm{pH} 6$ phosphate buffer $(0.5 \mathrm{M}$ total phosphate) were premixed in a 


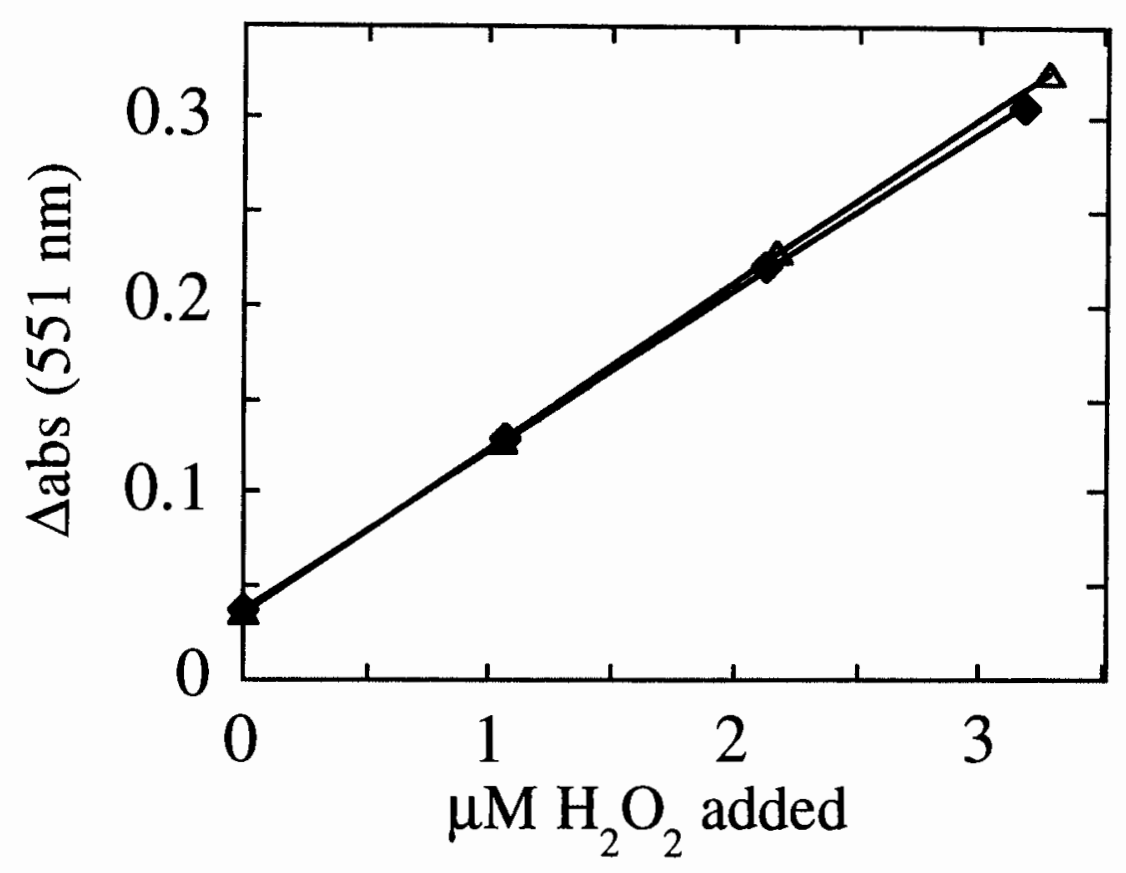

Figure 3.2. Hydrogen peroxide measurement using the modified DPD method described in section 3.2.1. Solutions are at $p H 3$ and contain $10 \mathrm{mg} / \mathrm{l}$ SRFA. Triangles: measurements in the absence of added Fe. Diamonds: measurements in the presence of $5 \mu \mathrm{M}$ added $\mathrm{Fe}(\mathrm{II})$ and $5 \mu \mathrm{M}$ added $\mathrm{Fe}(I I I)$.

Slopes of linear regressions are $0.0885\left(\varepsilon=22300 \mathrm{M}^{-1} \mathrm{~cm}^{-1}, r^{2}=1.000\right)$ in the absence of added $\mathrm{Fe}$, and $0.0852\left(\varepsilon=21500 \mathrm{M}^{-1} \mathrm{~cm}^{-1}, r^{2}=1.000\right)$ in the presence of Fe.

$5-\mathrm{cm}$ cell, to which $10 \mathrm{ml}$ of sample (filtered, if necessary) were then added, followed by $0.1 \mathrm{ml}$ of EDTA stock $\left(10^{-2} \mathrm{M} \mathrm{Na}_{2}\right.$ EDTA). After approximately 60 seconds, absorbance was measured at $522 \mathrm{~nm}$ (for the $\mathrm{Fe}$ (II) measurement) and at $551 \mathrm{~nm}$ (as a blank for the hydrogen peroxide measurement). $50 \mu \mathrm{l}$ of the DPD reagent $\left(3.8 \times 10^{-2} \mathrm{M}\right.$ in $0.1 \mathrm{M}$ $\mathrm{H}_{2} \mathrm{SO}_{4}$ ) were then added, followed by $25 \mu \mathrm{l}$ of the horseradish peroxidase 
reagent (100 units $/ \mathrm{ml})$. The absorbance at $551 \mathrm{~nm}$ was measured again after 45 seconds. DPD and peroxidase reagents were stored in the dark at $4^{\circ} \mathrm{C}$ and not kept for longer than two weeks.

Calibration curves in the presence of $\mathrm{Fe}(\mathrm{II})$ and $\mathrm{Fe}$ (III) and $10 \mathrm{mg} / \mathrm{l}$ SRFA ( $\mathrm{pH} 3$ ) demonstrate that this modified method eliminated the interference of iron at micromolar concentrations and that the fulvic acid did not interfere with $\mathrm{H}_{2} \mathrm{O}_{2}$ measurements (Figure 3.2). Calculated extinction coefficients $\left(22300 \mathrm{M}^{-1} \mathrm{~cm}^{-1}\right.$ and $21470 \mathrm{M}^{-1} \mathrm{~cm}^{-1}$ in the absence and presence of $\mathrm{Fe}$, respectively) agree well with the value found by Bader et al. (1988). For the Fe(II) measurement in the presence of fulvic acid, an extinction coefficient of $8300 \mathrm{M}^{-1} \mathrm{~cm}^{-1}$ was found for the bipyridine complex, in good agreement with the literature constant.

\subsubsection{Measurement of iron}

\subsubsection{Colorimetry}

$\mathrm{Fe}$ (II) was analyzed colorimetrically using the reagents bipyridine and ferrozine. Total Fe was measured using a reducing agent and ferrozine. The bipyridine measurement was made in conjunction with $\mathrm{H}_{2} \mathrm{O}_{2}$ analysis and is described in section 3.2.1 above. The ferrozine procedure we used is a slightly modifed version of the method developed by Stookey (1970).

For the Fe(II) measurements in chapters 4 and $5,1.0 \mathrm{ml}$ of the sample was added to $60 \mu \mathrm{l}$ of acid solution ( $3.6 \mathrm{M} \mathrm{H}_{2} \mathrm{SO}_{4}$ ). $240 \mu \mathrm{l}$ of ferrozine reagent $(4.9 \mathrm{mM})$ and $100 \mu \mathrm{l}$ acetate buffer (193 $\mathrm{g}$ ammonium acetate and $170 \mathrm{ml} 25 \% \mathrm{NH}_{4} \mathrm{OH}$ per $500 \mathrm{ml}$ water) were immediately added. Absorbance at $562 \mathrm{~nm}$ was measured within 90 seconds using a $5 \mathrm{~cm}$ small-volume cell. Because Fe(III) is slowly reduced by fulvic acid, immediate measurement of the absorbance was crucial. Masking of $\mathrm{Fe}$ (III) by EDTA was not found to alleviate this problem. Fulvic acid did not otherwise interfere with $\mathrm{Fe}$ measurement. 
For a measurement of total dissolved $\mathrm{Fe}$, the procedure was the same as for the $\mathrm{Fe}(\mathrm{II})$ measurement, except that $60 \mu \mathrm{l}$ of a reducing reagent (104 $\mathrm{g}$ of $\mathrm{OHNH}_{3} \mathrm{Cl}$ and $200 \mathrm{ml}$ of $32 \% \mathrm{HCl}$ in $500 \mathrm{ml}$ water) were used instead of $\mathrm{H}_{2} \mathrm{SO}_{4}$ in the first step. Also, the sample/reducing agent mixture was left to stand for several minutes before addition of the ferrozine and buffer, to allow complete reduction of $\mathrm{Fe}(\mathrm{III})$ to take place.

When Fe was measured in lepidocrocite suspensions, the samples were first filtered through $0.1 \mu \mathrm{m}$ cellulose nitrate filters. Filtering of solutions which did not contain lepidocrocite did not affect the iron measurements.

For a measurement of total $\mathrm{Fe}$ in the suspensions, a $1 \mathrm{ml}$ unfiltered sample of the solution was mixed with $1 \mathrm{ml}$ of the reducing reagent and left to stand for at least 48 hours. $4 \mathrm{ml}$ of ferrozine reagent and $1.5 \mathrm{ml}$ of the buffer were then added to this mixture and the solution was made up to a total volume of $25 \mathrm{ml}$ with water. Absorbance was measured at $562 \mathrm{~nm}$ in a $5 \mathrm{~cm}$ cell.

During the $\gamma$-irradiation experiments described in chapter 6 , a different procedure was used for $\mathrm{Fe}$ (II) analysis. The ferrozine was added directly to the samples within ten seconds after removal from the radiation chamber to prevent reoxidation of $\mathrm{Fe}(\mathrm{II})$ by the hydrogen peroxide produced during irradiation. In the samples below $\mathrm{pH} 4, \mathrm{NaHCO}_{3}$ was added to increase the $\mathrm{pH}$ to a value optimal for the formation of the $\mathrm{Fe}(\mathrm{II})$-ferrozine complexes (Stookey, 1970). The absorbance of the $\mathrm{Fe}(\mathrm{II})$-ferrozine complex at $562 \mathrm{~nm}$ was measured in a $10-\mathrm{cm}$ cell.

\subsubsection{Chemiluminescence}

In the $\mathrm{Fe}$ reduction experiments in chapter 4 and in the seawater experiments in chapter $6, \mathrm{Fe}$ (II) was analyzed in a flow system designed by King et al. (in press) using a highly sensitive method (Seitz and Hercules, 1972; Klopf and Nieman, 1983; O'Sullivan et al., submitted) 


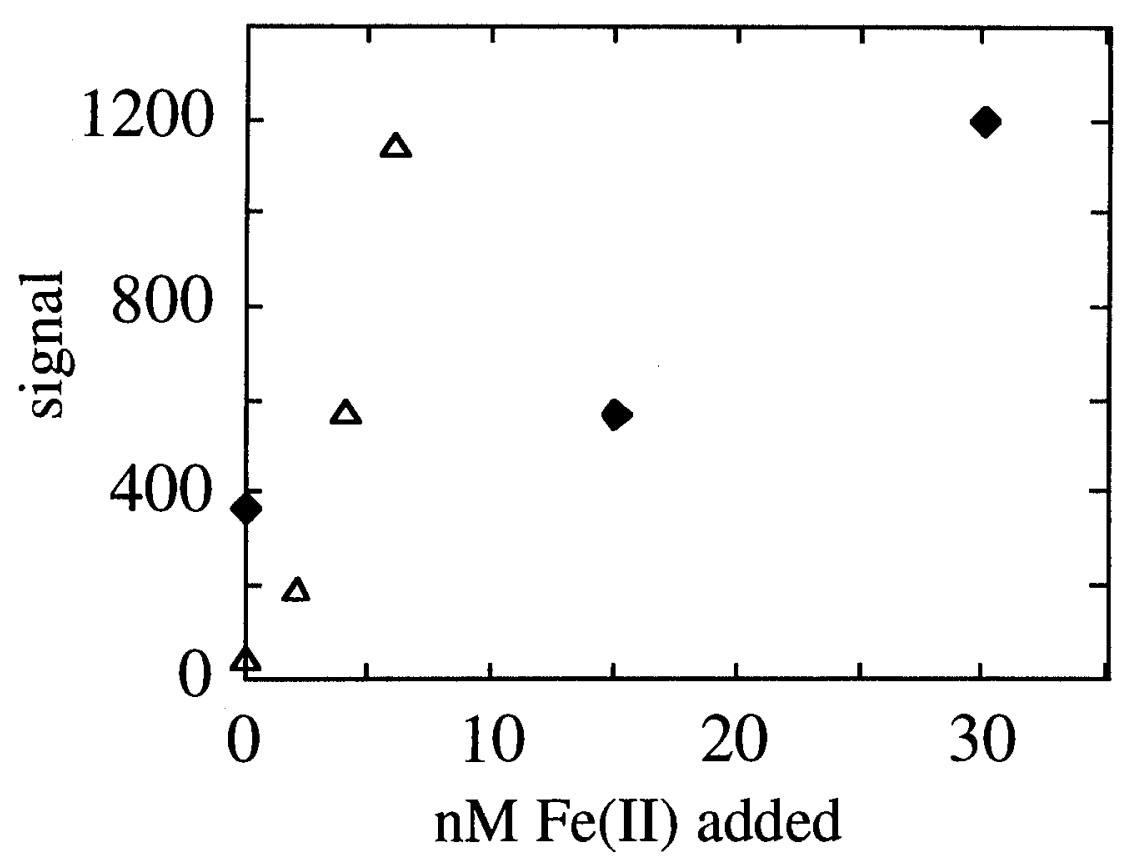

Figure 3.3. Integrated PMT signal as a function of added $\mathrm{Fe}(I I)$ in seawater solutions at $\mathrm{pH} 7.3$ (triangles) and in $10 \mathrm{mg} / \mathrm{l}$ SRFA solutions at pH 3 (diamonds). pH does not greatly affect the measurement in the seawater solutions.

which relies upon the production of chemiluminescence by the oxidation of $\mathrm{Fe}$ (II) in the presence of luminol. During analysis, an injection of sample solution was mixed with the luminol reagent in a mixing cell placed in front of a photomultiplier tube (PMT). An analog-to-digital converter sent the PMT signal to a computer, which integrated the signal during the 30 seconds of sample injection. Between injections, the mixing cell was rinsed by the carrier solution. This set-up is described in detail in King et al. (in press). Fluctuations in the dark current of the PMT resulted in a variability of \pm 100 units in the integrated signal, corresponding to a current fluctuation of approximately $\pm 0.5 \mathrm{nA}$. The luminol reagent was prepared in a $\mathrm{pH} 10$ borate buffer $(12.2 \mathrm{~g}$ boric acid, 


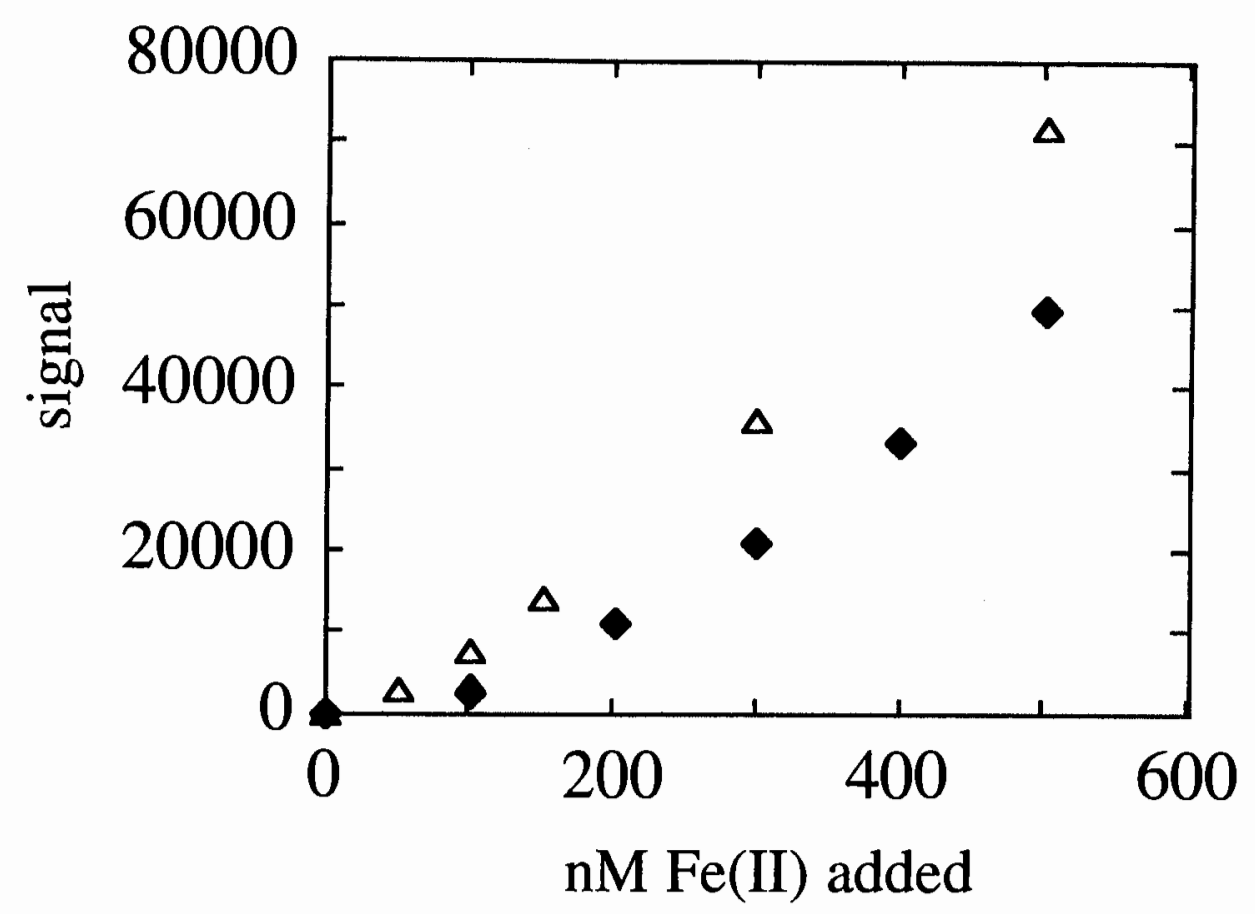

Figure 3.4. Integrated PMT signal as a function of added $F e(I I)$ in solutions of $10 \mathrm{mg} / \mathrm{SRFA}$ at $\mathrm{pH} 3$ (triangles) and $\mathrm{pH} 5$ (squares).

$6.9 \mathrm{~g} \mathrm{NaOH}, 0.1 \mathrm{~g}$ luminol in $1 \mathrm{l}$ of water) and left in the dark for several days before use. A $0.4 \mathrm{mM} \mathrm{NaHCO} 3$ solution was used as the carrier solution. When seawater samples were analyzed, both the carrier and the reagent solutions were made up in $0.7 \mathrm{M} \mathrm{NaCl}$ to prevent mixing problems due to density differences of the sample, reagent, and carrier solutions. New calibration curves were prepared for each experimental system and on each day. Because the efficiency of the luminol reagent is apparently affected by aging (King et al., in press), some variability in the calibration curves was observed from one day to the next (up to a factor of two difference in signal).

In the presence of $10 \mathrm{mg} / \mathrm{l}$ fulvic acid, the sensitivity of the method was found to be greatly decreased (Figure 3.3). This effect was stronger at 
$\mathrm{pH} 5$ than at $\mathrm{pH} 3$ (Figure 3.4). It is possible that the fulvic acid interferes with the measurement by scavenging one of the radical intermediates necessary for the production of chemiluminescence. A second possibility is that nanomolar concentrations of strong $\mathrm{Fe}(\mathrm{II})$ binding sites present in the fulvic acid prevent oxidation of $\mathrm{Fe}$ (II) and therefore its measurement by the luminol method. Because of this decrease in sensitivity, analysis of Fe(II) at nanomolar concentrations was not possible in the presence of fulvic acid. Measurements of $\mathrm{Fe}$ (II) concentrations above $50 \mathrm{nM}$ were still found to be reliable. In the seawater systems, $\mathrm{Cu}(\mathrm{II})$ at concentrations greater than $5 \mathrm{nM}$ was found to lower the sensitivity of the luminol method, and new calibration curves were prepared for the experiment in the presence of $10 \mathrm{nM} \mathrm{Cu}$ (II). $\mathrm{Mn}$ (II) (10 nM) did not interfere with the measurement. The detection limit of this method was approximately $1 \mathrm{nM}$ in the seawater solutions, 10 $\mathrm{nM}$ in the presence of $10 \mathrm{mg} / \mathrm{l} \mathrm{SRFA}$ at $\mathrm{pH} \mathrm{3}$, and $20 \mathrm{nM}$ in SRFA solutions at $\mathrm{pH} 5$.

\subsection{Experimental procedures}

\subsubsection{Fe(II) oxidation by $\mathrm{H}_{2} \mathrm{O}_{2}$}

The experiments examining the kinetics of the reaction of $\mathrm{Fe}$ (II) with $\mathrm{H}_{2} \mathrm{O}_{2}$ described in chapter 4 were carried out in the dark at constant temperature $\left(25^{\circ} \mathrm{C}\right)$ in a pyrex reactor equipped with a water jacket. All experiments were conducted in $10 \mathrm{mM} \mathrm{NaClO}_{4}$. For each experiment, the reaction solution of $\mathrm{Fe}$ (II) and SRFA at the desired concentrations was prepared the night before. The $\mathrm{pH}$ was adjusted to the desired value with $\mathrm{HClO}_{4}$ or $\mathrm{NaOH}$. Solutions were de-aerated by purging overnight with nitrogen which had first been scrubbed of trace amounts of oxygen with a Jones reductor (Skoog and West, 1969). Aerated solutions were bubbled with a $20 \% \mathrm{O}_{2} / 80 \% \mathrm{~N}_{2}$ ("synthetic air") mixture prior to and during the experiments. For experiments in the presence of $\mathrm{NO}_{(\mathrm{aq})}$, solutions were 
bubbled with a $1000 \mathrm{ppm} \mathrm{NO}_{(\mathrm{g})} / \mathrm{N}_{2}$ mixture (aerated solutions were simultaneously bubbled with the $\mathrm{O}_{2} / \mathrm{N}_{2}$ mixture) for several hours prior to, and during, the experiments.

To initiate the reaction, $\mathrm{H}_{2} \mathrm{O}_{2}$ was injected by syringe into the solutions through a rubber septum. For the de-aerated solutions, great care was taken not to introduce oxygen into the system, and the $\mathrm{H}_{2} \mathrm{O}_{2}$ stock solutions were de-aerated before use. Aliquots of the solutions for analysis were removed with a syringe attached to the sampling outlet. $\mathrm{H}_{2} \mathrm{O}_{2}$ and $\mathrm{Fe}$ (II) were determined using the modified DPD method described in section 3.2.1. Total Fe was determined using ferrozine (section 3.2.2.1). The $\mathrm{pH}$ was monitored continuously using a combined glass electrode (Metrohm) filled with $\mathrm{NaClO}_{4}$, which had been calibrated with standard buffer solutions (Merck).

\subsection{2 $\mathrm{Fe}(\mathrm{III})$ dark reduction experiments}

For the Fe(III) dark reduction experiments described in chapter 4, solutions of $10 \mathrm{mg} / \mathrm{SRFA}$ in $10 \mathrm{mM} \mathrm{NaClO}_{4}$ were prepared and the $\mathrm{pH}$ was adjusted to the desired value with $\mathrm{HClO}_{4}$ or $\mathrm{NaOH}$. Fe(III) was added from acidified $\mathrm{Fe}\left(\mathrm{NO}_{3}\right)_{3} \cdot 9 \mathrm{H}_{2} \mathrm{O}$ stock solutions freshly prepared every day. $\mathrm{Fe}$ (II) concentration was monitored using the luminol chemiluminescence flow system (section 3.2.2.2). When Fe(II) concentrations were too high to be measured by this method ( $>2 \mu \mathrm{M})$, ferrozine was used. Ferrozine measurements agreed well with the measurements carried out using the luminol method. Solutions were kept in a water bath at $25^{\circ} \mathrm{C}$ for temperature control during the experiments.

\subsubsection{Adsorption isotherms}

For the adsorption isotherms in chapter 5, lepidocrocite was added from a stock suspension to solutions of varying concentrations of SRFA. The solutions were stirred overnight at room temperature $\left(20-22^{\circ} \mathrm{C}\right)$. Solutions were then centrifuged (10,000 r.p.m., 20 minutes) and the 
supernatant was analyzed spectrophotometrically. SRFA concentration in the supernatant was determined by comparing the absorbance spectrum to that of a reference solution of $10 \mathrm{mg} / \mathrm{l}$ fulvic acid (300 to $600 \mathrm{~nm}$ ). The shape of the spectrum in the supernatant was not significantly different from that in the reference solution, indicating that preferential adsorption of some fraction of the fulvic acid did not take place. No decrease in SRFA concentration was observed from stirring and centrifugation of solutions without added lepidocrocite.

At $\mathrm{pH} 5$, centrifugation was not sufficient to remove all the lepidocrocite from the supernatant. Small concentrations of these particles had a significant effect on the absorbance spectra. To minimize this problem, the supernatant was filtered $(0.45 \mu \mathrm{m}$, cellulose nitrate) after centrifugation. Since small amounts of fulvic acid were found to be removed by the filter $(<5 \%)$, spectra were compared to a reference spectrum of a solution of $10 \mathrm{mg} / \mathrm{l}$ fulvic acid which had also been filtered.

\subsubsection{Experiments in lepidocrocite suspensions}

The experiments in chapter 5 were conducted in the reactor set-up described in section 3.3.1. All solutions contained $10 \mathrm{mM} \mathrm{NaClO}_{4}$ and $10 \mathrm{mg} / 1$ SRFA. Lepidocrocite, when present, was added from a stock suspension kept in the dark at $4^{\circ} \mathrm{C}$ in a polypropylene bottle. The lepidocrocite solutions were vigorously stirred before and during the experiments to prevent settling of the particles. The same stock suspension was used for all the experiments. To de-aerate systems, the air in the headspace of the reactor was removed by connecting the reactor to a vacuum pump. The headspace was then filled with nitrogen gas. This procedure was repeated several times. To allow equilibration of the lepidocrocite surface with the solution, solutions were left to condition overnight in the dark before experiments were begun. Aerated solutions were bubbled with synthetic air, de-aerated solutions with scrubbed nitrogen gas, as described in section 3.3.1. Solutions were irradiated with 
Chapter 3

white light by a 1000W high pressure xenon lamp (OSRAM) through a quartz window on the bottom of the reactor (see section 3.4).

\subsection{5 $\gamma$-radiolysis experiments (Chapter 6)}

Continuous radiolysis of water is a well-characterized method of generating superoxide in the absence of photochemical reactions (Hoigné, 1975; Sedlak and Hoigné, 1993; Sedlak and Hoigné, 1994). An $\mathrm{O}_{2}^{-}$flux of approximately $18 \mathrm{nM} / \mathrm{s}$, several orders of magnitude higher than the measured production rate in sunlit open-ocean seawater (Moore et al., 1993; Micinski et al., 1993), was generated by exposing solutions to $\gamma$ radiation emitted by a ${ }^{60} \mathrm{Co}$ source (type GAMMACELL, radiation 0.42 $\mathrm{kGy} \mathrm{h}^{-1}$ at the center of the source; see Sedlak and Hoigné, 1993, for details of this experimental setup).

All solutions were air-saturated and contained $10 \mathrm{mM}$ formaldehyde (to convert radiolytically-produced $\mathrm{OH}$ radical to $\mathrm{O}_{2}^{-}$) and $2.5 \mathrm{mM} \mathrm{NaHCO}_{3}$ (as a buffer). Iron was initially added to the solutions as either Fe(II) or $\mathrm{Fe}$ (III) from acidified stock solutions, prepared each day, of $\left(\mathrm{NH}_{4}\right)_{2} \mathrm{Fe}(\mathrm{II})\left(\mathrm{SO}_{4}\right)_{2} \cdot 6 \mathrm{H}_{2} \mathrm{O}$ and $\mathrm{Fe}(\mathrm{III})\left(\mathrm{ClO}_{4}\right)_{3} \cdot 9 \mathrm{H}_{2} \mathrm{O}$. $\mathrm{NaCl}$ was added to solutions from a $5 \mathrm{M} \mathrm{NaCl}$ stock solution which had been passed through columns filled with chelex resin prior to use. The $\mathrm{pH}$ was adjusted with $\mathrm{HClO}_{4}$ and measured with a combined $\mathrm{pH}$ electrode (Metrohm) calibrated at room temperature using standard buffers (Merck). All experiments were performed at room temperature $\left(21-23^{\circ} \mathrm{C}\right)$.

Test solutions in 50-ml polypropylene flasks were placed in the irradiation chamber until steady-state concentrations of $\mathrm{Fe}$ (II) were reached ( 6 minutes for the solutions containing $300 \mathrm{nM} \mathrm{Fe}, 2$ minutes for the $60 \mathrm{nM}$ solutions). Longer exposures were avoided to prevent high hydrogen peroxide concentrations from accumulating. Fe(II) was measured using ferrozine (section 3.2.2.1). 
The procedure for the copper experiments was nearly identical to the one used for the iron experiments. Reaction solutions had the same composition as described above; instead of iron, $300 \mathrm{nM} \mathrm{Cu}$ (II) were added from a stock solution of $\mathrm{CuCl}_{2} \cdot 2 \mathrm{H}_{2} \mathrm{O} . \mathrm{Cu}(\mathrm{I})$ was measured spectrophotometrically using bathocuprine disulfonic acid (Moffett and Zika, 1987a) in a 10-cm cell. Total copper was also measured, in an aliquot taken from each sample prior to irradiation, by the addition of a reducing agent $\left(\mathrm{HONH}_{3} \mathrm{Cl}\right)$ to the sample before the addition of the colorimetric reagent.

\subsubsection{Seawater experiments (chapter 6)}

Seawater was collected from the Northern Atlantic, $36^{\circ} 14^{\prime} \mathrm{N}, 70^{\circ} 32^{\prime} \mathrm{W}$ in July 1990, filtered, and stored at room temperature. Immediately before each experiment, a 50-ml sample of this water in a pyrex volumetric flask was acidified to $\mathrm{pH} 7.3$ with ultrapure $\mathrm{HCl} .5 \mathrm{nM}$ of $\mathrm{Fe}(\mathrm{II})$ or $\mathrm{Fe}(\mathrm{III})$ were added from freshly prepared acidic stock solutions of $\left(\mathrm{NH}_{4}\right)_{2} \mathrm{Fe}(\mathrm{II})\left(\mathrm{SO}_{4}\right)_{2} \cdot 6 \mathrm{H}_{2} \mathrm{O}$ or $\mathrm{Fe}(\mathrm{III})\left(\mathrm{NO}_{3}\right)_{3} \cdot 9 \mathrm{H}_{2} \mathrm{O} . \mathrm{Mn}(\mathrm{II})$ and $\mathrm{Cu}(\mathrm{II})$, when present, were added from acidic stock solutions of $\mathrm{MnSO}_{4} \cdot 4 \mathrm{H}_{2} \mathrm{O}$ or $\mathrm{CuSO}_{4} \cdot 5 \mathrm{H}_{2} \mathrm{O}$. The samples were then placed directly in front of the light source in a pyrex beaker containing crushed ice, to maintain a temperature of $5^{\circ} \mathrm{C}$ during illumination. (Light of wavelengths below $300 \mathrm{~nm}$ was filtered out by the pyrex glass of the reaction vessel and beaker.) The total incident light on the flasks in this system was roughly equivalent to that on the reaction vessel used for the previous experiments (see actinometry measurements in section 3.4.1). Fe(II) was analyzed in a flow system by the luminol chemiluminescence method (section 3.2.2.2). 


\subsection{Characterization of light conditions in the irradiated systems}

\subsubsection{Actinometry}

Chemical actinometry can be used to accurately measure average incident light intensity if the quantum yield of the actinometer is constant within the range of wavelengths of the light hitting the reaction vessel. Because no chemical actinometer satisfies this condition for the full range of wavelengths of the white light produced by our lamp, we measured the average incident light intensity on the reaction vessel through a narrow band filter (transmission maximum at $436 \mathrm{~nm}$ ) using ferrioxalate actinometry (Hatchard and Parker, 1956). Potassium ferrioxalate $\left(\mathrm{K}_{3} \mathrm{Fe}\left(\mathrm{C}_{2} \mathrm{O}_{4}\right)_{3} \cdot 3 \mathrm{H}_{2} \mathrm{O}\right.$ was synthesized from $\mathrm{FeCl}_{3}$ and potassium oxalate and purified by recrystallization. The $0.15 \mathrm{M}$ solutions of ferrioxalate were bubbled with nitrogen during irradiation in the quartz-bottom reaction vessel. Aliquots of the solution were removed and $\mathrm{Fe}$ (II) measured using ferrozine. The rate of $\mathrm{Fe}$ (II) formation was roughly a linear function of the power setting at which the lamp was run. At $200 \mathrm{~W}$, the power setting used in all of our experiments, the formation rate of $\mathrm{Fe}$ (II) was $38.9 \mu \mathrm{M} \mathrm{min}{ }^{-1}$. At a ferrioxalate concentration of 0.15 $\mathrm{M}$ and an optical depth of about $3 \mathrm{~cm}$ (solution volume $0.2 \mathrm{l}$, vessel radius $4.5 \mathrm{~cm}$ ), all of the incident light on the reactor was absorbed by the ferrioxalate complex. Under these conditions, the incident photon flux per volume is equal to the rate of $\mathrm{Fe}(\mathrm{II})$ formation divided by the quantum yield. An Fe(II) formation rate of $38.9 \mu \mathrm{M} \mathrm{min}^{-1}$ corresponds to a photon flux of $20.2 \mu \mathrm{E} \mathrm{m} \mathrm{m}^{-2} \mathrm{sec}^{-1}$, assuming a quantum yield of 1.01 for the ferrioxalate reaction within the range of wavelengths passing through the narrow band filter (Hatchard and Parker, 1956).

The total light intensity hitting the vessel in our experiments, when the light was not filtered, could be calculated from the value of the photon flux of the filtered light, the transmission spectrum of the filter, and the 
spectrum of unfiltered light. At a power setting of $200 \mathrm{~W}$, the incident light intensity on the reaction vessel was calculated to be $0.5 \mathrm{~kW} \mathrm{~m}^{-2}$, or approximately one half of the intensity of sunlight at mid-latitude solar noon.

3.4.2 Comparison of the average light intensity in different reaction solutions

At the concentrations used in our experiments, fulvic acid and lepidocrocite both absorb significant amounts of light within the path length of the reaction solution. This means that the average light intensity in the vessel is smaller than the incident light intensity, and the average light intensity in a solution containing both fulvic acid and lepidocrocite is smaller than the average light intensity in a solution containing fulvic acid alone. If we assume that the amount of light scattering by the lepidocrocite particles is negligible, we can calculate the effect of lepidocrocite and fulvic acid on the average light intensity in the solutions from their absorption spectra.

At each wavelength $\lambda$, the light intensity at a depth $\mathrm{x}$ into the solution, $\mathrm{I}_{\lambda}(\mathrm{x})$, is given by:

$\mathrm{I}_{\lambda}(\mathrm{x})=\mathrm{I}_{\lambda, 0} \cdot \mathrm{e}^{-2.303 \cdot \alpha_{\lambda} \cdot \mathrm{x}}$

where $\mathrm{I}_{\lambda, 0}$ is the incident light intensity at wavelength $\lambda$, and $\alpha_{\lambda}$ is the attenuation coefficient of the solution in units of distance ${ }^{-1}$ (Leifer, 1988). The $\alpha_{\lambda}$ values of a solution of $10 \mathrm{mg} / 1$ SRFA and those of a solution of $10 \mathrm{mg} / \mathrm{l}$ SRFA plus $45 \mu \mathrm{M} \gamma-\mathrm{FeOOH}$, measured using a spectrophotometer, are shown in Figure 3.5 (the light attenuation by the reference solution used in the spectrophotometer, distilled water, was negligible). 


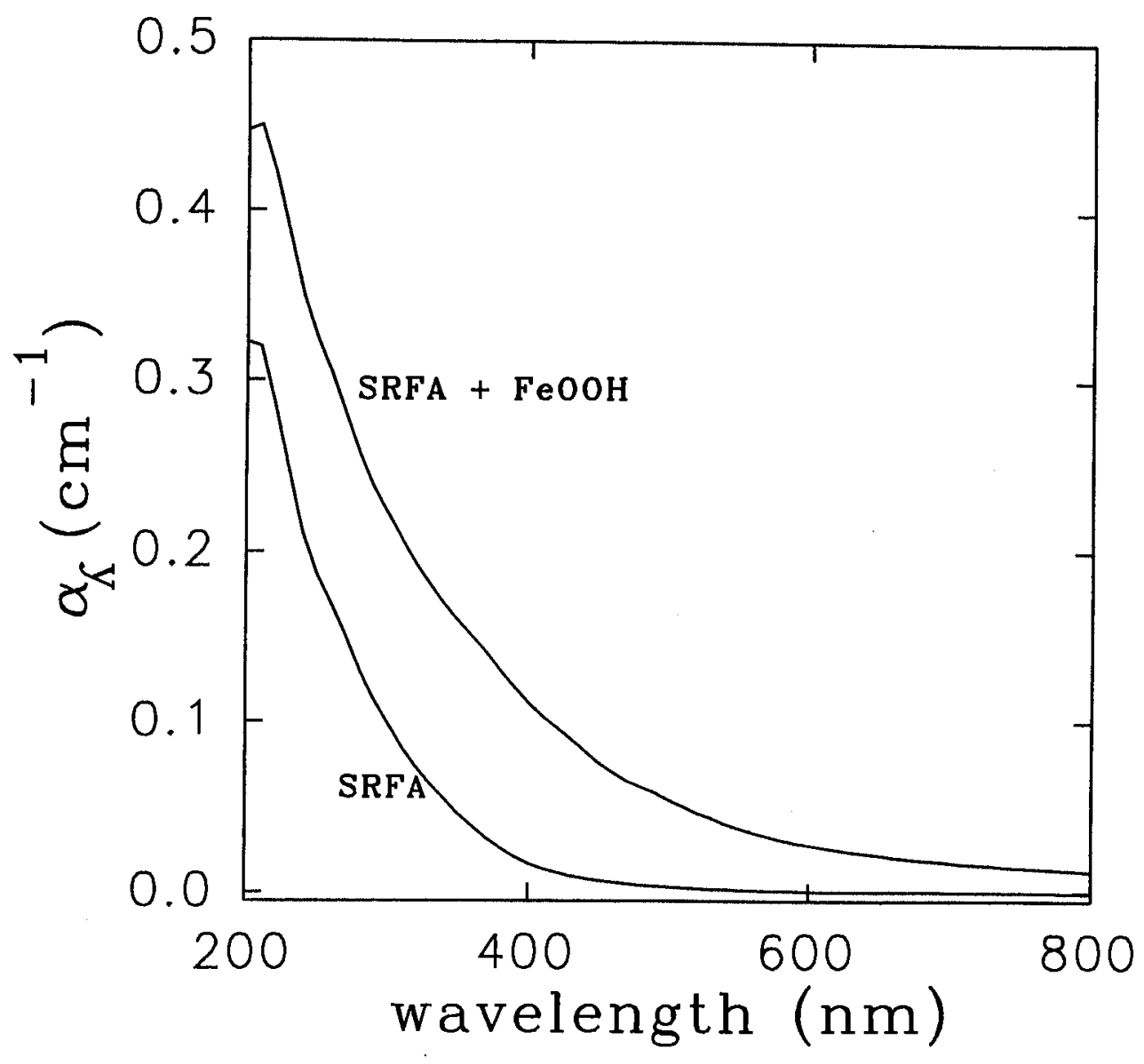

Figure 3.5. Comparison of the attenuation coefficients of a solution containing $10 \mathrm{mg} / \mathrm{l}$ SRFA and a solution containing $10 \mathrm{mg} / \mathrm{l}$ SRFA plus approximately $45 \mu \mathrm{M} \gamma$-FeOOH. 


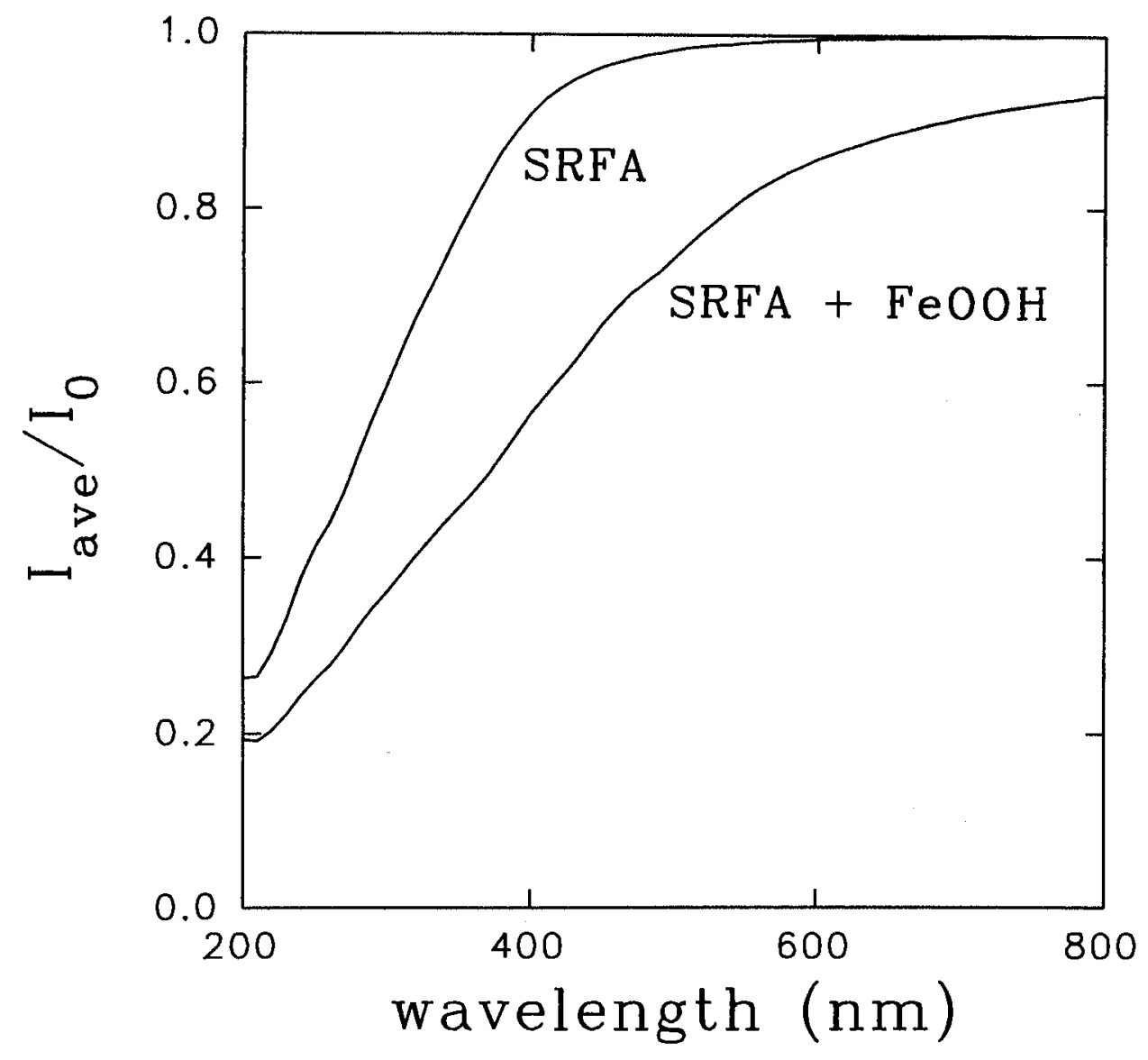

Figure 3.6. Comparison of calculated average light intensity divided by incident light intensity in a solution containing $10 \mathrm{mg} / \mathrm{S} S \mathrm{SFA}$ and $a$ solution containing $10 \mathrm{mg} / \mathrm{l}$ SRFA plus approximately $45 \mu \mathrm{M}$-FeOOH. The optical depth $L$ of the solutions in our reactor was $5 \mathrm{~cm}(320 \mathrm{ml}$ total solution volume). 
The average light intensity $I_{\lambda \text {,ave }}$ in solutions of optical depth $L$ is then given by:

$$
\mathrm{I}_{\lambda, \text { ave }}=\frac{1}{\mathrm{~L}} \int_{0}^{\mathrm{L}} \mathrm{I}_{\lambda}(\mathrm{x}) \mathrm{dx}=\frac{\mathrm{I}_{\lambda, 0}}{2.303 \cdot \alpha_{\lambda} \cdot \mathrm{L}}\left(1-\mathrm{e}^{-2.303 \cdot \alpha_{\lambda} \cdot \mathrm{L}}\right)
$$

Calculations using this equation and the $\alpha_{\lambda}$ values shown in Figure 3.5 indicate that, depending on the wavelength of the light, $60 \%-90 \%$ as many photons are available in the solutions containing both lepidocrocite and fulvic acid compared to solutions containing only fulvic acid (Figure 3.6). We would therefore expect that the rates of the fulvic acid photoreactions of interest decrease correspondingly in the presence of lepidocrocite. Without knowing the wavelength dependence of the apparent quantum yields of these reactions, we cannot predict the magnitude of the decrease in their rates with complete accuracy, but Figure 3.6 indicates that the rates in the presence of lepidocrocite should not differ from the rates in its absence by more than a factor of two.

\subsection{Optimization of unknown kinetic parameters}

Because of the complexity of the kinetics in the systems examined in this work, simple mathematical procedures to extract rate constants from data sets, such as linearizations, were not always possible. In these cases we used the procedure described below to test the validity of different possible kinetic models and to find the rate constants (or unknown initial concentrations of reactants) that optimized the fit of a model to the data.

A kinetics problem consists of the initial concentrations of reactants, the possible chemical reactions in the system, and the rate constants of these reactions. The computer program ACUCHEM (Braun et al., 1988) can calculate the concentrations of reactants versus time in a complicated chemical brew by finding a numerical solution to the system of non-linear differential equations defined by the kinetics problem. 
If some of the rate constants in the kinetics problem are unknown, one could try to optimize them by trial and error: inserting guesses of the unknown parameters into the ACUCHEM input file, comparing the ACUCHEM output with the data, and repeating this procedure until the fit is satisfactory (or until one gives up in despair). If a reasonable fit can be obtained in this manner, one at least knows that the chemical reactions in the set-up can account for the behavior of the system, even if one cannot be sure that the problem has a unique answer.

The method we used to optimize parameters given a kinetic model is essentially an automated version of this trial and error method. An initial guess of the values of the unknown parameters was sent to a MATLAB program. (MATLAB is a mathematics software/programming package sold by The Math Works, Inc., Natick, MA 01760). This program inserted the parameters into an ACUCHEM input file and ran ACUCHEM. Next, the MATLAB program compared the output of reactant concentrations as a function of time calculated by ACUCHEM with the experimental data and computed the total error (sum of the square of the differences) of this "fit". A simplex routine within MATLAB was used to generate the next iterations of parameter guesses until the total error was minimized. The simplex routine was particularly well-suited for this problem because it required only an evaluation of the function itself (in our case, the total error as a function of the various fitting parameters) while other iterative optimization routines require further information, such as the function's derivatives.

When an appropriate kinetic model had been chosen, our method efficiently found a reasonable solution to the unkown parameters. Although the mimimum in the total error found by the simplex routine is not necessarily unique, we have found that in our kinetic models, the best fits found by the program were independent of the initial guess of parameters, indicating that the problems were well-constrained. Tests of the routine, using artificial data sets and a kinetic problem similar in 
form to the ones examined in this work, were able to recover the input parameters to within a few percent when a random "analytical error" of $\pm 5 \%$ was added to the "data". 


\section{Chapter 4: Iron redox cycling in the dark -- Fenton's reaction in the presence of fulvic acid}

\subsection{Introduction}

Both $\mathrm{Fe}(\mathrm{II})$ and hydrogen peroxide are common constituents of oxygenated natural waters. In sunlit surface waters containing natural organic matter, photochemical reactions can result in the rapid formation of both: $\mathrm{Fe}$ (II) through ligand-to-metal charge transfer reactions of $\mathrm{Fe}$ (III)-organo complexes (either in solution or on the surface of iron oxides), and hydrogen peroxide mainly through the reduction of oxygen by photo-excited organic substances. Photochemical reactions are not the only source of $\mathrm{Fe}(\mathrm{II})$ and hydrogen peroxide. Humic substances have been shown to reduce $\mathrm{Fe}$ (III) to $\mathrm{Fe}$ (II) in absence of light (Szilàgyi, 1971; Langford et al., 1977; Skogerboe and Wilson, 1981). Microbial processes are also potential sources of both Fe(II) (Fischer, 1988) and hydrogen peroxide (Palenik et al., 1987). If hydrogen peroxide is present at sufficient concentrations, it will oxidize Fe(II) faster than oxygen does. Hydrogen peroxide is likely to be a dominant oxidant of $\mathrm{Fe}$ (II) not only in acidic natural waters, where the rate of oxidation of $\mathrm{Fe}$ (II) by oxygen is very slow (Figure 2.4), but also in marine waters at $\mathrm{pH} 8$ (Millero and Sotolongo, 1989). The oxidation of Fe(II) by hydrogen peroxide (also called Fenton's reaction), is therefore of interest in a variety of natural water systems.

Organic substances can affect both the rate and the products of Fenton's reaction. Carboxylate ligands are known to accelerate the effective rate of the reaction by forming complexes with $\mathrm{Fe}(\mathrm{II})$ which react faster than the aquo complexes (Rush et al., 1990; Sedlak and Hoigné, 1993). Although it is often assumed that the $\mathrm{OH} \cdot$ radicals produced by Fenton's reaction oxidize another $\mathrm{Fe}(\mathrm{II}), \mathrm{OH} \cdot$ is also rapidly scavenged by organic matter. The intermediate product formed by this reaction can reduce oxygen to $\mathrm{HO}_{2} / \mathrm{O}_{2}^{-}$, which then forms hydrogen peroxide by dismutation 
or reaction with $\mathrm{Fe}(\mathrm{II})$. Finally, if organic reducing agents are present, $\mathrm{Fe}$ (II) may be regenerated from the Fe(III) formed by oxidation. In this study, we examine Fenton's reaction in the absence of light in systems containing hydrogen peroxide, fulvic acid and iron at concentrations similar to those found in acidic surface waters. We show that fulvic acid simultaneously plays the role of a carboxylate ligand, a radical scavenger, and a reductant of Fe(III). By examining each of these roles in detail, we can construct a kinetic model predicting the behavior of $\mathrm{Fe}(\mathrm{II})$ and hydrogen peroxide in our experimental systems.

\subsection{Fulvic acid as a ligand and its effect on the rate of Fenton's reaction}

\subsubsection{Background}

Hydrogen peroxide is degraded and Fe(II) is oxidized by Fenton's reaction. The stochiometry of this reaction is:

$\mathrm{Fe}(\mathrm{II})+\mathrm{H}_{2} \mathrm{O}_{2} \longrightarrow \mathrm{Fe}(\mathrm{III})+\mathrm{OH} \cdot+\mathrm{OH}^{-}$

The overall (apparent) rate constant of this reaction is the sum of the rate constants $\mathrm{k}$ of the reactions each of the $\mathrm{Fe}$ (II) species present multiplied by the fraction $\alpha$ of the total $\mathrm{Fe}(\mathrm{II})$ present as this species:

$$
\mathrm{k}_{\mathrm{app}}=\sum_{\mathrm{x}} \mathrm{k}_{\mathrm{x}} \cdot \alpha_{\mathrm{x}}
$$

Even a minor species $\left(\alpha_{\mathrm{X}}<<1\right)$ can have a large effect on $k_{\text {app }}$ if the reaction rate constant $\mathrm{k}_{\mathrm{x}}$ of this species is much higher than that of the major species. For example, the $\mathrm{pH}$-dependence of $\mathrm{k}_{\mathrm{app}}$ is a result of the fact that, in the absence of other ligands, the $\mathrm{kFeH}{ }^{-} \alpha_{\mathrm{FeOH}}+$ term dominates the sum above even though $\alpha_{\mathrm{FeOH}}$ is much smaller than $\alpha_{\mathrm{Fe}^{2+}}$ within the $\mathrm{pH}$ range normal for natural waters (Moffett and Zika, 1987b, Millero and Sotolongo, 1989). An analogous effect has been observed in the presence of organic ligands: Sedlak and Hoigné (1993) demonstrated 
that oxalate strongly accelerates the apparent rate of reaction (1) even though only a small portion of the Fe(II) is complexed by the ligand. Other carboxylate ligands behave similarly (Rush et al., 1990).

In the presence of some organic substances, such as tannins, the apparent rate of oxidation of $\mathrm{Fe}$ (II) by oxygen is decreased (Theis and Singer, 1974). This effect could simply be due to reduction of Fe(III) by these substances, resulting in a slower net oxidation rate (Stumm and Morgan, 1981). An alternative explanation is that $\mathrm{Fe}(\mathrm{II})$ complexed by these compounds reacts with oxygen more slowly than $\mathrm{Fe}(\mathrm{II})$-aquo complexes. If the latter explanation is true, then the rate of $\mathrm{Fe}$ (II) oxidation by hydrogen peroxide is probably also reduced by these substances. Note that while even minor species can have an accelerating effect on $\mathrm{Fe}$ (II) oxidation, stabilization of Fe(II) through complexation can occur only if an $\mathrm{Fe}(\mathrm{II})$-organic complex is a major species.

In the case of fulvic acid, the numerous carboxylate binding sites probably dominate its metal complexation behavior. We would therefore expect an increase in the rate of $\mathrm{Fe}(\mathrm{II})$ oxidation by hydrogen peroxide in the presence of fulvic acid. We assume that Fe(II)-stabilizing binding sites are not present in sufficient concentrations to have an effect in our experimental systems.

In the presence of fulvic acid, then, $\mathrm{k}_{\mathrm{app}}$ is given by:

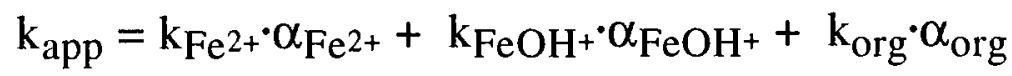

where the subscript "org" refers to the complexes of Fe(II) with the carboxylate sites present in fulvic acid. If different types of binding sites participate in the binding of $\mathrm{Fe}(\mathrm{II})$, a $\mathrm{k}_{\mathrm{org}} \cdot \alpha_{\mathrm{org}}$ term for each site will be needed.

To allow direct comparison of the results of experiments when initial $\mathrm{Fe}$ (II) concentrations and the behavior of $\mathrm{Fe}(\mathrm{II})$ over time vary from one experiment to the next, the data can be linearized as follows: 
The decrease of hydrogen peroxide concentration over time due to reaction (1) is described by the second order rate equation:

$\frac{\mathrm{d}\left[\mathrm{H}_{2} \mathrm{O}_{2}\right]}{\mathrm{dt}}=-\mathrm{k}_{\mathrm{app}}[\mathrm{Fe}(\mathrm{II})]\left[\mathrm{H}_{2} \mathrm{O}_{2}\right]$

where $\mathrm{k}_{\mathrm{app}}$ is given by equation (3). Integrating equation (4) gives:

$$
\ln \left(\frac{\left[\mathrm{H}_{2} \mathrm{O}_{2}\right]_{\mathrm{t}}}{\left[\mathrm{H}_{2} \mathrm{O}_{2}\right]_{\mathrm{o}}}\right)=\mathrm{k}_{\mathrm{app}} \int_{0}^{\mathrm{t}}[\mathrm{Fe}(\mathrm{II})]_{\mathrm{t}} \mathrm{dt}
$$

If $\mathrm{Fe}(\mathrm{II})$ were present in large excess (i.e. invariable with time), or present in constant proportion to hydrogen peroxide (in the absence of reactions other than reaction 1) this equation would have a simple solution. However, because of the reduction of iron by fulvic acid in our systems, the concentration of $\mathrm{Fe}$ (II) is not a simple function of time. For this reason, we estimated the integral using the $\mathrm{Fe}$ (II) measurements made during the course of the experiments:

$$
\int_{0}^{\mathrm{t}}[\mathrm{Fe}(\mathrm{II})]_{\mathrm{t}} \mathrm{dt} \approx \sum_{\mathrm{i}} \frac{1}{2}\left(\mathrm{t}_{\mathrm{i}+1}-\mathrm{t}_{\mathrm{i}}\right)\left([\mathrm{Fe}(\mathrm{II})]_{\mathrm{i}+1}+[\mathrm{Fe}(\mathrm{II})]_{\mathrm{i}}\right)
$$

Plotting $\ln \left(\mathrm{H}_{2} \mathrm{O}_{2}\right)_{t} /\left(\mathrm{H}_{2} \mathrm{O}_{2}\right)_{\mathrm{o}}$ versus this estimate of $\int[\mathrm{Fe}(\mathrm{II})]_{\mathrm{t}} \mathrm{dt}$ (which could be described as a time-weighted average $\mathrm{Fe}$ (II) concentration, multiplied by time) yields a linear function with a slope equal to $k_{a p p}$.

\subsubsection{Results}

To determine whether the $\mathrm{k}_{\mathrm{org}} \cdot \alpha_{\mathrm{org}}$ term in equation (3) is significant, we examined the effect of fulvic acid concentration on the rate of Fenton's reaction in de-oxygenated systems at $\mathrm{pH} 3$ and 5. At $\mathrm{pH} 3$, the effect of fulvic acid concentration is negligible (Figure 4.1), while at pH 5, an increase in concentration of fulvic acid results in significant acceleration of the degradation of hydrogen peroxide (Figure 4.2). This 


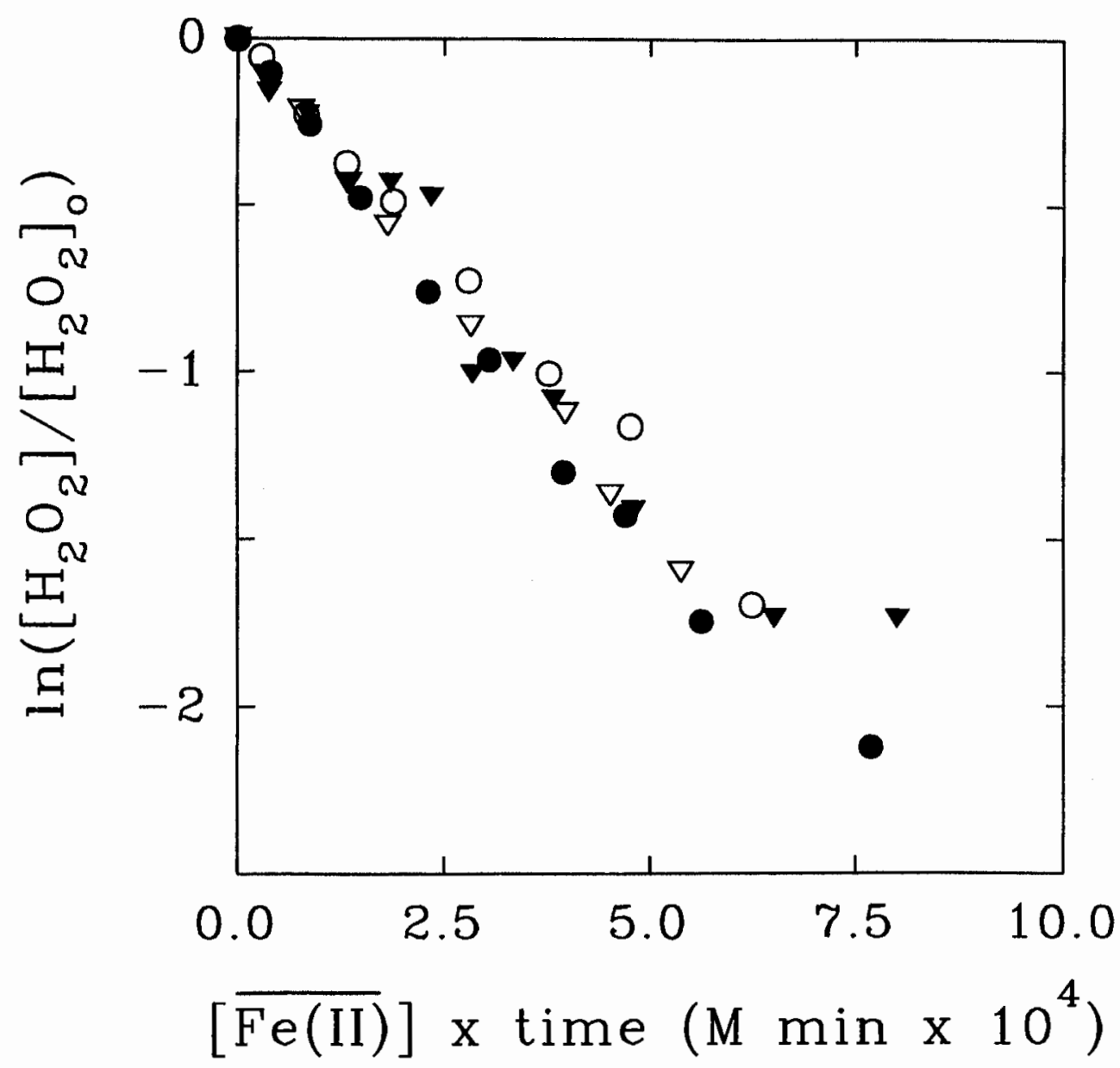

Figure 4.1. Comparison of the rates of hydrogen peroxide degradation at various fulvic acid concentrations in de-aerated solutions at pH 3. Initial concentrations: $\left[\mathrm{H}_{2} \mathrm{O}_{2}\right]_{O} 1 \mu \mathrm{M},\left[\mathrm{Fe}^{2+}\right]_{o} 5 \mu \mathrm{M}$ in each experiment. See text for an explanation of this linearization of the data. Fulvic acid concentrations: $O \quad 0 \mathrm{mg} / \mathrm{l}, \quad \rightarrow$ and $\nabla 10 \mathrm{mg} / \mathrm{l}, \nabla 30 \mathrm{mg} / \mathrm{l}$. 


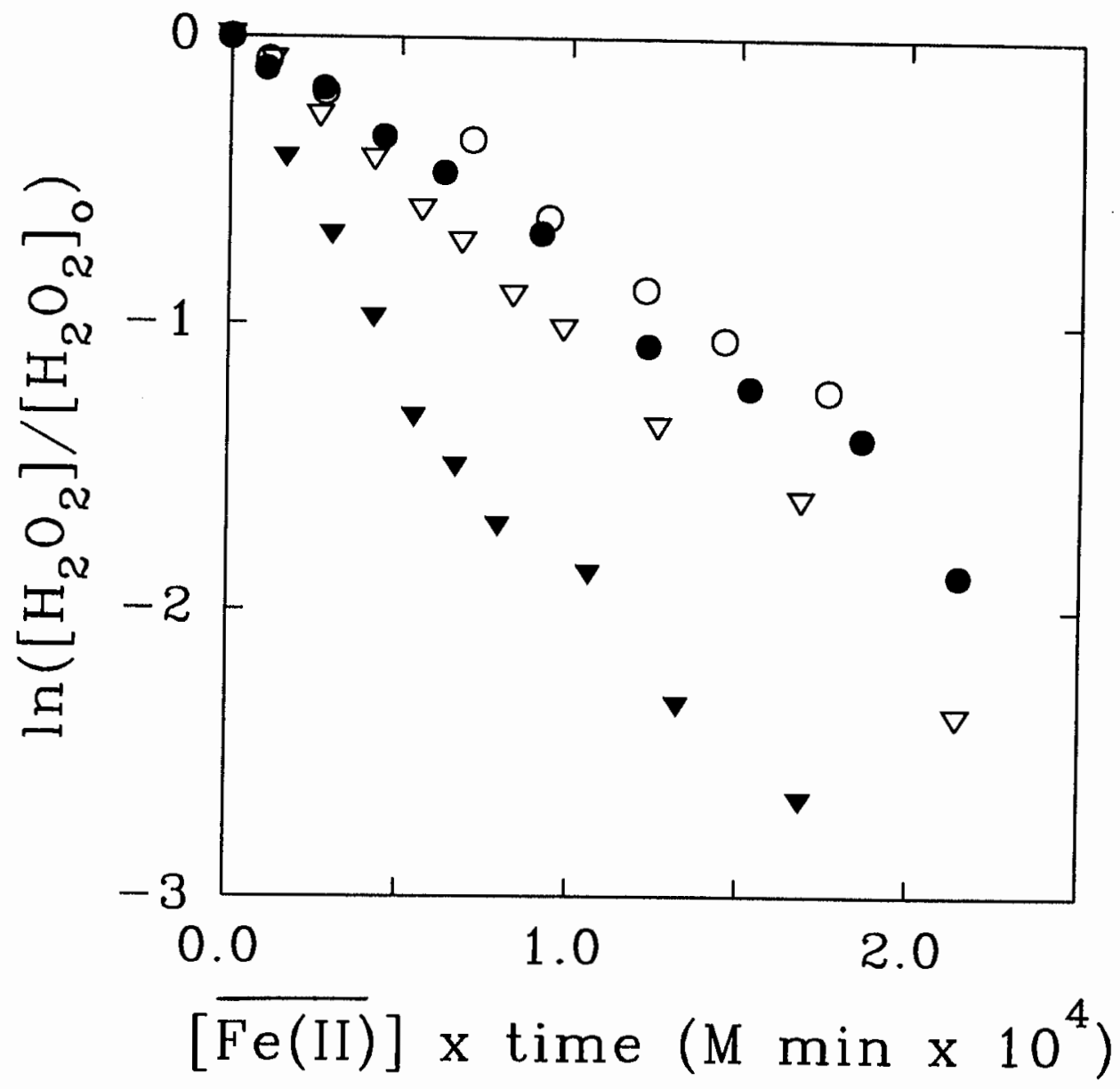

Figure 4.2. Comparison of the rates of hydrogen peroxide degradation at various fulvic acid concentrations in de-aerated solutions at $\mathrm{pH} 5$. Initial concentrations: $\left[\mathrm{H}_{2} \mathrm{O}_{2}\right]_{o} 1 \mu \mathrm{M},\left[\mathrm{Fe}^{2+}\right]_{o} 2 \mu \mathrm{M}$ in each experiment. See text for an explanation of this linearization of the data. Fulvic acid concentrations: $O \quad 0 \mathrm{mg} / \mathrm{l}, \quad-3 \mathrm{mg} / \mathrm{l}, \quad \nabla 10 \mathrm{mg} / \mathrm{l}, \quad \nabla 30 \mathrm{mg} / \mathrm{l}$. 


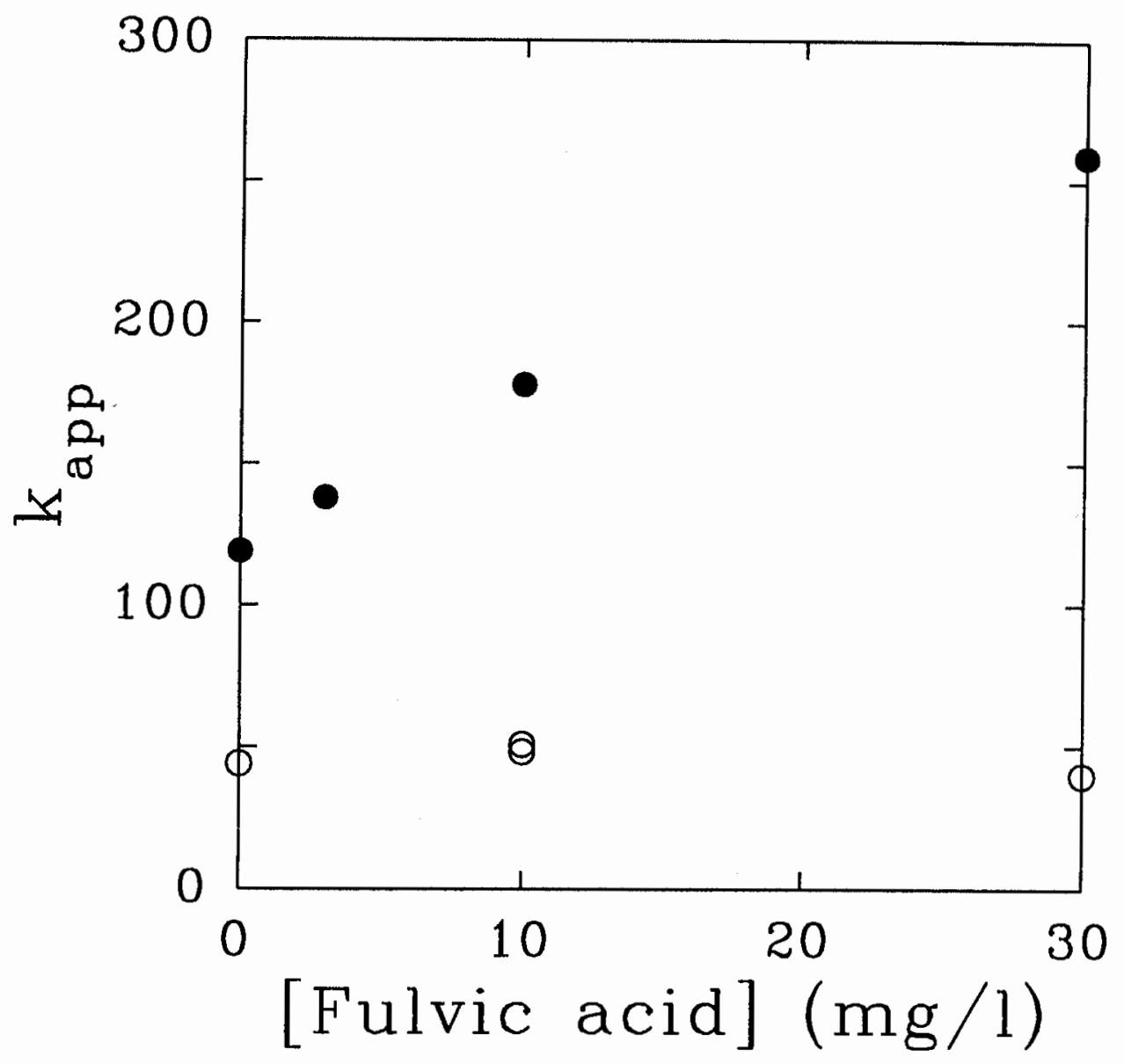

Figure 4.3. The apparent rate constant of Fenton's reaction (reaction 1 in text) as a function of fulvic acid concentration at $p H 3(O)$ and pH 5 (०). $k_{\text {app }}$ was calculated from linear regressions of the data in Figures 4.1 and 4.2 . 
behavior indicates a $\mathrm{pH}$-dependent complexation of $\mathrm{Fe}$ (II) by fulvic acid. If we assume that only a small portion of the total $\mathrm{Fe}$ (II) is present as the organic complex in these systems, so that $\alpha_{\mathrm{Fe}^{2+}}$ and $\alpha_{\mathrm{FeOH}}$ do not change as a function of fulvic acid concentration, then the observed $k_{\text {app }}$ should be a function of $\alpha_{\text {org }}$ at each $\mathrm{pH}$ :

$\mathrm{k}_{\mathrm{app}}=\mathrm{k}_{\mathrm{app},[\mathrm{FA}]=0}+\mathrm{k}_{\mathrm{org}} \cdot \alpha_{\mathrm{org}}$

where $\mathrm{k}_{\mathrm{app},[\mathrm{FA}]=0}$ is the apparent reaction rate in the absence of fulvic acid. If the iron binding site in the fulvic acid is present in excess of the $\mathrm{Fe}$ (II), then $\alpha_{\text {org }}$ should be a linear function of fulvic acid concentration and a plot of $\mathrm{k}_{\mathrm{app}}$ versus fulvic acid concentration will yield a straight

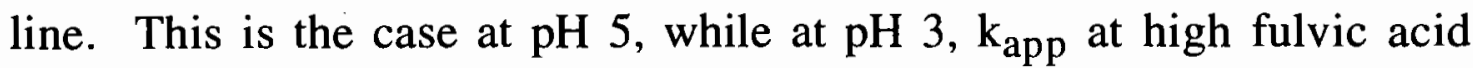
concentrations is approximately equal to $\mathrm{k}_{\mathrm{app},[\mathrm{FA}]=0}$ (Figure 4.3). This indicates that less $\mathrm{Fe}$ (II) is complexed by fulvic acid at $\mathrm{pH} 3$ than at $\mathrm{pH} 5$ (so that at $\mathrm{pH} 3, \mathrm{k}_{\mathrm{org}} \cdot \alpha_{\text {org }}$ is much smaller than $\mathrm{k}_{\mathrm{app},[\mathrm{FA}]=0}$ at the fulvic acid concentrations studied), presumably because of competition of $\mathrm{Fe}^{2+}$ and $\mathrm{H}^{+}$for the metal binding sites.

We conclude that with regard to the effect of fulvic acid on the rate of Fenton's reaction, the substance behaves similarly to a small carboxylic acid like oxalate. Liang et al. (1993) observed a similar effect of humic substances on the rate of $\mathrm{Fe}(\mathrm{II})$ oxidation by oxygen. We find no evidence of significant amounts of Fe(II)-stabilizing binding sites such as those proposed by Theis and Singer (1974).

\subsection{Fulvic acid as a scavenger of $\mathrm{OH} \cdot \ldots$ production of $\mathrm{HO}_{2} / \mathrm{O}_{2}^{-}$}

\subsubsection{Background}

One product of Fenton's reaction (reaction 1) is $\mathrm{OH}^{*}$, which can rapidly oxidize organic substances as well as Fe(II). The rate constant of the 
reaction of $\mathrm{OH} \cdot$ with humic substances is on the order of $3 \times 10^{4} \mathrm{~s}^{-1}(\mathrm{mg} / 1$ DOC) $)^{-1}$ (Hoigné et al., 1989). In our systems (10 mg/l SRFA and 0-5 $\mu \mathrm{M}$ $\mathrm{Fe}(\mathrm{II}))$, the reaction of $\mathrm{OH} \cdot$ with fulvic acid should therefore outcompete the reaction of $\mathrm{OH} \cdot$ with $\mathrm{Fe}(\mathrm{II})\left(\mathrm{k}=3 \times 10^{8} \mathrm{M}^{-1} \mathrm{~s}^{-1}\right.$, Christensen and Sehested, 1981).

In the presence of oxygen, $\mathrm{HO}_{2} / \mathrm{O}_{2}^{-}\left(\mathrm{pK}_{\mathrm{a}} 4.8\right.$, Bielski et al., 1985) is a common product of the reaction of $\mathrm{OH}^{\cdot}$ with organic compounds, such as benzene, formate, glyoxylate, ethanol, methanol, and humic acid (Stahelin, 1983). For example, the reaction of benzene with $\mathrm{OH} \cdot$ results in phenol and $\mathrm{HO}_{2} / \mathrm{O}_{2}^{-}$(Dorfman et al., 1962). The first step is the addition of $\mathrm{OH}^{\cdot}$ to the ring and formation of a carbon-centered radical:

$\mathrm{OH}^{\cdot}+$

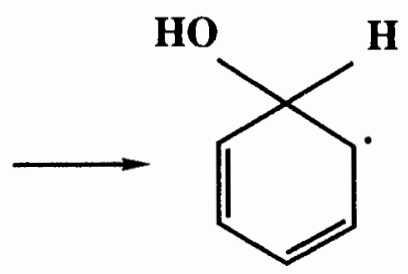

Molecular oxygen then adds at the $\beta$-carbon site, forming an organic peroxy radical:

HO<smiles>O=[N+]([O-])[C]1C=CC=CC1</smiles>

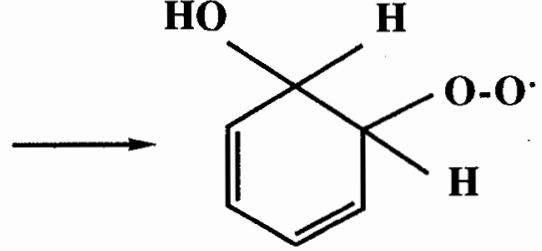

The peroxy radical degrades, resulting in phenol and $\mathrm{HO}_{2} / \mathrm{O}_{2}^{-}$:<smiles>[O-][C@H]1C=CC=C[C@H]1O</smiles><smiles>C[InH2]</smiles>
$+\mathrm{HO}_{2} / \mathrm{O}_{2}^{-}$

Formation of $\mathrm{HO}_{2} / \mathrm{O}_{2}^{-}$from $\mathrm{OH}$ in the presence of fulvic acid and oxygen could occur through a similar mechanism. 
$\mathrm{HO}_{2} / \mathrm{O}_{2}^{-}$degrades by dismutation, forming hydrogen peroxide by the overall reaction:

$2 \mathrm{HO}_{2} / \mathrm{O}_{2}^{-} \stackrel{\mathrm{H}^{+}}{\longrightarrow} \mathrm{H}_{2} \mathrm{O}_{2}+\mathrm{O}_{2}$

$\mathrm{HO}_{2} / \mathrm{O}_{2}^{-}$may also act either as a reductant or as an oxidant of iron:

$$
\begin{aligned}
& \mathrm{Fe}(\mathrm{II})+\mathrm{HO}_{2} / \mathrm{O}_{2}^{-} \stackrel{\mathrm{H}^{+}}{\longrightarrow} \mathrm{Fe}(\mathrm{III})+\mathrm{H}_{2} \mathrm{O}_{2} \\
& \mathrm{Fe}(\mathrm{III})+\mathrm{HO}_{2} / \mathrm{O}_{2}^{-} \stackrel{-\mathrm{H}^{+}}{\longrightarrow} \mathrm{Fe}(\mathrm{II})+\mathrm{O}_{2}
\end{aligned}
$$

Thus the $\mathrm{HO}_{2} / \mathrm{O}_{2}^{-}$generated in the presence of oxygen not only regenerates hydrogen peroxide but may also participate in the iron redox cycle. The ratio of hydrogen peroxide formed per $\mathrm{HO}_{2} / \mathrm{O}_{2}^{-}$could vary from 0 to 1 depending on which of the three reactions above is the dominant reaction pathway.

\subsubsection{Results}

There is a significant effect of oxygen on the apparent degradation rate of hydrogen peroxide in the presence of fulvic acid and Fe(II) (Figures 4.4 and 4.5). To show that this effect is not due to an actual slowing of the rate of reaction (1), but to a regeneration of hydrogen peroxide in the presence of oxygen via $\mathrm{HO}_{2} / \mathrm{O}_{2}{ }^{-}$, we conducted an experiment in the presence of $\mathrm{NO}_{(\mathrm{aq})} \cdot \mathrm{NO}_{(\mathrm{aq})}$ is an efficient superoxide scavenger, forming $\mathrm{NO}_{3}{ }^{-}$(Blough and Zafiriou, 1985; Micinski et al., 1993).

$$
\mathrm{NO}_{(\mathrm{aq})}+\mathrm{HO}_{2} \mathrm{OO}_{2}^{-} \longrightarrow \mathrm{OONO}^{-} \longrightarrow \longrightarrow \mathrm{NO}_{3}^{-}
$$

In a solution containing both $\mathrm{NO}_{(\mathrm{aq})}$ and oxygen at $\mathrm{pH} 3$, the rate of hydrogen peroxide degradation by $\mathrm{Fe}(\mathrm{II})$ is the same as the rate observed in the deoxygenated system (Figure 4.4), confirming the role of superoxide. (The presence of $\mathrm{NO}_{(\mathrm{aq})}$ in the de-oxygenated system has no effect on the rate of hydrogen peroxide degradation.) 


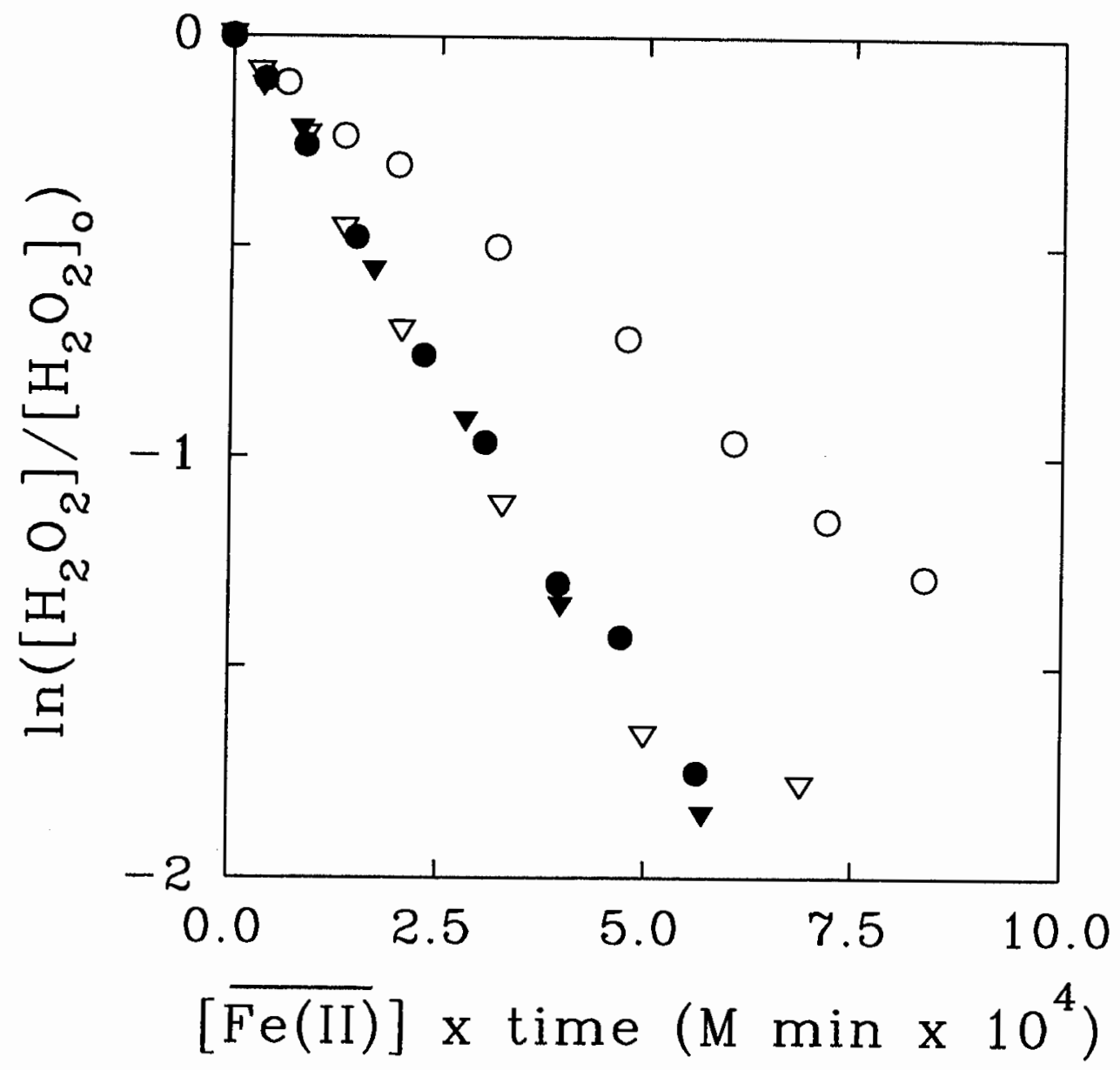

Figure 4.4. Comparison of the rates of hydrogen peroxide degradation in aerated ( $O$ symbols) and de-aerated ( symbols) systems at $p H 3$. $\nabla$ and $\boldsymbol{\nabla}$ symbols represent experiments conducted in the presence of $N O_{(a q)}$ in aerated and de-aerated solutions, respectively. Fulvic acid concentration was $10 \mathrm{mg} /$ in all solutions.

Initial concentrations:

$\left[\mathrm{H}_{2} \mathrm{O}_{2}\right]_{o} 1 \mu \mathrm{M},\left[\mathrm{Fe}^{2+}\right]_{o} 5 \mu \mathrm{M}$. 


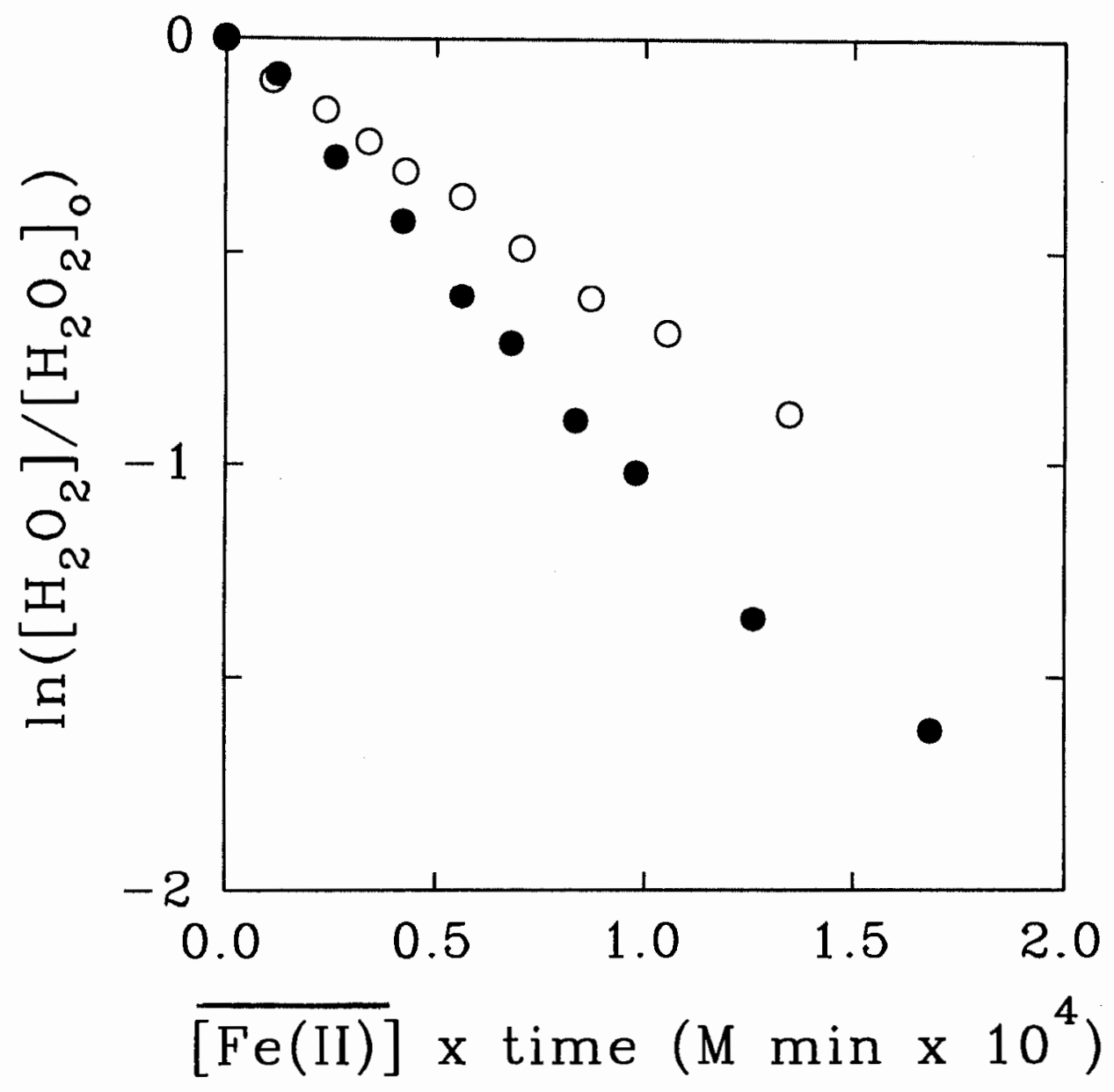

Figure 4.5. Comparison of the rates of hydrogen peroxide degradation in aerated ( $O$ symbols) and de-aerated ( symbols) systems at $p H 5$. Fulvic acid concentration was $10 \mathrm{mg} / \mathrm{l}$ in all solutions. Initial concentrations:

$\left[\mathrm{H}_{2} \mathrm{O}_{2}\right]_{o} 1 \mu \mathrm{M},\left[\mathrm{Fe}^{2+}\right]_{o} 2 \mu \mathrm{M}$. 
From the difference in slopes between the aerated and de-aerated experiments in Figures 4.4 and 4.5, we calculate that $46 \%$ (at pH 3 ) and $39 \%$ (at $\mathrm{pH} \mathrm{5)}$ of the hydrogen peroxide degraded by reaction (1) is regenerated by the superoxide mechanism. If we assume that superoxide reacts mainly by reaction (12), so that each $\mathrm{HO}_{2} / \mathrm{O}_{2}^{-}$formed results in one molecule of hydrogen peroxide, we can conclude that the efficiency of superoxide formation from the reaction of $\mathrm{OH} \cdot$ with fulvic acid is approximately $46 \%$ and $39 \%$ at $\mathrm{pH} 3$ and 5 respectively. If reaction (13) also plays a role, this stochiometry cannot be determined so easily. However, we expect that most of the Fe(III) in this system is complexed by fulvic acid (see below). In general, Fe(III)-organo complexes are much less reactive with $\mathrm{HO}_{2} / \mathrm{O}_{2}^{-}$than inorganic $\mathrm{Fe}$ (III) complexes (Bielski et al., 1985; Sedlak and Hoigné, 1993), so we would expect reaction (13) to be insignificant in this system.

\subsection{Fulvic acid as a reductant of $\mathrm{Fe}($ III)}

The reduction of $\mathrm{Fe}$ (III) by fulvic acid has been observed previously (Szilàgyi, 1971; Langford et al., 1977; Skogerboe and Wilson, 1981), but the effects of $\mathrm{pH}$ and ligand-to-metal ratio on the kinetics of this reaction have not been examined in detail.

To gain a better understanding of this process, we have studied the kinetics of iron reduction in the absence of hydrogen peroxide at $\mathrm{pH} 3$ and 5 in aerated systems containing, initially, $10 \mathrm{mg} / \mathrm{l} \mathrm{SRFA}$ and varying amounts of $\mathrm{Fe}$ (III). In all of the experiments at both $\mathrm{pH} 3$ and $\mathrm{pH} 5$, we observed a very fast initial reduction, followed by much slower processes (Figures 4.6 and 4.7). This behavior could be the result of reduction by two (or more) reducing sites: after a limited amount of fast-reducing sites have been oxidized, the reduction proceeds more slowly at other sites. The amount of Fe(III) reduced by the fast process should then depend only on the total number of sites available for this reaction. However, our data show that the total amount of Fe(III) reduced by the 
fast process increased when the concentration of initially added $\mathrm{Fe}$ (III) was increased, even though the concentration of fulvic acid (and therefore the total number of reducing sites) was kept constant. In fact, the fraction of $\mathrm{Fe}$ (III) reduced by the fast process remained nearly constant even when the iron-to-ligand ratios were varied by over an order of magnitude.

We interpret these results as a competition between different functional groups present on the fulvic acid: an Fe(III) binding ligand $\mathrm{L}$ and an Fe(III) reducing site L'. Dissolved Fe(III) can thus either be complexed by L:

$\mathrm{Fe}(\mathrm{III})+\mathrm{L} \longrightarrow \mathrm{Fe}(\mathrm{III})-\mathrm{L}$

or reduced by L':

$\mathrm{Fe}(\mathrm{III})+\mathrm{L}^{\prime} \longrightarrow \mathrm{Fe}(\mathrm{II})+\mathrm{L}_{\mathrm{OX}}^{\prime}$

(For simplicity the net charges on the species have been omitted.) If the rates of both reactions are very fast, and both $\mathrm{L}$ and $\mathrm{L}^{\prime}$ are present in excess, the fraction of iron that is reduced in the fast step will be $\mathrm{k}_{16} /\left(\mathrm{k}_{15}+\mathrm{k}_{16}\right)$ independent of the iron-to-ligand ratio (where $\mathrm{k}_{15}$ and $\mathrm{k}_{16}$ are the pseudo-first order rate constants of reactions 15 and 16). All of the remaining $\mathrm{Fe}$ (III) left in the solution is present as the $\mathrm{Fe}$ (III)-L complex. This complex may then dissociate, releasing Fe(III) which can again be reduced, giving rise to the slower rate of formation of $\mathrm{Fe}$ (II) observed after the initial fast reduction step:

$\mathrm{Fe}(\mathrm{III})-\mathrm{L} \longrightarrow \mathrm{Fe}(\mathrm{III})+\mathrm{L}$

Equation (17) implies that the rate of reduction after completion of the fast step should be proportional to the amount of $\mathrm{Fe}$ (III) (as Fe(III)-L) remaining in solution. However, at both $\mathrm{pH} 3$ and $\mathrm{pH} \mathrm{5}$, we observed that the reduction rate slowed down significantly in the 100 minutes following the initial fast reduction, even though the amount of $\mathrm{Fe}$ (III) (as $\mathrm{Fe}$ (III)-L) 


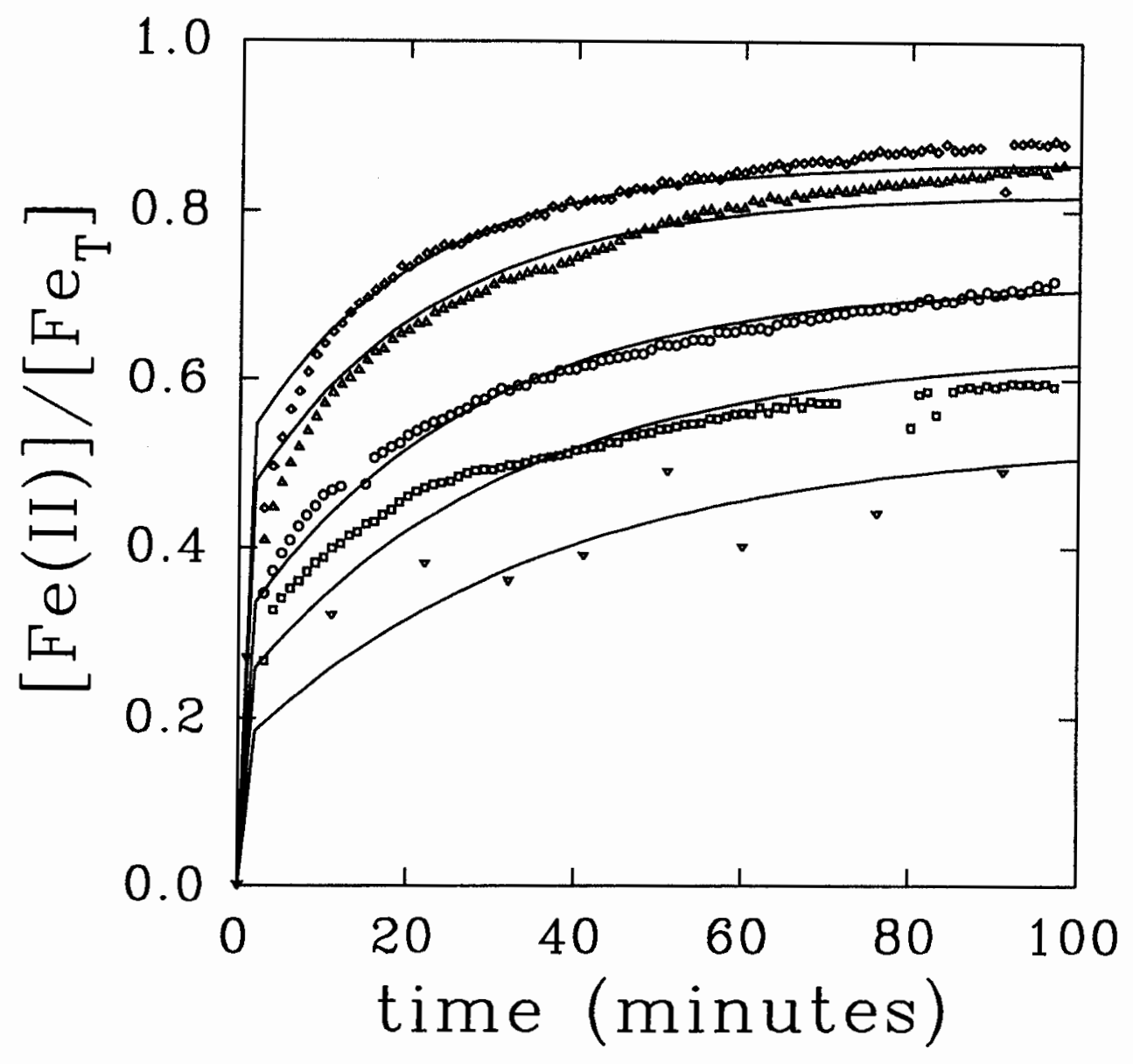

Figure 4.6. Reduction of Fe(III) by fulvic acid in the dark in aerated solutions at $\mathrm{pH}$ 3. Fulvic acid concentration $10 \mathrm{mg} / \mathrm{l}$. Total Fe(III) added: $\diamond 150 \mathrm{nM}, \Delta 500 \mathrm{nM}, \quad \mathrm{O} 1.50 \mu \mathrm{M}$, squares $5.00 \mu \mathrm{M}$, $\nabla 1.00 \mu M \mathrm{Fe}(I I I)$ added to a solution already containing $4.9 \mu \mathrm{M} \mathrm{Fe}(I I)$. In the last experiment $(\nabla),\left[F e^{2+}\right] /\left[F e_{T}\right]$ on the $y$-axis refers to the fraction of the added Fe(III) that is reduced over time and Fe(II) was measured using ferrozine instead of the chemiluminescence method. 


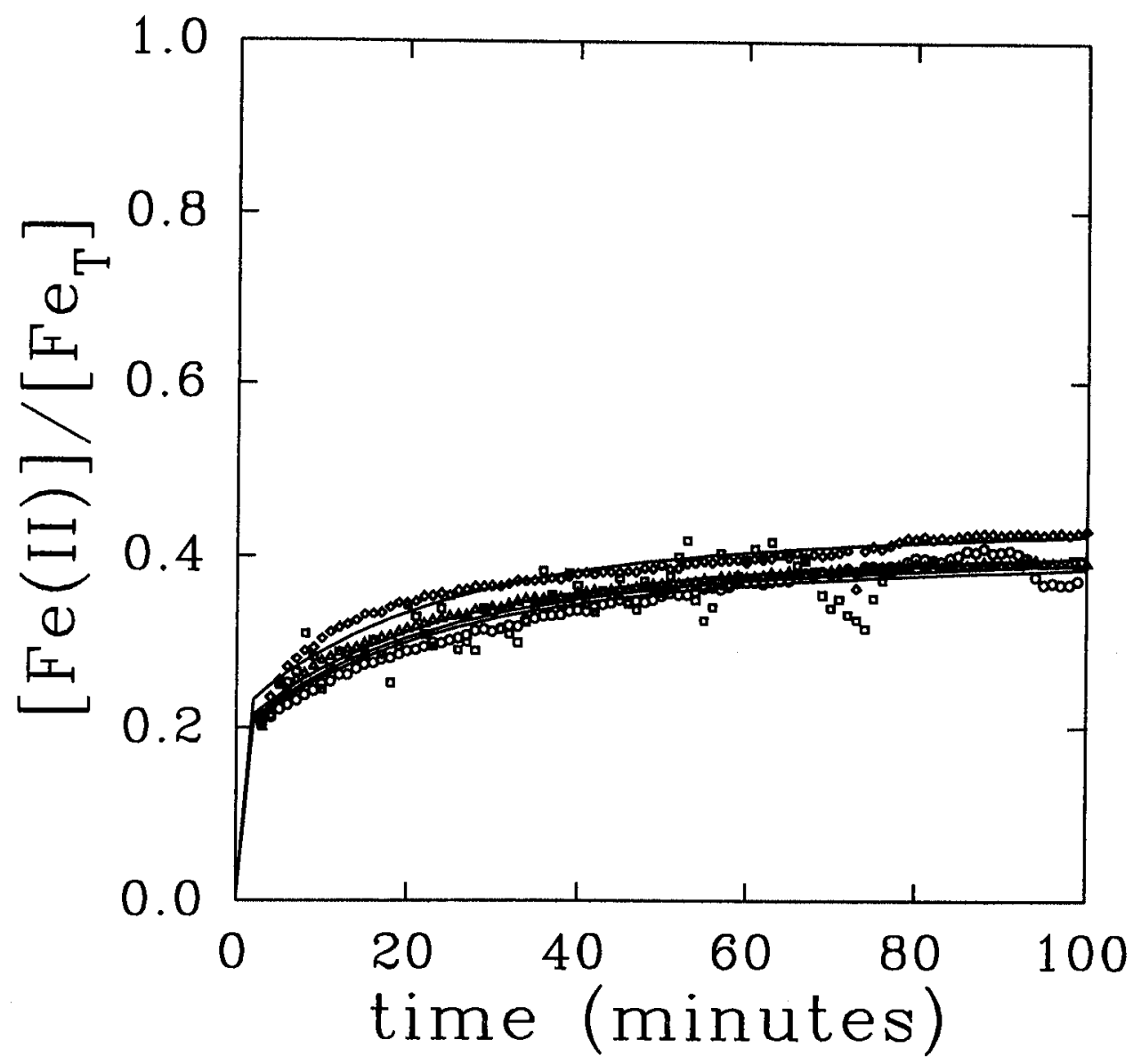

Figure 4.7. The reduction of $\mathrm{Fe}$ (III) by fulvic acid in the dark in aerated solutions at $\mathrm{pH} 5$. Fulvic acid concentration $10 \mathrm{mg} / \mathrm{l}$. Total Fe(III) added: $\diamond 500 \mathrm{nM}, \Delta 1.50 \mu \mathrm{M}$, O $5.00 \mu \mathrm{M}$, squares $1.00 \mu \mathrm{M}$ added to a solution containing $2.0 \mu \mathrm{M} \mathrm{Fe}(\mathrm{II})$. In the last experiment (squares), $\left[\mathrm{Fe}^{2+}\right] /\left[\mathrm{Fe}_{T}\right]$ on the $y$-axis refers to the fraction of the added $\mathrm{Fe}(I I I)$ that is reduced over time. 
had not changed much in this time period. We conclude that the dissociation rate of the Fe(III)-L complex slows down over time. This effect was also observed by Choppin and Clark (1991) for the dissociation of $\mathrm{UO}_{2}$-humate complexes, and could indicate either a slow rearrangement of the fulvic acid, resulting in stronger binding of the metal, or simply a redistribution of the Fe(III) among different fulvic acid binding sites. We represent this process as the reaction:

$\mathrm{Fe}(\mathrm{III})-\mathrm{L} \longrightarrow \mathrm{Fe}(\mathrm{III})-\mathrm{L} "$

where $\mathrm{Fe}(\mathrm{III})-\mathrm{L} "$ represents an $\mathrm{Fe}(\mathrm{III})$ complex which dissociates more slowly than Fe(III)-L:

$\mathrm{Fe}(\mathrm{III})-\mathrm{L} " \longrightarrow \mathrm{Fe}(\mathrm{III})+\mathrm{L} "$

The reduction kinetics observed in our data can be adequately described by a kinetic model consisting of reactions 15 to 19 . Fitting parameters were the ratio $\mathrm{k}_{16} /\left(\mathrm{k}_{15}+\mathrm{k}_{16}\right)$ and the rates of reactions 17,18 and 19 . The rate constants which gave the best fits to the data were found using the computer fitting routine described in section 3.5 and are listed in Table 4.1. Adequate fits could be obtained by assuming the rate constants of reactions 17 to 19 to be independent of iron-to-ligand ratios (so that the same $\mathrm{k}_{17}, \mathrm{k}_{18}$ and $\mathrm{k}_{19}$ were used to model all the experiments at one $\mathrm{pH}$ ). However, because the data show a slight decrease of the fraction of iron reduced in the fast initial step with increasing total iron concentration, the ratio $\mathrm{k}_{16} /\left(\mathrm{k}_{15}+\mathrm{k}_{16}\right)$ was assumed to vary as a function of the total iron in the experiments. A plausible explanation for this observation is that micromolar concentrations of $\mathrm{Fe}(\mathrm{II})$ (either present initially or produced by reduction of $\mathrm{Fe}(\mathrm{III})$ ) affect the rate of reduction $\mathrm{k}_{16}$, possibly through complexation at the reducing site L'. At $\mathrm{pH} 5$ the fraction of iron reduced by the fast reaction is much smaller than at $\mathrm{pH} 3$, but there is little effect of total Fe(II) on this fraction. 
Table 4.1. Reactions and parameters used in the kinetic model described in section 4.5

\begin{tabular}{|c|c|c|}
\hline Reactions $a$ & \multicolumn{2}{|c|}{ parameters used in model } \\
\hline Dark reduction of $F e(I I I)$ by fulvic acid & $\mathrm{pH} 3$ & $\mathrm{pH} 5$ \\
\hline $\mathrm{Fe}(\mathrm{III})+\mathrm{L} \longrightarrow \mathrm{Fe}(\mathrm{III})-\mathrm{L}$ & fast & fast \\
\hline $\mathrm{Fe}(\mathrm{III})+\mathrm{L}^{\prime} \longrightarrow \mathrm{Fe}(\mathrm{II})+\mathrm{L}_{\mathrm{ox}}^{\prime}$ & fast & fast \\
\hline $\begin{array}{l}\text { total Fe(III) added } \\
(\mu M) \\
(0.150) \\
(0.500) \\
(1.50) \\
(5.00) \\
(1.00)+F e(I I) e\end{array}$ & $\begin{array}{l}0.51 \\
0.45 \\
0.31 \\
0.23 \\
0.17\end{array}$ & $\begin{array}{c}-- \\
0.22 \\
0.20 \\
0.19 \\
0.19\end{array}$ \\
\hline $\mathrm{Fe}(\mathrm{III})-\mathrm{L} \longrightarrow \mathrm{Fe}(\mathrm{III})+\mathrm{L}$ & $1.163 \times 10^{-3}$ & $9.151 \times 10^{-4}$ \\
\hline $\mathrm{Fe}(\mathrm{III})-\mathrm{L} \longrightarrow \mathrm{Fe}(\mathrm{III})-\mathrm{L}^{\prime \prime}$ & $2.552 \times 10^{-4}$ & $6.215 \times 10^{-4}$ \\
\hline $\mathrm{Fe}(\mathrm{III})-\mathrm{L}^{\prime \prime} \longrightarrow \mathrm{Fe}(\mathrm{III})+\mathrm{L}^{\prime \prime} \quad$ (19) $c$ & $7.050 \times 10^{-6}$ & $1.957 \times 10^{-5}$ \\
\hline Additional reactions used in kinetic model & & \\
\hline $\mathrm{Fe}(\mathrm{II})+\mathrm{H}_{2} \mathrm{O}_{2} \longrightarrow \mathrm{Fe}(\mathrm{III})+\mathrm{OH}^{\cdot}+\mathrm{OH}^{-}(1)^{d}$ & 48.2 & 178 \\
\hline yield of $\mathrm{HO}_{2} / \mathrm{O}_{2}^{-}$from $\mathrm{OH} \cdot$ reaction with SRFA & $46 \%$ & $39 \%$ \\
\hline $\mathrm{Fe}(\mathrm{II})+\mathrm{HO}_{2} / \mathrm{O}_{2}^{--->} \mathrm{Fe}(\mathrm{III})+\mathrm{H}_{2} \mathrm{O}_{2}$ & fast & fast \\
\hline
\end{tabular}

$a$ Numbers of reactions as used in the text

${ }^{b} \mathrm{k}_{15}$ and $\mathrm{k}_{16}$ are pseudo-first order rate constants in $\mathrm{s}^{-1}$. Because the rates of reactions (15) and (16) are faster than the time scale of the measurements (minutes), only the ratio of these parameters could be determined from the data (see text).

$c$ Rate constants in $\mathrm{s}^{-1}$

$d$ Apparent rate constant in $\mathrm{M}^{-1} \mathrm{~s}^{-1}$

$e$ Initial concentrations of $\mathrm{Fe}(\mathrm{II}): 4.9 \mu \mathrm{M}(\mathrm{pH} 3)$ and $2.0 \mu \mathrm{M}(\mathrm{pH} \mathrm{5})$

$f$ We assumed that all of the $\mathrm{HO}_{2} / \mathrm{O}_{2}^{-}$produced reacted immediately with $\mathrm{Fe}(\mathrm{II})$. 


\subsection{A kinetic model of the reactions in the $\mathrm{Fe}(\mathrm{II})-\mathrm{SRFA}-\mathrm{H}_{2} \mathrm{O}_{2}$ system}

In an oxygenated solution containing $\mathrm{Fe}(\mathrm{II}), \mathrm{SRFA}$, and $\mathrm{H}_{2} \mathrm{O}_{2}$, then, dissolved $\mathrm{Fe}(\mathrm{II})$ is oxidized by hydrogen peroxide and $\mathrm{HO}_{2} / \mathrm{O}_{2}{ }^{-}$, and reduced by a dark reaction with fulvic acid (Figure 4.8). We can construct a kinetic model of this system using the rate constants $\left(\mathrm{k}_{\mathrm{app}}\right)$ of the reaction of $\mathrm{Fe}(\mathrm{II})$ and hydrogen peroxide derived in section 4.2 , the efficiency of $\mathrm{HO}_{2} / \mathrm{O}_{2}^{-}$formation from $\mathrm{OH} \cdot$ in the presence of oxygen, calculated from Figures 4.4 and 4.5 in section 4.3 (under the assumption that all $\mathrm{HO}_{2} / \mathrm{O}_{2}{ }^{-}$formed reacts with $\mathrm{Fe}(\mathrm{II})$ via reaction 12 ), and the description of iron reduction kinetics explained in section 4.4 (Table 4.1). Our model accurately predicts the concentrations of $\mathrm{Fe}(\mathrm{II})$ and hydrogen peroxide over time in de-aerated and aerated fulvic acid solutions at $\mathrm{pH} 3$ and $\mathrm{pH} 5$ (Figures 4.9 and 4.10). On the time scale of our experiments, a net oxidation of $\mathrm{Fe}(\mathrm{II})$ takes place, although a portion of the $\mathrm{Fe}(\mathrm{II})$ that is oxidized by hydrogen peroxide and $\mathrm{HO}_{2} / \mathrm{O}_{2}{ }^{-}$is reduced again by the fulvic acid (Figure 4.8).

It can be seen that an iron redox cycle, resulting in consumption of oxygen (through the process which produces $\mathrm{HO}_{2} / \mathrm{O}_{2}{ }^{-}$, see reactions 8 - 10) and oxidation of fulvic acid, can be maintained in the dark at acidic $\mathrm{pH}$ values when hydrogen peroxide is present. Fulvic acid plays competing roles in the iron redox chemistry of this system. As a carboxylate ligand, it accelerates the oxidation of $\mathrm{Fe}(\mathrm{II})$ by hydrogen peroxide. The scavenging of $\mathrm{OH} \cdot$ by fulvic acid results in further production of $\mathrm{Fe}(\mathrm{II})$ oxidants. While these processes increase the rate of oxidation of $\mathrm{Fe}(\mathrm{II})$, fulvic acid also acts as an efficient reductant of $\mathrm{Fe}(\mathrm{III})$, even at $\mathrm{pH} 5$. 


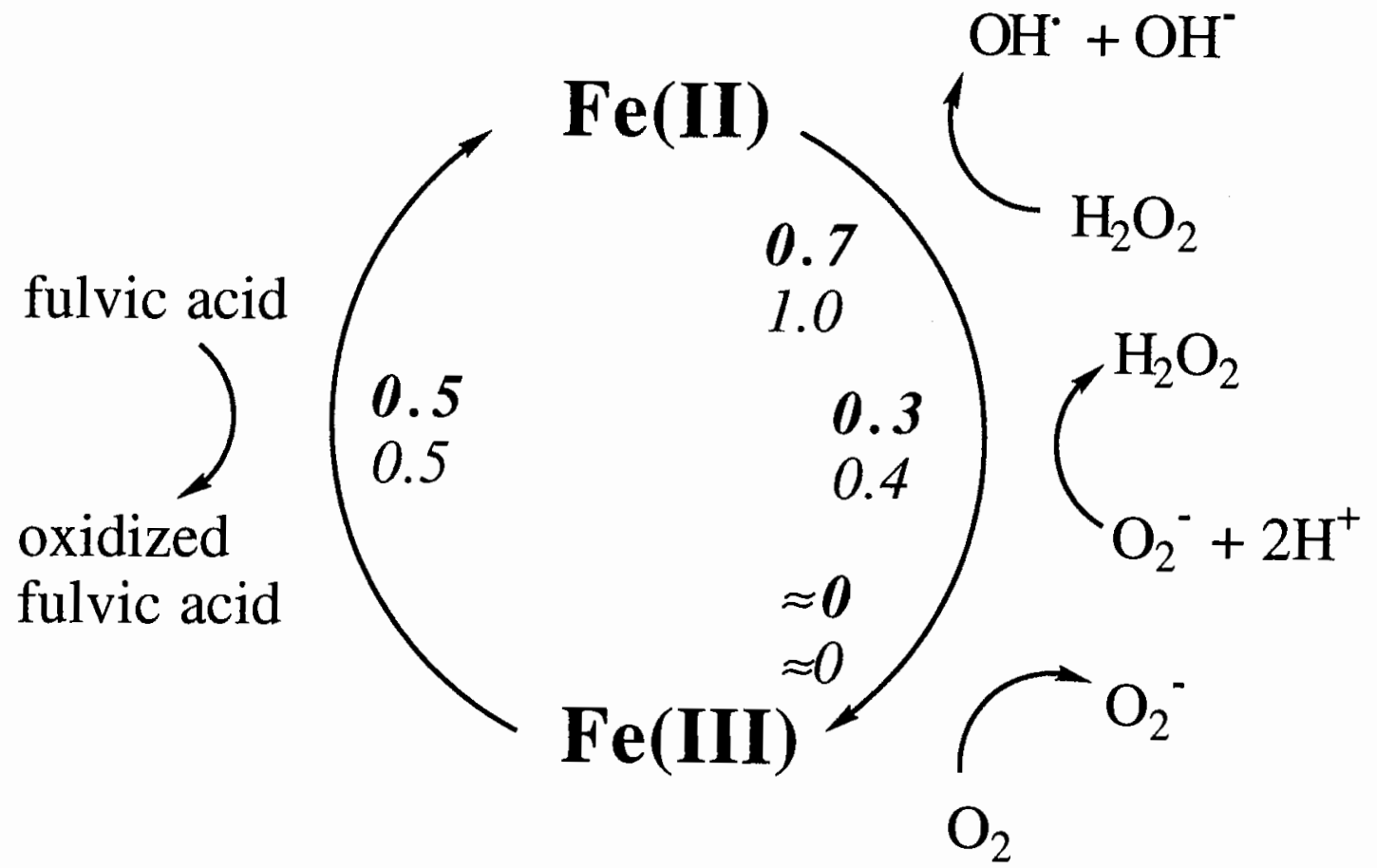

Figure 4.8. Summary of iron redox reactions in aerated solutions containing, intially, micromolar concentrations of $\mathrm{Fe}(\mathrm{II})$ and hydrogen peroxide and $10 \mathrm{mg} / \mathrm{l}$ SRFA. The numbers in italics indicate the amount of iron (in $\mu M$ ) oxidized or reduced by each process after 100 minutes reaction time in the experiments shown in Figures 4.9 and 4.10 (results of model calculations; model parameters are listed inTable 4.1). Numbers on the first line (in boldface) represent the experiment at $\mathrm{pH} 3$, numbers on the second line (not boldface) the experiment at $\mathrm{pH} 5$. 

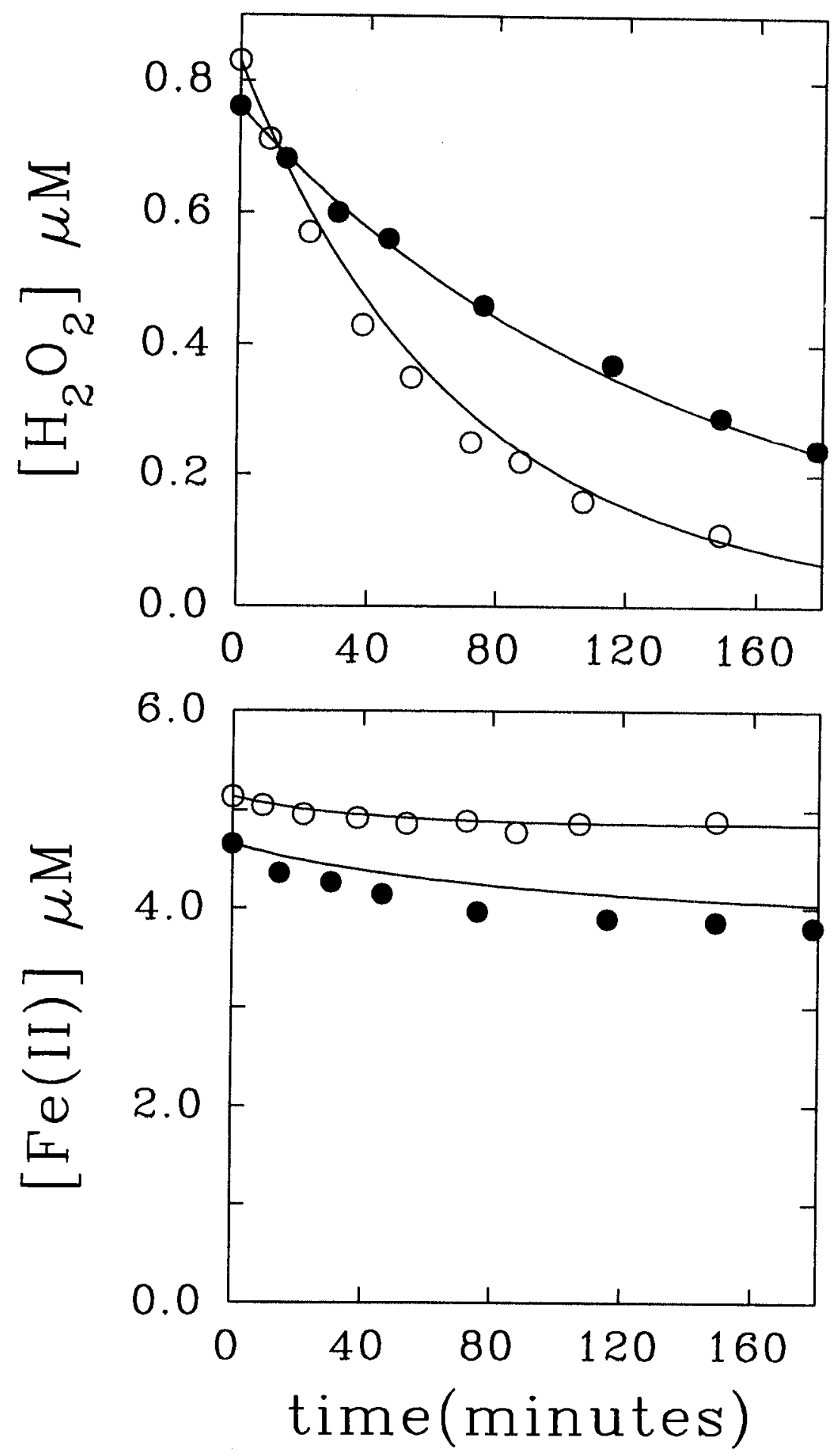

Figure 4.9. Kinetics of degradation of hydrogen peroxide and oxidation of $\mathrm{Fe}(\mathrm{II})$ in the presence of $10 \mathrm{mg} / \mathrm{l}$ fulvic acid at $\mathrm{pH} 3$. - aerated solution, $O$ de-aerated solution. Solid lines represent model fit. 

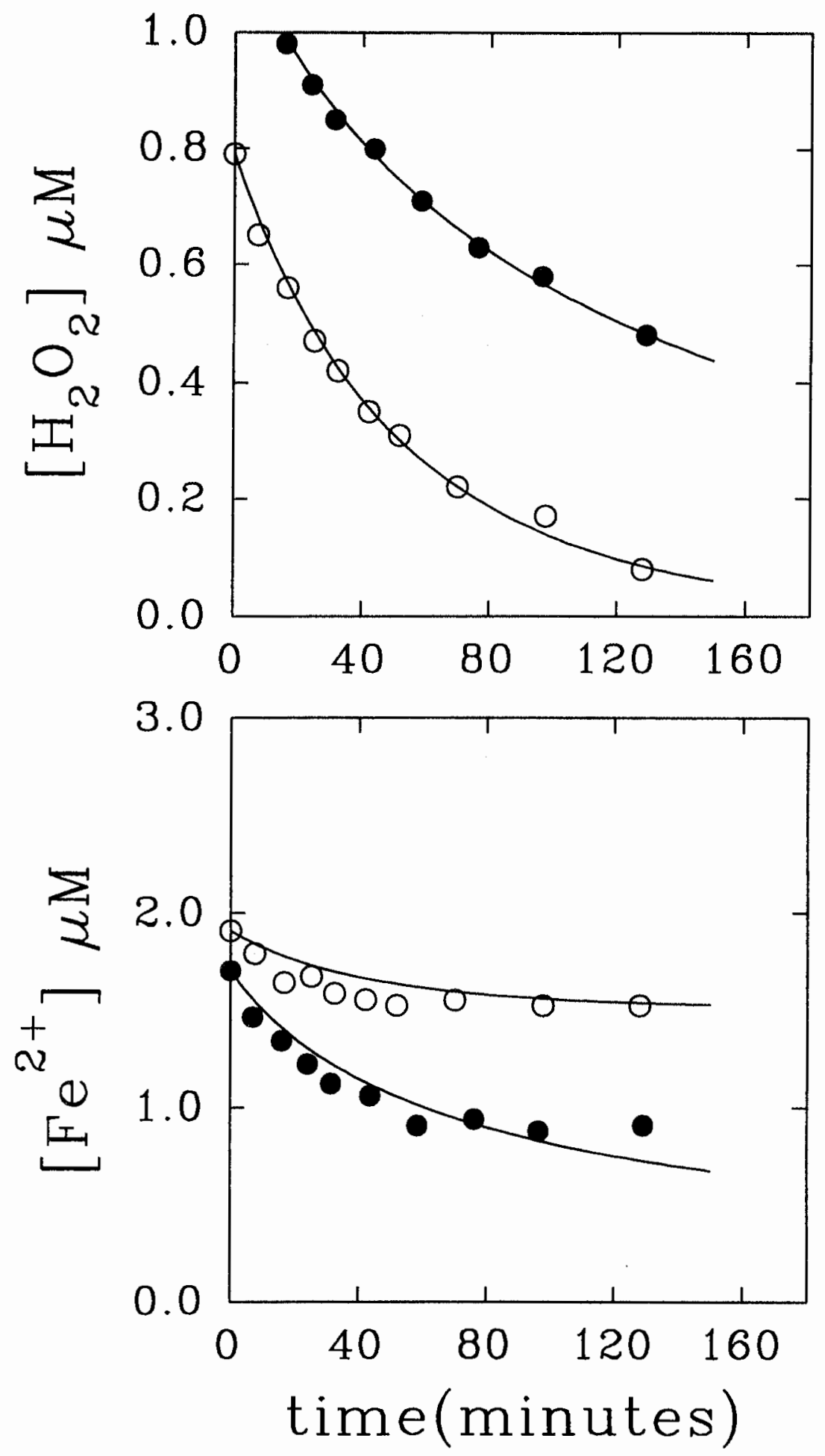

Figure 4.10. Kinetics of degradation of hydrogen peroxide and oxidation of $\mathrm{Fe}(\mathrm{II})$ in the presence of $10 \mathrm{mg} / \mathrm{l}$ fulvic acid at $\mathrm{pH} 5$. - aerated solution, $O$ de-aerated solution. Solid lines represent model fit. 


\section{Chapter 5: Photochemical iron cycling in the presence of fulvic acid and lepidocrocite $(\gamma$-FeOOH $)$}

\subsection{Introduction}

In a typical surface water, light and dissolved organic matter are involved in the chemistry of iron, and reactions taking place in solution and on iron oxide surfaces both play a role. The result is a complicated interplay of many reactions (Figure 1.1). If one measures the net change in the concentrations of dissolved $\mathrm{Fe}(\mathrm{II})$ and $\mathrm{Fe}$ (III) over time in such a system, one is only observing the net effect of competing oxidizing and reducing processes, and of competing dissolution and precipitation processes. One can then attempt to find a qualitative explanation of the behavior of this system, using one's knowledge of the chemical reactions possibly occurring there. However, in a complicated system (such as the one considered here), where many reactions are occurring at once, our intuition fails to tell us whether the explanation is really sufficient to describe the data.

In this study, an attempt is made to gain a more detailed understanding of the effects of light and fulvic acid on iron chemistry. We proceed by dividing the system into "parts", that is, by studying the rates of individual reactions in simpler systems, for example in the absence of oxygen or light. To see if the "whole" can be explained as the sum of its "parts", we employ a kinetic model built from the information gained in simpler systems. The difficulty in this approach for this particular system lies in the impossibility of a clean separation of its "parts": even in the simpler experimental systems, various competing reactions are involved. One example is the system described in the previous chapter. In the absence of light and iron oxide surfaces, several oxidation and 
reduction reactions already contribute to the redox cycling of iron. And these reactions make up only a small part of the iron chemistry in the system we are examining here.

Our goal in this systematic approach, then, is to obtain an overview of the reactions occurring in the fulvic acid-iron oxide system in the presence of light, an assessment of the relative importance of the various reactions involved, and a basis for comparing the behavior of fulvic acid in this system to that of well-defined model ligands used to represent fulvic acid in numerous past studies.

\subsection{Background}

\subsubsection{Photo-reduction of dissolved Fe(III) by fulvic acid}

As discussed in the previous chapter, fulvic acid acts as a reductant of dissolved $\mathrm{Fe}$ (III). At $\mathrm{pH}$ values below 5, this reaction proceeds rapidly in the dark. In the light, we would expect photo-reduction of dissolved $\mathrm{Fe}$ (III) (present as $\mathrm{Fe}$ (III)-fulvate complexes) to be an additional source of $\mathrm{Fe}(\mathrm{II})$.

The mechanism of photochemical iron reduction by humic substances is thought to proceed by a mechanism similar to that observed for simple $\mathrm{Fe}$ (III)-carboxylate complexes, such as citrate (Waite and Morel, 1984b), oxalate (Zuo and Hoigné, 1992) or malonate (Faust and Zepp, 1993). Absorption of a photon results in an excited, ligand-to-metal charge transfer state of the metal-ligand complex (for simplicity, we omit the designation of charges on the species in the reactions that follow):

$\mathrm{RCOOFe}(\mathrm{III}) \stackrel{\mathrm{h} v}{\rightleftharpoons} \mathrm{RCOOFe}(\mathrm{II})^{*}$

The excited state (designated by an asterisk) is either thermally deactivated (reverse of reaction 1) or dissociates, resulting in the formation 
of reduced iron and an oxidized organic radical (Balzzani and Carassiti, 1970):

$\mathrm{RCOOFe}(\mathrm{II})^{*} \longrightarrow \mathrm{Fe}(\mathrm{II})+\mathrm{RCOO}^{*}$

The quantum yield of this reaction, or the yield of charge transfer products formed per photon absorbed, is equal to $k_{2} / k_{2}+k_{-1}$, where $k_{-1}$ is the rate constant of the back reaction of reaction (1) and $k_{2}$ is the rate constant of reaction (2).

Several different reaction pathways are possible for the radical formed in reaction (2). In the case of oxalate, the radical undergoes rapid decarboxylation (Mulazzani et al., 1986) resulting in $\mathrm{CO}_{2}$ and a carboncentered radical:

$\mathrm{C}_{2} \mathrm{O}_{4^{-}} \longrightarrow \mathrm{CO}_{2}+\mathrm{CO}_{2}^{*^{-}}$

The carbon-centered radical can reduce another iron:

$\mathrm{CO}_{2} \cdot^{-}+\mathrm{Fe}(\mathrm{III}) \longrightarrow \mathrm{Fe}(\mathrm{II})+\mathrm{CO}_{2}$

The radical may also reduce oxygen, if it is present, to superoxide or its protonated form, hydroperoxyl radical (Zuo and Hoigné, 1992; Faust and Zepp, 1993):

$\mathrm{CO}_{2}^{*^{-}}+\mathrm{O}_{2} \stackrel{\mathrm{H}^{+}}{\longrightarrow} \mathrm{HO}_{2} / \mathrm{O}_{2}^{-}+\mathrm{CO}_{2}$

In a de-aerated solution, reactions (2) and (3) are followed by reaction (4), so that two moles of $\mathrm{Fe}$ (III) are reduced per mole of oxalate oxidized. In the presence of oxygen, reaction (5) becomes the dominant sink of the intermediate radical. In this case only one mole of Fe(III) is initially reduced per mole of oxalate oxidized. In addition, the $\mathrm{HO}_{2} / \mathrm{O}_{2}$ produced by reaction (5), or its dismutation product hydrogen peroxide (reaction 11 below) may oxidize Fe(II), leading to a further decrease in the apparent yield of $\mathrm{Fe}(\mathrm{II})$ per oxalate oxidized (Zuo and Hoigné, 1992; Faust and Zepp, 1993; and below). 
A variety of $\mathrm{Fe}$ (III)-carboxylate complexes other than $\mathrm{Fe}$ (III)-oxalate participate in reactions (1) and (2). In the case of these substances, other reactions of the intermediate radical product besides reactions (3) or (4) and (5) may occur. The carboxylate radical formed in reaction (2) may reduce $\mathrm{Fe}(\mathrm{III})$ or $\mathrm{O}_{2}$ directly (Faust and Zepp, 1993). The carboncentered radical resulting from decarboxylation (reaction 3) of a larger carboxylic acid than oxalate may be more stable than $\mathrm{CO}_{2}{ }^{-}$. Formation of organic peroxy radicals or polymerization are two possible consequences (Blough and Zepp, in press).

\subsubsection{Photo-reductive dissolution of iron oxides}

Carboxylate ligands adsorbed to the surfaces of iron oxides can participate in the same ligand-to-metal charge transfer reactions shown above for dissolved $\mathrm{Fe}(\mathrm{III})$-carboxylate complexes (see for example Waite and Morel, 1984b and 1984c; Cunningham et al., 1988; Siffert and Sulzberger, 1991; Goldberg et al., 1993; Pehkonen et al., 1993). The first step in this process is the formation of a surface Fe(III)-ligand complex (Schindler and Stumm, 1987; Dzombak and Morel, 1990):

$$
\equiv \mathrm{FeOH}+\mathrm{RCOOH} \rightleftharpoons \equiv \mathrm{Fe}(\mathrm{III})-\mathrm{OOCR}+\mathrm{H}_{2} \mathrm{O}
$$

where the symbol $\equiv$ is used to designate a site on the iron oxide surface. Absorption of light by the surface complex results in an excited state, which may be thermally deactivated or dissociate, as in reactions (1) and (2) above:

$\equiv \mathrm{Fe}(\mathrm{III})-\mathrm{OOCR} \stackrel{\mathrm{hv}}{\rightleftharpoons} \equiv \mathrm{Fe}(\mathrm{II})-\mathrm{OOCR}^{*}$

The difference is that dissociation results in formation of $\mathrm{Fe}(\mathrm{II})$ that is still attached at the surface of the iron oxide:

$\equiv \mathrm{Fe}(\mathrm{II})-\mathrm{OOCR}^{*} \longrightarrow \equiv \mathrm{Fe}(\mathrm{II})+\mathrm{RCOO}{ }^{*}$ 
Analagous to reactions (3) and (4), the organic radical or its decarboxylation product may reduce additional $\equiv \mathrm{Fe}$ (III) to $\equiv \mathrm{Fe}$ (II). Thus, the formation of two moles of $\mathrm{Fe}$ (II) per mole of oxalate oxidized in the absence of oxygen is also observed when the photochemistry takes place on the surface of an iron oxide particle (Siffert and Sulzberger, 1991).

For photo-reductive dissolution to take place, the $\equiv \mathrm{Fe}$ (II) surface species must then detach:

$\equiv \mathrm{Fe}(\mathrm{II}) \longrightarrow \quad \equiv+\mathrm{Fe}(\mathrm{II})$

However, in the presence of oxygen or other oxidants, the $\equiv \mathrm{Fe}(\mathrm{II})$ surface species may be re-oxidized before it can detach.

$\equiv \mathrm{Fe}(\mathrm{II})+\mathrm{O}_{2} \stackrel{\mathrm{H}^{+}}{\longrightarrow} \equiv \mathrm{Fe}(\mathrm{III})+\mathrm{HO}_{2} / \mathrm{O}_{2}{ }^{-}$

Because the rate of oxidation of $\mathrm{Fe}$ (II) bound at an iron oxide surface is much faster than that of dissolved $\mathrm{Fe}^{2+}$, this reaction can take place under solution conditions where we would expect the rate of oxidation of dissolved Fe(II) to be insignificant (Tamura et al., 1976). Depending on the rate of detachment (reaction 9) versus the rate of reoxidation (reaction 10), ligand-to-metal charge transfer reactions at the surface of iron oxides may lead to little or no photo-reductive dissolution of iron, even though the ligand is still oxidized (Sulzberger and Laubscher, submitted).

Photo-oxidation of organic substances at the surfaces of iron oxides or other semiconductors can also take place by an alternative mechanism. The iron oxide itself may absorb light, resulting in the transfer of valence band electrons to the conduction band of the solid and formation of "holes" in the valence band. If the "holes" are scavenged by an organic compound at the surface of the iron oxide particle, before recombination of the electrons and holes can take place, the compound is oxidized and $\mathrm{Fe}(\mathrm{II})$ is formed at the surface of the particle. The products and kinetic 
description of this mechanism are identical to those of the ligand-to-metal charge transfer reaction (Waite, 1990), and the absorption spectrum of the bulk iron oxide overlaps that of the Fe(III)-fulvate complex. It is therefore difficult to determine whether this process also plays a role in the experiments desribed below.

\subsubsection{Photo-formation of Fe(II) oxidants}

In order to be able to construct a reasonable kinetic model of the iron oxidation and reduction reactions taking place in our systems, we must keep track of the oxidants which are produced during an experiment. Within the acidic $\mathrm{pH}$ range considered in this study, the oxidation of $\mathrm{Fe}$ (II) by oxygen itself is insignificant. However, the irradiation of humic substances in the presence of oxygen results in the formation of $\mathrm{HO}_{2} / \mathrm{O}_{2}{ }^{-}$radical (Cooper et al., 1989; Hoigné et al., 1989; Sturzenegger, 1989). The mechanism of this reaction is not known, but may occur via reduction of $\mathrm{O}_{2}$ by aqueous electrons or triplet states, both formed when humic substances are photo-excited (Cooper et al., 1989, Blough and Zepp, in press). Reaction with oxygen of the primary photo-products of ligand-to-metal charge transfer reactions could also result in the formation of $\mathrm{HO}_{2} / \mathrm{O}_{2}^{-}$(see above).

The end product of $\mathrm{HO}_{2} / \mathrm{O}_{2}^{-}$dismutation is hydrogen peroxide, by the reaction:

$2 \mathrm{HO}_{2} / \mathrm{O}_{2}^{-} \stackrel{\mathrm{H}^{+}}{\longrightarrow} \mathrm{H}_{2} \mathrm{O}_{2}+\mathrm{O}_{2}$

This reaction may be catalyzed in the presence of small amounts of trace metals by the reactions:

$$
\begin{aligned}
& \mathrm{HO}_{2} / \mathrm{O}_{2}^{-}+\mathrm{M}_{\mathrm{Ox}} \stackrel{\mathrm{H}^{+}}{\longrightarrow} \mathrm{M}_{\mathrm{red}}+\mathrm{O}_{2} \\
& \mathrm{HO}_{2} / \mathrm{O}_{2}^{-}+\mathrm{M}_{\mathrm{red}} \stackrel{\mathrm{H}^{+}}{\longrightarrow} \mathrm{M}_{\mathrm{Ox}}+\mathrm{H}_{2} \mathrm{O}_{2}
\end{aligned}
$$


In the presence of a high flux of $\mathrm{HO}_{2} / \mathrm{O}_{2}{ }^{-}$, a steady-state ratio of $\mathrm{M}_{\mathrm{ox}}$ and $\mathrm{M}_{\text {red }}$ is quickly established, so that reactions (12) and (13) proceed at equal rates (see chapter 6). In this case, the overall stochiometry of $\mathrm{HO}_{2} / \mathrm{O}_{2}^{-}$dismutation is equal to that in reaction (11): 0.5 moles of hydrogen peroxide are formed for every mole of $\mathrm{HO}_{2} / \mathrm{O}_{2}^{-}$consumed. However, if the flux of $\mathrm{HO}_{2} / \mathrm{O}_{2}^{-}$is small compared to the concentration of either $M_{o x}$ or $M_{r e d}$, or if other reactions of $M_{o x}$ or $M_{r e d}$ prevent the steady-state ratio from being reached, the stochiometry of hydrogen peroxide formation could be anything between 0 (if reaction 12 dominates) and 1 (of reaction 13 dominates) mole of hydrogen peroxide formed per mole of $\mathrm{HO}_{2} / \mathrm{O}_{2}^{-}$consumed.

Both $\mathrm{HO}_{2} / \mathrm{O}_{2}^{-}$and hydrogen peroxide are important oxidants of $\mathrm{Fe}(\mathrm{II})$ in the $\mathrm{pH}$ range of our experiments (see previous chapter and King et al., in press). As indicated by reaction 12 above, the reduction of $\mathrm{Fe}$ (III) by $\mathrm{HO}_{2} / \mathrm{O}_{2}^{-}$is also possible, but is likely to be very slow when the $\mathrm{Fe}(\mathrm{III})$ is complexed by fulvic acid (chapter 4 ).

\subsection{Results and discussion}

\subsubsection{Adsorption of fulvic acid on the $\gamma-\mathrm{FeOOH}$ surface}

Formation of $\mathrm{Fe}(\mathrm{III})$-fulvate surface complexes is a necessary prerequisite for the photo-reductive dissolution of lepidocrocite by fulvic acid. Adsorption isotherms of SRFA on the lepidocrocite surface show that at both $\mathrm{pH} 3$ and 5, the concentrations of adsorbed SRFA as a function of dissolved SRFA rise steeply and reach a plateau at very small concentrations of dissolved SRFA (Figure 5.1). This behavior is consistent with a strong Langmuir-type adsorption of fulvic acid to the iron oxide surface. The saturation concentration of humic substances on an iron oxide surface apparently decreases with increasing $\mathrm{pH}$, as has previously been observed by Tipping (1981). We approximate the 


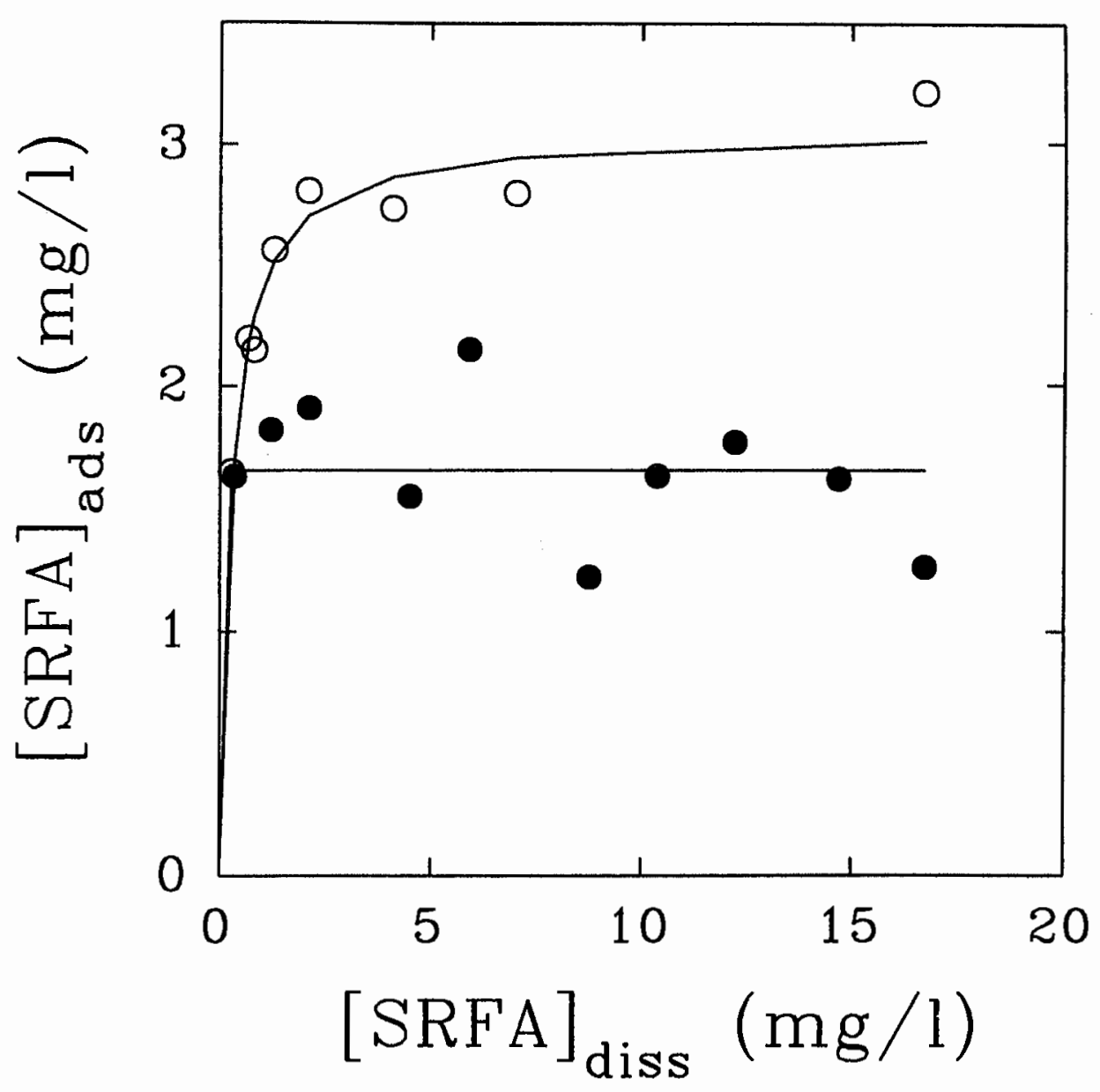

Figure 5.1. Adsorbed versus dissolved SRFA concentration at pH $3(O)$ and $\mathrm{pH} 5\left(^{\bullet}\right)$ in lepidocrocite suspensions (approximately $450 \mu \mathrm{M}$ total $\mathrm{Fe}$ ). Saturation concentrations are approximately $3.1 \mathrm{mg} / \mathrm{l}$ and $1.7 \mathrm{mg} / \mathrm{l}$ at $p H 3$ and 5 respectively. The saturation concentration at $p H 3$ was determined using a fit of the data to the Langmuir equation; that at $\mathrm{pH} 5$ was estimated as the average concentration of adsorbed SRFA over the range of dissolved SRFA concentrations shown here. 
saturation concentration of adsorbed SRFA as $6.9 \times 10^{-6} \mathrm{~g} \mathrm{SRFA} / \mu \mathrm{M} \mathrm{Fe}$ at $\mathrm{pH} 3$ (using a least-squares fit of the Langmuir equation) and $3.8 \times 10^{-6}$ $\mathrm{g}$ SRFA $/ \mu \mathrm{M} \mathrm{Fe}$ at $\mathrm{pH} 5$ (taking the average of the $[\mathrm{SRFA}]_{\mathrm{ads}}$ values shown) (solid lines in Figure 5.1). Under the conditions of the reductive dissolution experiments, in the presence of $10 \mathrm{mg} / 1 \mathrm{SRFA}$ and approximately $45 \mu \mathrm{M} \mathrm{Fe}$ of lepidocrocite, the SRFA was present in great excess of the available surface sites. We expect $0.31 \mathrm{mg} / \mathrm{l}$ of the total SRFA to be adsorbed at $\mathrm{pH} 3$ and $0.17 \mathrm{mg} / \mathrm{l}$ at $\mathrm{pH} 5$.

At $\mathrm{pH} 5$, it was necessary to filter the samples after centrifugation to remove all of the lepidocrocite particles from the solution before analysis. Some interaction of fulvic acid with the filter or with lepidocrocite particles on the filter may have occurred, leading to higher scatter in the data than that observed at $\mathrm{pH} 3$.

\subsubsection{Photo-reductive dissolution of $\gamma-\mathrm{FeOOH}$ by fulvic acid}

The rate of formation of dissolved iron by photo-reductive dissolution of lepidocrocite in the presence of $10 \mathrm{mg} / \mathrm{l}$ Suwannee River fulvic acid (SRFA) is strongly affected both by $\mathrm{pH}$ and the presence of oxygen (Figures 5.2 and 5.3).

The decrease in the rate of reductive dissolution with increasing $\mathrm{pH}$ has been observed for a number of ligands (Waite and Morel, 1984b; Pehkonen et al., 1993; Sulzberger and Laubscher, in press). To see if it can be explained by the decrease in the amount of SRFA adsorbed to the surface of the oxide as the $\mathrm{pH}$ is increased, we must compare the apparent first-order rate constants (rate of photo-reduction divided by the concentration of surface complex) at the two $\mathrm{pH}$ values. If we assume that the SRFA has an average molecular weight of 800 daltons (Aiken et al., 1989) and that each adsorbed fulvic acid molecule forms a 1:1 complex with surface Fe(III), then the concentration of surface Fe(III)- 
complexes is $3.5 \times 10^{-7} \mathrm{M}$ in the de-aerated system at $\mathrm{pH} 3$ (Figure 5.2) and $2.1 \times 10^{-7} \mathrm{M}$ in the de-aerated system at $\mathrm{pH} 5$ (Figure 5.3). The dissolution rates (from linear least square fits of the data in Figures 5.2 and 5.3) are $5.0 \times 10^{-10} \mathrm{Ms}^{-1}$ and $2.1 \times 10^{-10} \mathrm{Ms}^{-1}$ at $\mathrm{pH} 3$ and 5 respectively, leading to an overall apparent first-order rate constant of $1.4 \times 10^{-3} \mathrm{~s}^{-1}(\mathrm{pH} 3)$ and $1.0 \times 10^{-3} \mathrm{~s}^{-1}(\mathrm{pH} 5)$ in the de-aerated lepidocrocite suspensions. A slight effect of $\mathrm{pH}$ on the rate constants remains, which could be due to a $\mathrm{pH}$ dependence of $\equiv \mathrm{Fe}$ (II) detachment rates, leading to an accumulation of $\mathrm{Fe}$ (II) on the surface of the iron oxide, and therefore a blocking of surface sites for reductive dissolution (Sulzberger and Laubscher, in press).

The apparent first-order rate constant of photochemical ligand-to-metal charge transfer is a function of the amount of light absorbed by the complex and the quantum yield of the charge transfer reaction, and therefore depends on both light intensity and intrinsic properties of the complex. One might expect that different polycarboxylic acids resemble each other in these properties. Our apparent first-order rate constant of the surface Fe(III)-SRFA complex is of the same order of magnitude as the apparent constant measured by Waite and Morel (1984b) for surface citrate complexes on lepidocrocite, $3.5 \times 10^{-3} \mathrm{~s}^{-1}$. The light source used by Waite and Morel produced a spectrum close to that of our light source, with a total light intensity of $1.0 \mathrm{~kW} / \mathrm{m}^{2}$, or approximately twice that used in our experiments. However, Waite and Morel's dissolution rate was measured in aerated systems and may therefore represent an underestimate of the actual amount of iron photo-reduced at the surface.

In the presence of oxygen, the rate of formation of total dissolved $\mathrm{Fe}$ is decreased at both pH 3 and pH 5 (Figures 5.2 and 5.3). This effect of oxygen is due either to a decrease in the total amount of iron reduced per fulvic acid oxidized (for example because reaction 5 outcompetes reaction 4 in the presence of oxygen), or to oxidation of some of the surfacebound $\mathrm{Fe}$ (II) (reaction 10) before detachment can take place. Both 


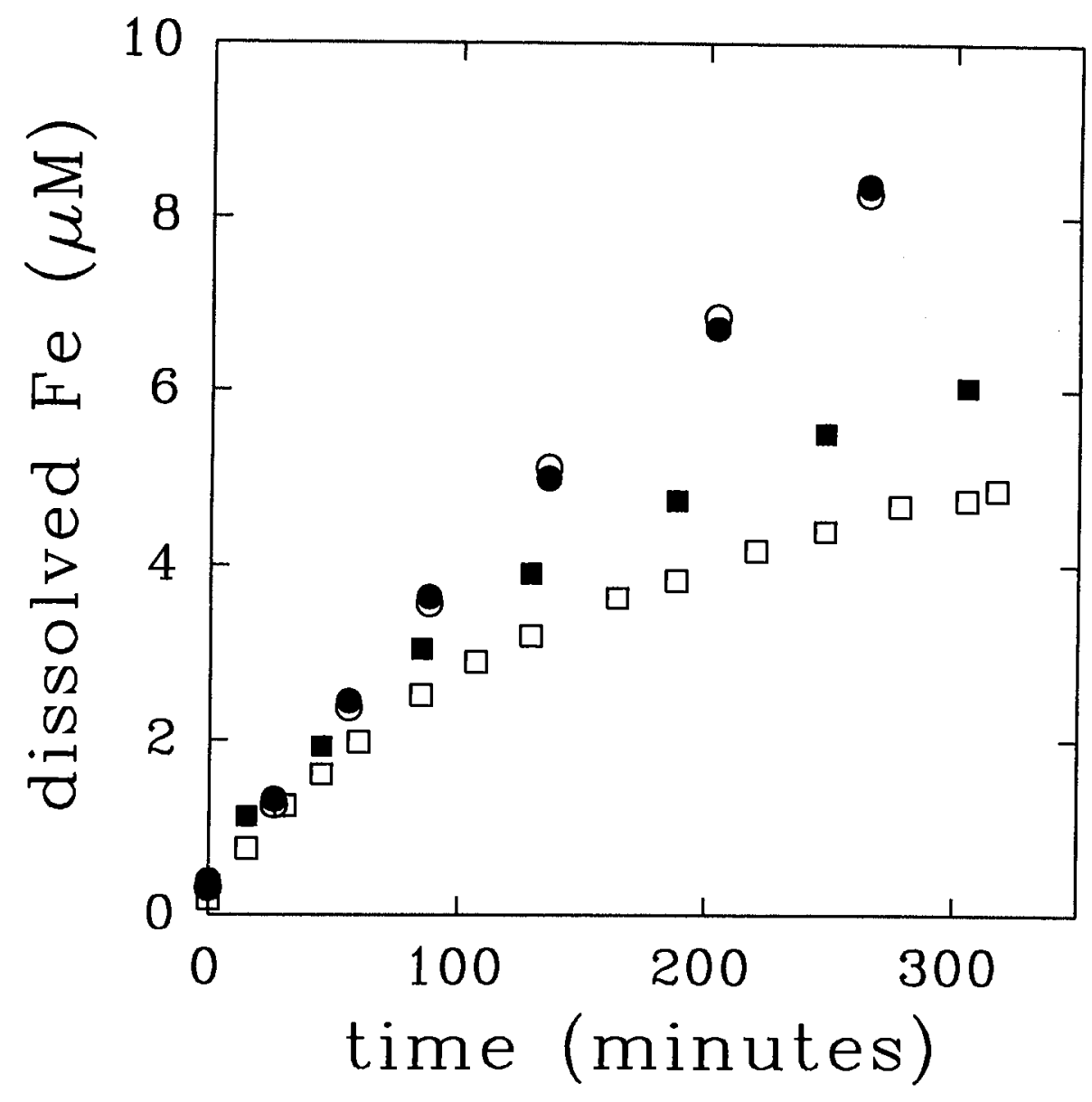

Figure 5.2. Reductive dissolution of lepidocrocite in de-aerated (circles) and aerated (squares) solutions of $10 \mathrm{mg} / \mathrm{SRFA}$ at pH 3. Filled symbols represent total dissolved Fe concentrations, hollow symbols are $\mathrm{Fe}(\mathrm{II})$. Total lepidocrocite concentrations in these experiments were 40.0 $\mu M F e$ in the de-aerated system and $40.3 \mu M$ in the aerated system. 


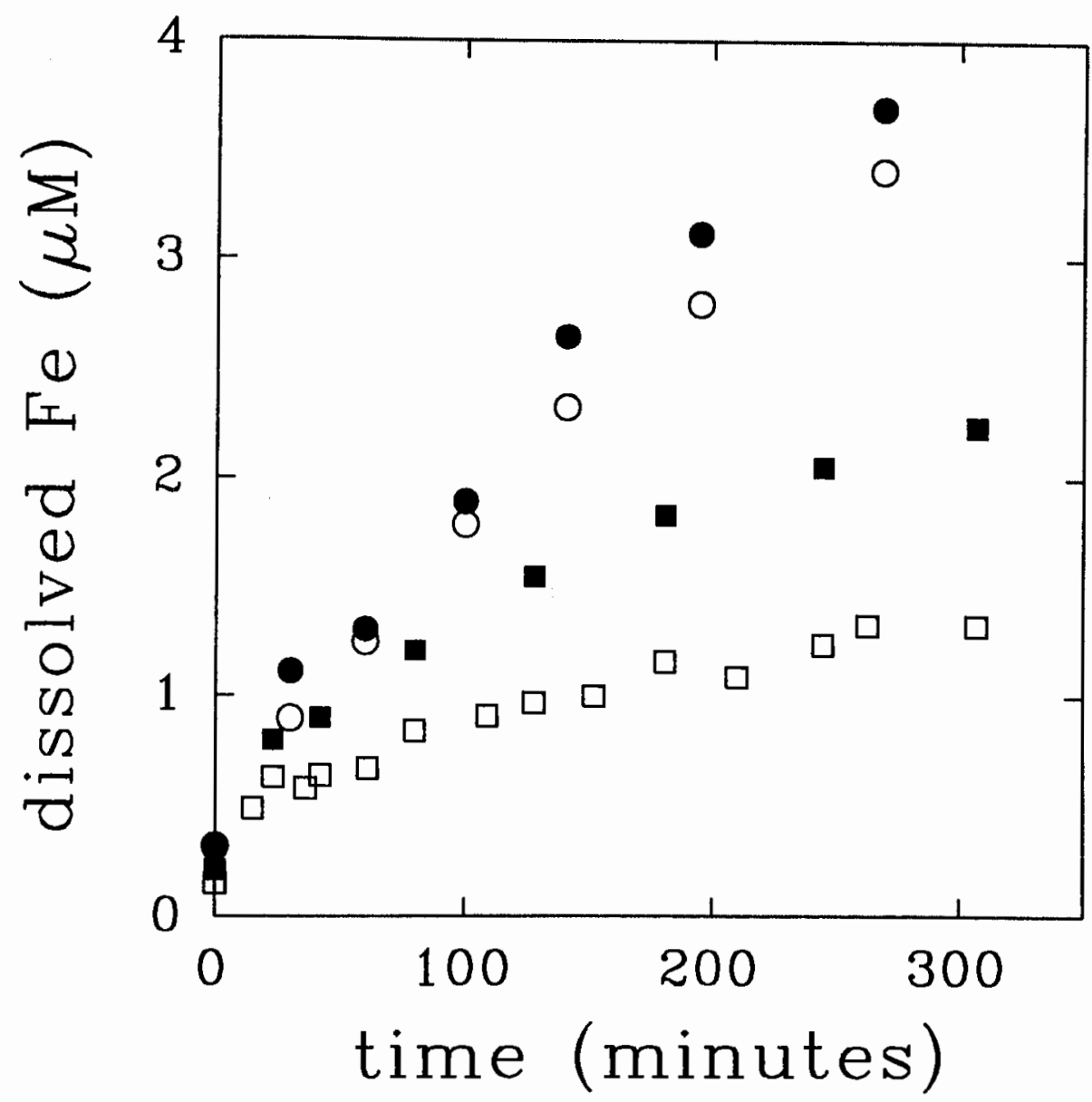

Figure 5.3. Reductive dissolution of lepidocrocite in de-aerated (circles) and aerated (squares) solutions of $10 \mathrm{mg} / \mathrm{l} \mathrm{SRFA}$ at pH 5. Filled symbols represent total dissolved Fe concentrations, hollow symbols are $\mathrm{Fe}(\mathrm{II})$. Total lepidocrocite concentrations in these experiments were 44.6 $\mu M \mathrm{Fe}$ in the de-aerated system and $50.0 \mu \mathrm{M}$ in the aerated system. 
reactions (5) and (10) should result in the production of $\mathrm{HO}_{2} / \mathrm{O}_{2}^{-}$radical, but it is unclear whether this radical will undergo further reactions at the iron oxide surface (possibly oxidizing another $>\mathrm{Fe}[\mathrm{III}]$ ) or end up in solution. Interestingly, in the presence of either oxalate (Sulzberger and Laubscher, submitted) or fulvic acid (Figure 5.2), the lepidocrocite in the aerated system at $\mathrm{pH} 3$ is dissolved at approximately one half of the rate observed in the de-aerated system. This could be an indication that the decrease in rate is due to a process that is independent of the ligand involved, such as reaction (10). A decrease in rate of slightly greater magnitude is found at $\mathrm{pH} 5$ compared to that at $\mathrm{pH} 3$ (Figure 5.3), consistent with a slowing of $\mathrm{Fe}(\mathrm{II})$ detachment (reaction 9) with increasing $\mathrm{pH}$.

In the absence of oxygen, all of the dissolved Fe(II) produced by photoreductive dissolution in the fulvic acid-lepidocrocite system remains in reduced form. However, in aerated systems, a significant part of the dissolved iron is re-oxidized at both $\mathrm{pH} 3$ and 5 (Figures 5.2 and 5.3). Under some conditions, the dissolved Fe(III) formed this way may reprecipitate, causing a further decrease in the net formation rate of dissolved iron. However, under the conditions of our experiments, micromolar concentrations of dissolved Fe(III) remain in solution. If $\mathrm{Fe}$ (III) is added to a lepidocrocite suspension in the presence of fulvic acid, all of it is still present in the dissolved form after 100 minutes (Figure 5.4). Fe(III) formed when $\mathrm{Fe}(\mathrm{II})$ is oxidized by hydrogen peroxide in the lepidocrocite/fulvic acid system at $\mathrm{pH} 5$ is also not removed from solution (Figure 5.5). These results demonstrate that the observed decrease in the rate of formation of total dissolved $\mathrm{Fe}$ in the presence of oxygen in our experiments is not due to re-oxidation of dissolved $\mathrm{Fe}$ (II) followed by precipitation of $\mathrm{Fe}(\mathrm{III})$. 


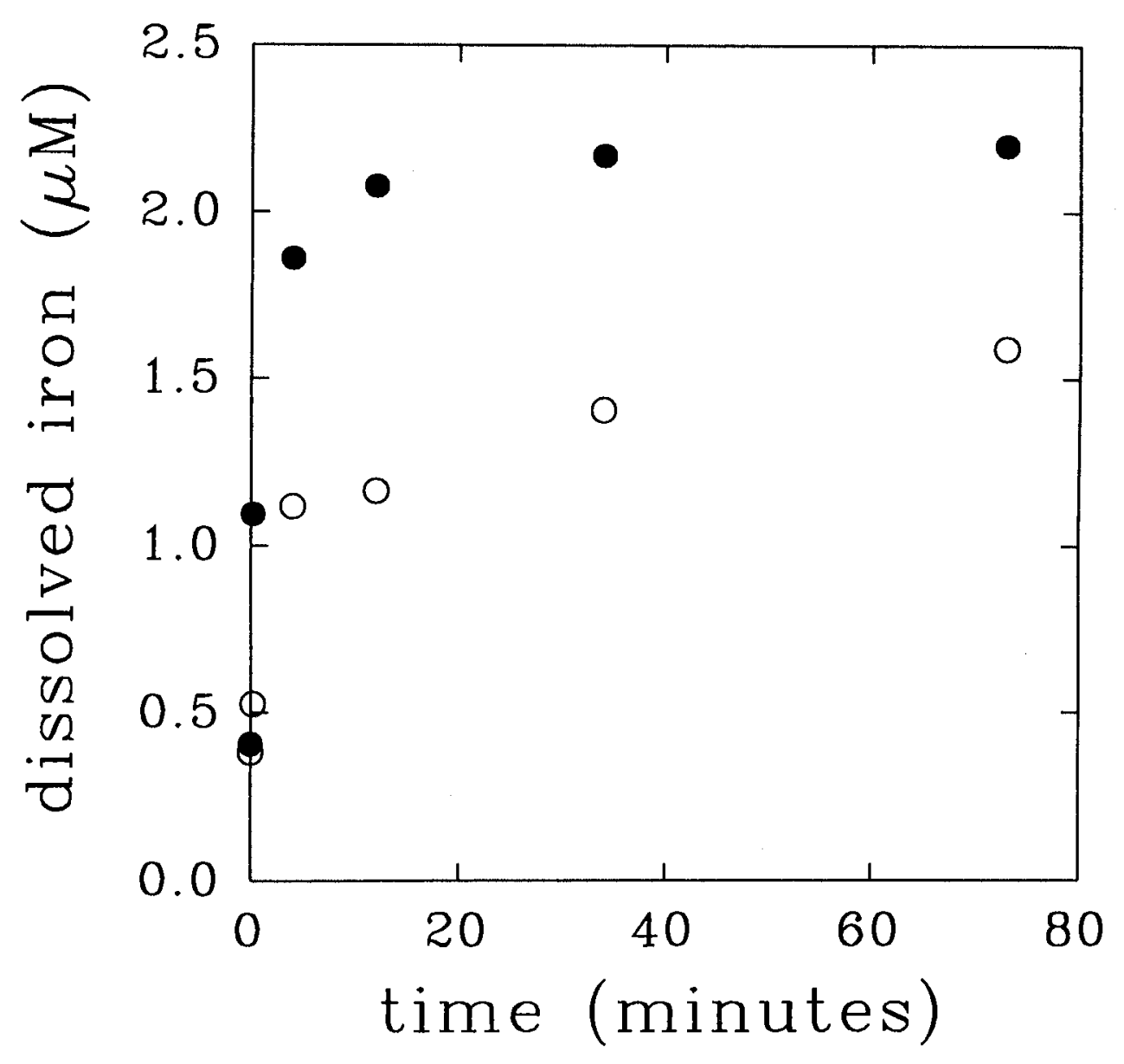

Figure 5.4. Total dissolved Fe (filled symbols) and Fe(II) (hollow symbols) in a lepidocrocite suspension (total Fe approx. $45 \mu \mathrm{M}$ ) containing $10 \mathrm{mg} / \mathrm{l} \mathrm{SRFA}$ and $0.3 \mu \mathrm{M} \mathrm{Fe}$ (II) at pH 3. 2.0 $\mu \mathrm{M}$ of $\mathrm{Fe}(I I I)$ were added to the suspension at $t=0$. 


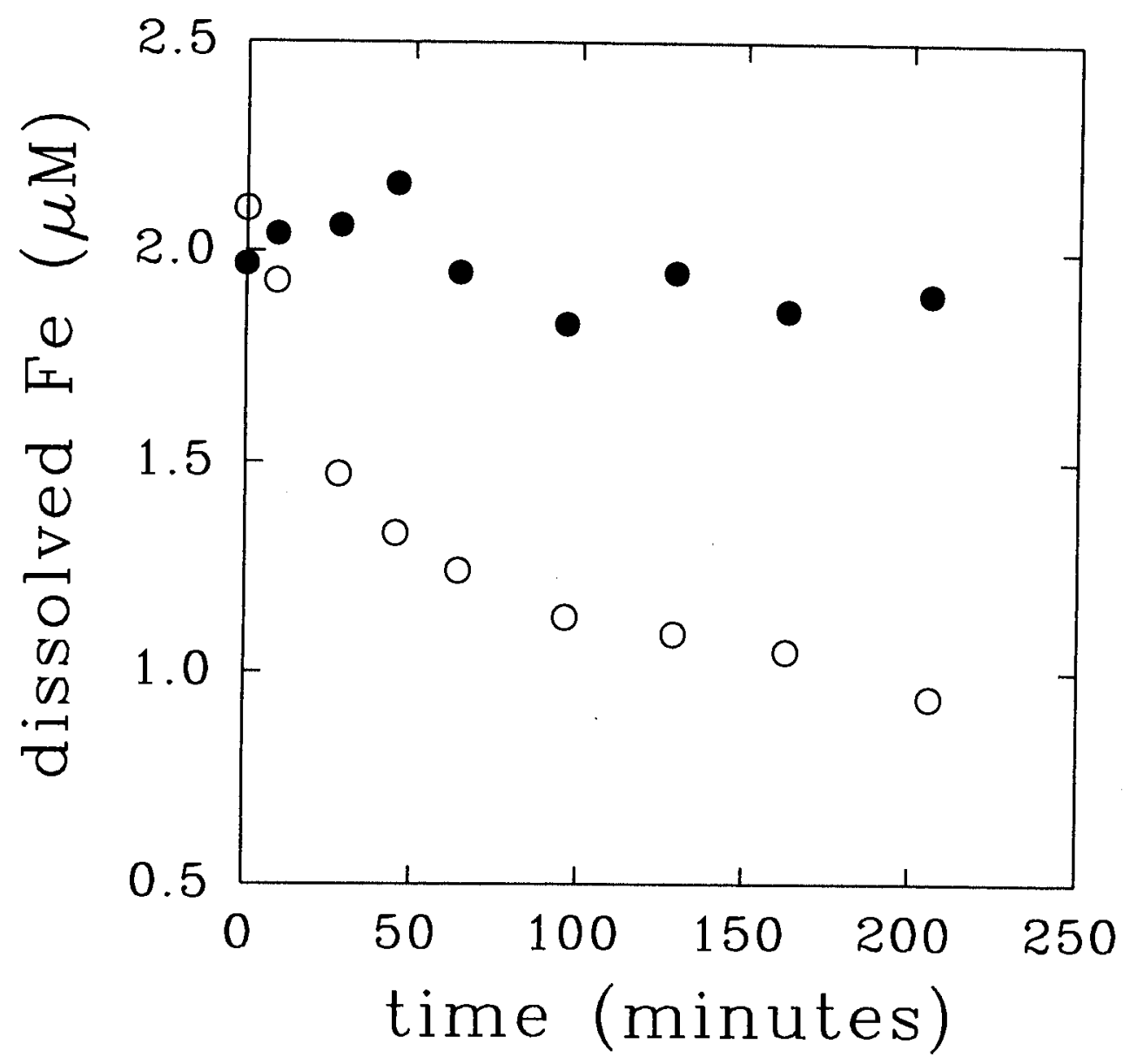

Figure 5.5. Total dissolved Fe (filled symbols) and Fe(II) (hollow symbols) in a lepidocrocite suspension (total Fe approx. $45 \mu M$ ) containing initially $10 \mathrm{mg} / \mathrm{l} S R F A$ and $2.0 \mu \mathrm{M} \mathrm{Fe}(I I)$ at $\mathrm{pH}$ 5. At $t=0,2.0$ $\mu M$ of hydrogen peroxide were added to initiate $F e(I I)$ oxidation. 


\subsubsection{Redox cycling of dissolved iron in the presence of light}

The formation of dissolved $\mathrm{Fe}$ (III) in the aerated lepidocrocite suspensions indicates that photo-reductive dissolution of the iron oxide is followed by some amount of redox cycling in solution. The reactions of this cycle that take place in the dark, oxidation of $\mathrm{Fe}$ (II) by hydrogen peroxide and dark reduction of $\mathrm{Fe}(\mathrm{III})$ by fulvic acid, were explored in detail in the previous chapter. In this section, the photo-production of $\mathrm{HO}_{2} / \mathrm{O}_{2}{ }^{-}$and hydrogen peroxide, both of which can oxidize $\mathrm{Fe}(\mathrm{II})$, and the photo-reduction of $\mathrm{Fe}(\mathrm{III})$ complexed by fulvic acid, are examined.

$\mathrm{HO}_{2} / \mathrm{O}_{2}^{-}$and then hydrogen peroxide are formed when fulvic acid is irradiated in the presence of oxygen. The formation rate of hydrogen peroxide in an irradiated aerated solution of $10 \mathrm{mg} / \mathrm{l} \mathrm{SRFA}$ is the same at pH 3 and 5 and remains constant over several hours ( $\nabla$ and $\boldsymbol{\nabla}$ symbols in Figure 5.6). As observed by Sturzenegger (1989), hydrogen peroxide is not formed in the absence of oxygen (filled circles in Figure 5.6), although a slow formation rate may be observed in a de-aerated solution if traces of $\mathrm{O}_{2}$ are still present (hollow circles in Figure 5.6). In the presence of $\mathrm{NO}_{(\mathrm{aq})}$, an $\mathrm{HO}_{2} / \mathrm{O}_{2}^{-}$scavenger (Blough and Zafiriou, 1985; Micinski et al., 1993), the formation rate of hydrogen peroxide slows down considerably (squares in Figure 5.6), lending support to Sturzenegger's conclusion that the hydrogen peroxide is formed via reduction of $\mathrm{O}_{2}$ to $\mathrm{O}_{2}^{-}$by the photo-excited fulvic acid. The small production rate of hydrogen peroxide that was observed in the presence of $\mathrm{NO}(\mathrm{aq})$ could indicate that $\mathrm{NO}$ was not present in sufficient concentrations to scavenge all of the $\mathrm{HO}_{2} / \mathrm{O}_{2}^{-}$produced.

To examine the combined effect of $\mathrm{HO}_{2} / \mathrm{O}_{2}^{-}$and hydrogen peroxide on the oxidation of $\mathrm{Fe}(\mathrm{II})$, we irradiated a solution at $\mathrm{pH} 3$ containing $10 \mathrm{mg} / \mathrm{l} \mathrm{SRFA}$ and an initial concentration of $1 \mu \mathrm{M} \mathrm{Fe}$ (II). The Fe(II) is oxidized at a slow net rate when the solution is irradiated ( $\Lambda$ symbols in Figure 5.7). The formation rate of hydrogen peroxide is also increased 


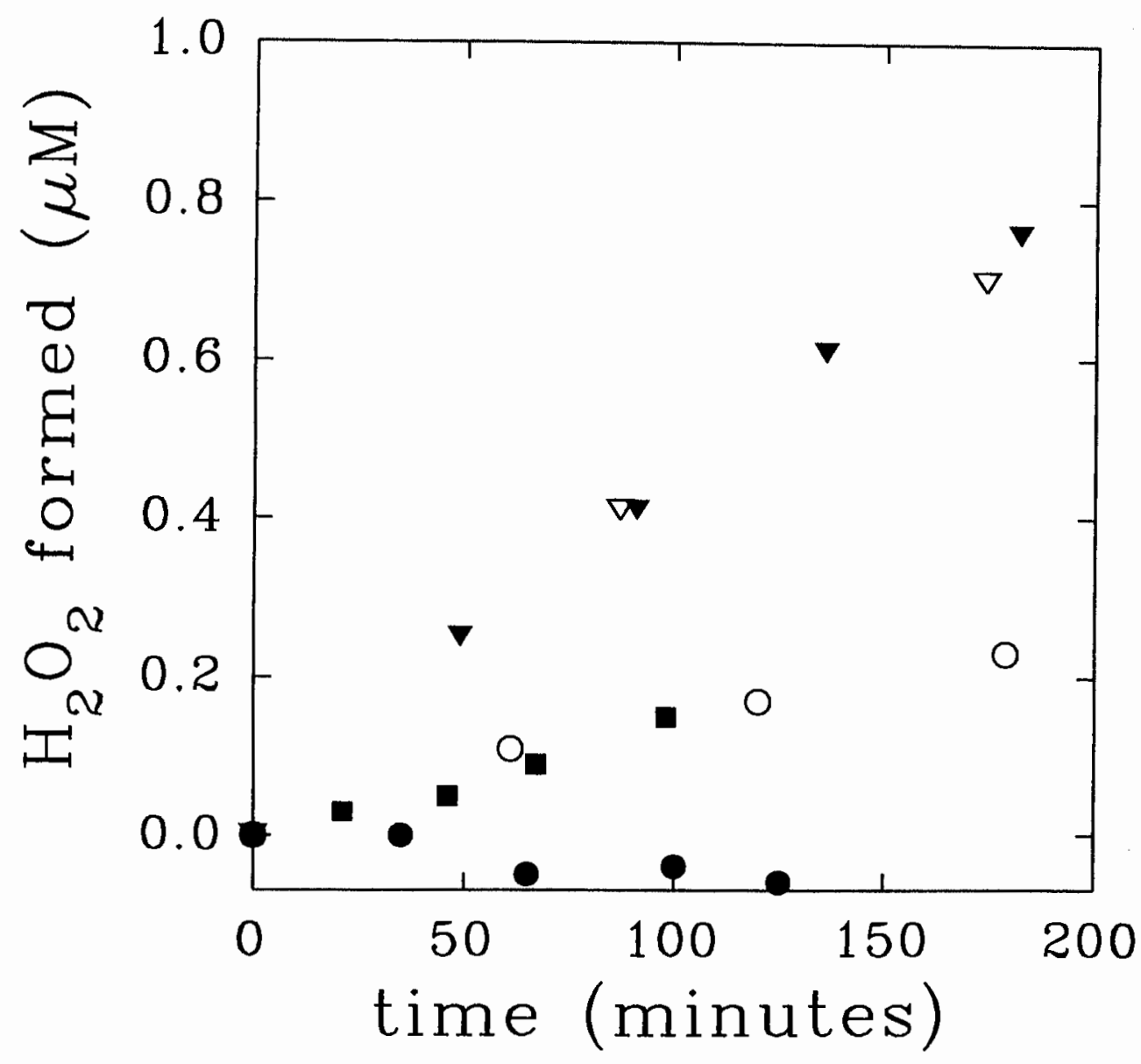

Figure 5.6. Comparison of photo-formation rate of hydrogen peroxide under various conditions. All systems contained $10 \mathrm{mg} / \mathrm{l} \mathrm{SRFA}$ and were irradiated beginning at $t=0$.

hollow triangles: aerated, $\mathrm{pH} 3$

filled triangles: aerated, $\mathrm{pH} 5$

filled and hollow circles: de-aerated solutions at pH 3

squares: aerated and saturated with 1000ppm $\mathrm{NO} / \mathrm{N}_{2}$ gas mixture 


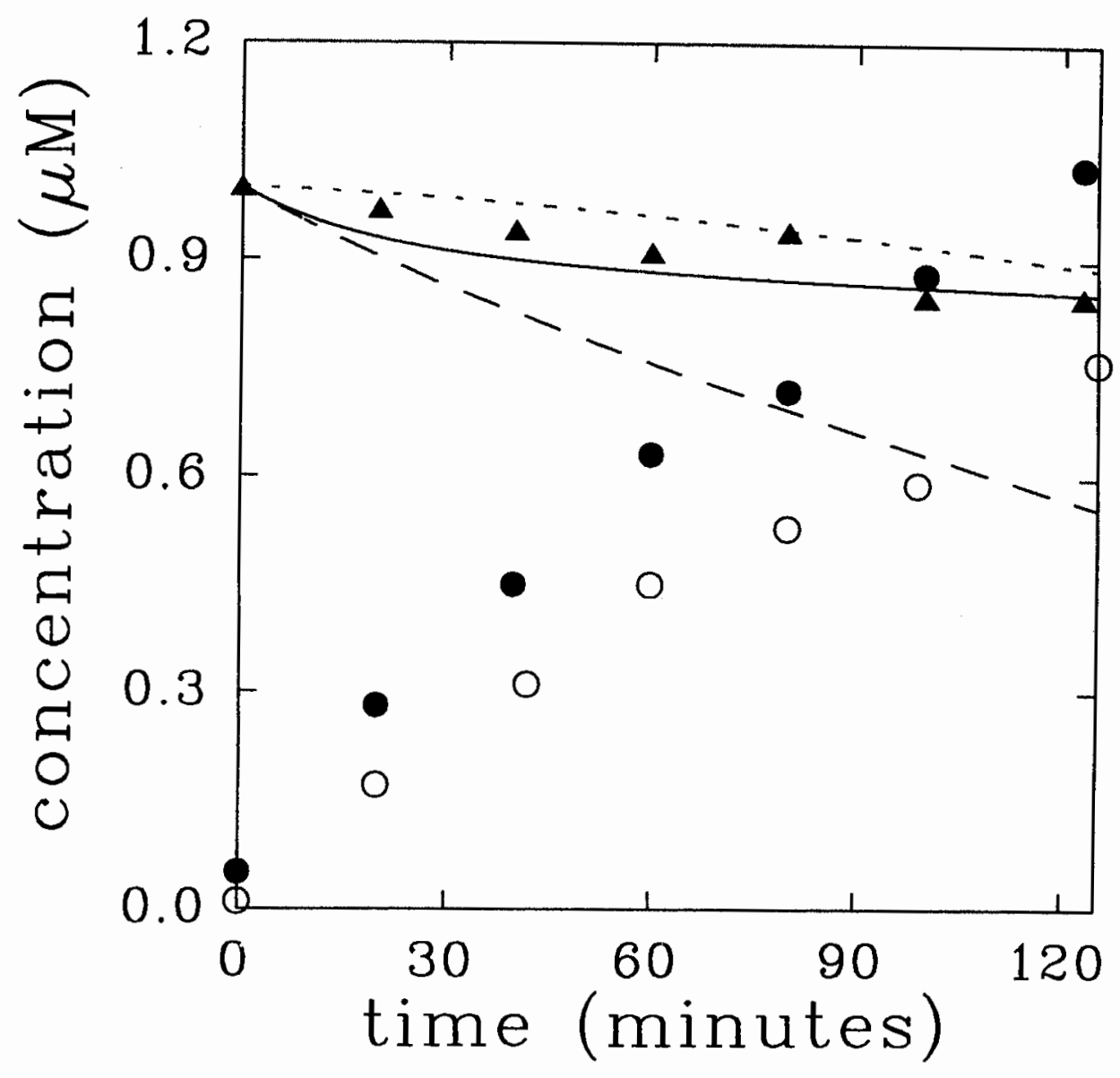

Figure 5.7. Formation of hydrogen peroxide (filled circles) and oxidation of $\mathrm{Fe}(I \mathrm{I})$ (triangles) in an irradiated $10 \mathrm{mg} / \mathrm{l} \mathrm{SRFA}$ solution at pH 3 containing, initially, $1.0 \mu \mathrm{MFe}(I I)$. The rate of formation of hydrogen peroxide in the absence of added $F e(I I)$ is shown for comparison (hollow circles). Three model calculations of $\mathrm{Fe}(I I)$ oxidation are also shown (for details see text):

(1) dotted line: a model calculation of $F e(I I)$ oxidation assuming that hydrogen peroxide is the only oxidant and that $\mathrm{Fe}(I I I)$ reduction by fulvic acid proceeds at the same rate in the light as in the dark.

(2) dashed line: a calculation with the model described in (1) but also including $\mathrm{HO}_{2} / \mathrm{O}_{2}^{-}$as an oxidant of $\mathrm{Fe}(\mathrm{II})$.

(3) solid line: an acceleration of $F e(I I I)$ reduction by fulvic acid in the light was included in addition to the processes considered in (1) and (2). 
compared to a solution under the same conditions which did not contain the added Fe(II) ( versus O symbols in Figure 5.7).

The net amount of $\mathrm{Fe}(\mathrm{II})$ oxidized in this experiment depends not only on the rate of oxidation, but also on the rate at which Fe(III) is reduced. A kinetic model calculation shows that the observed net rate of disappearance of $\mathrm{Fe}(\mathrm{II})$ is too large to be accounted for simply by the reaction of $\mathrm{Fe}$ (II) with photo-produced hydrogen peroxide. The dotted line in Figure 5.7 represents the results of a calculation in which only hydrogen peroxide formation at a linear rate, $\mathrm{Fe}$ (II) oxidation by hydrogen peroxide, and dark $\mathrm{Fe}(\mathrm{III})$ reduction by fulvic acid were included as possible reactions. Kinetic parameters for the reaction of $\mathrm{Fe}(\mathrm{II})$ with hydrogen peroxide and the dark reduction of $\mathrm{Fe}(\mathrm{III})$ by fulvic acid under the conditions of this experiment were taken from chapter 4 . This calculation neglects the acceleration of the reduction of Fe(III) by fulvic acid in the light (see below), and will therefore underestimate the net amount of $\mathrm{Fe}$ (II) oxidized. In any case, a maximum of only a few percent of the Fe(II) should be oxidized after 100 minutes of irradiation if hydrogen peroxide is the only oxidant in this system.

A second possible model includes the reactions listed in the previous paragraph (linear hydrogen peroxide formation rate, $\mathrm{Fe}$ (II) oxidation by hydrogen peroxide, Fe(III) dark reduction by fulvic acid), and also assumes that all of the hydrogen peroxide formed results from the reaction:

$\mathrm{HO}_{2} / \mathrm{O}_{2}^{-}+\mathrm{Fe}(\mathrm{II}) \stackrel{\mathrm{H}^{+}}{\longrightarrow} \mathrm{H}_{2} \mathrm{O}_{2}+\mathrm{Fe}(\mathrm{III})$

In addition to $\mathrm{Fe}$ (II) oxidation by hydrogen peroxide, then, one mole of $\mathrm{Fe}(\mathrm{II})$ is oxidized for every mole of hydrogen peroxide formed from $\mathrm{HO}_{2} / \mathrm{O}_{2}{ }^{-}$. This model predicts a net oxidation rate that is much faster than the observed rate (dashed line in Figure 5.7). This is not surprising since this model still neglects the photo-reduction of dissolved Fe(III) by 
fulvic acid. If we include this reaction, with an apparent first order rate constant of $6 \times 10^{-4} \mathrm{~s}^{-1}$ (determined as the parameter which gave the best fit of the data), we obtain an adequate description of the behavior of $\mathrm{Fe}(\mathrm{II})$ (solid line in Figure 5.7).

Comparison of the formation rate of hydrogen peroxide in irradiated solutions of $10 \mathrm{mg}$ SRFA in the presence and absence of $1 \mu \mathrm{M}$ added $\mathrm{Fe}$ (II) (filled and hollow circles in Figure 5.7) provides further evidence that reaction (14) is a predominant sink of $\mathrm{O}_{2}{ }^{-}$. If we assume that the rate of formation of $\mathrm{HO}_{2} / \mathrm{O}_{2}{ }^{-}$is not changed by the added $\mathrm{Fe}$ (II), then the faster rate of formation of hydrogen peroxide in the presence of $\mathrm{Fe}$ (II) must result from a change in stochiometry of hydrogen peroxide formation: one mole of hydrogen peroxide is formed per mole of $\mathrm{HO}_{2} / \mathrm{O}_{2}{ }^{-}$produced if reaction (14) is the dominant pathway of $\mathrm{HO}_{2} / \mathrm{O}_{2}{ }^{-}$ reaction, while the dismutation reaction (reaction 11 above) results in only 0.5 moles of hydrogen peroxide per mole of $\mathrm{HO}_{2} / \mathrm{O}_{2}$ -

\subsection{A kinetic model of iron cycling in the irradiated lepidocrocite-SRFA system}

When aerated lepidocrocite suspensions are irradiated in the presence of fulvic acid, dissolved $\mathrm{Fe}$ (II) and $\mathrm{Fe}$ (III) accumulate while the concentration of hydrogen peroxide levels off after some time, both at $\mathrm{pH} 3$ (Figure 5.8) and at $\mathrm{pH} 5$ (Figure 5.9). Based on the information gained from the previous experiments, we can construct a kinetic model of the Fe redox reactions taking place on the iron oxide surface and in solution (Figure 5.10). The purpose of this modeling work was not to extract universally applicable kinetic constants from our data, but instead to test whether our understanding of the individual reactions occurring in these systems is sufficient to explain the systems' behavior. If in the model we have neglected a significant source or sink of hydrogen peroxide, or an important iron reduction or oxidation process, this should 


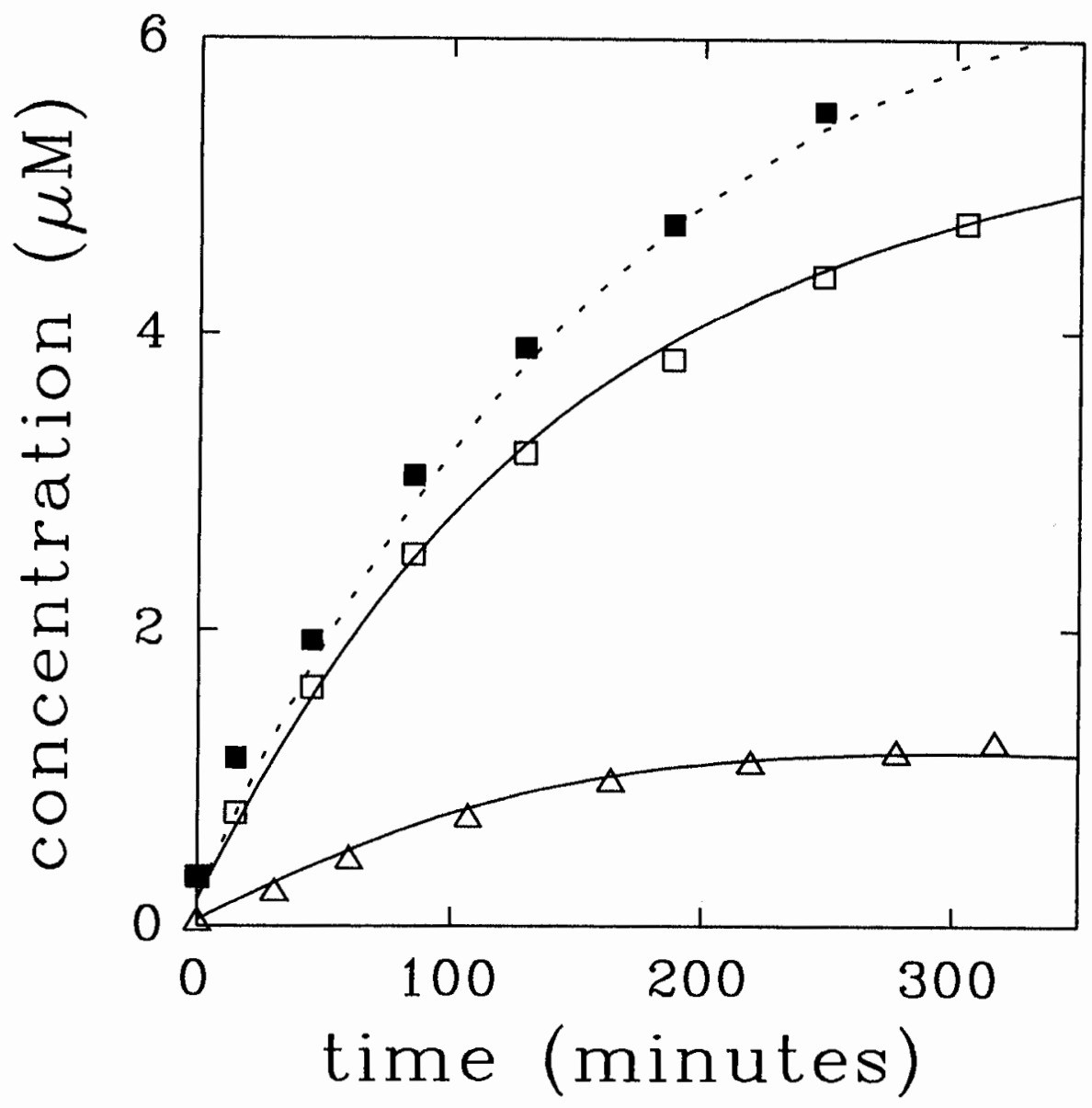

Figure 5.8. $\quad$ Total dissolved Fe (filled squares), $\mathrm{Fe}(\mathrm{II})$ (hollow squares) and hydrogen peroxide (triangles) in the aerated, irradiated lepidocrocite suspension at $p H 3$. Dashed lines represent the modeled iron dissolution rate; solid lines represent model fit of the $F e(I I)$ and hydrogen peroxide data (see text). 


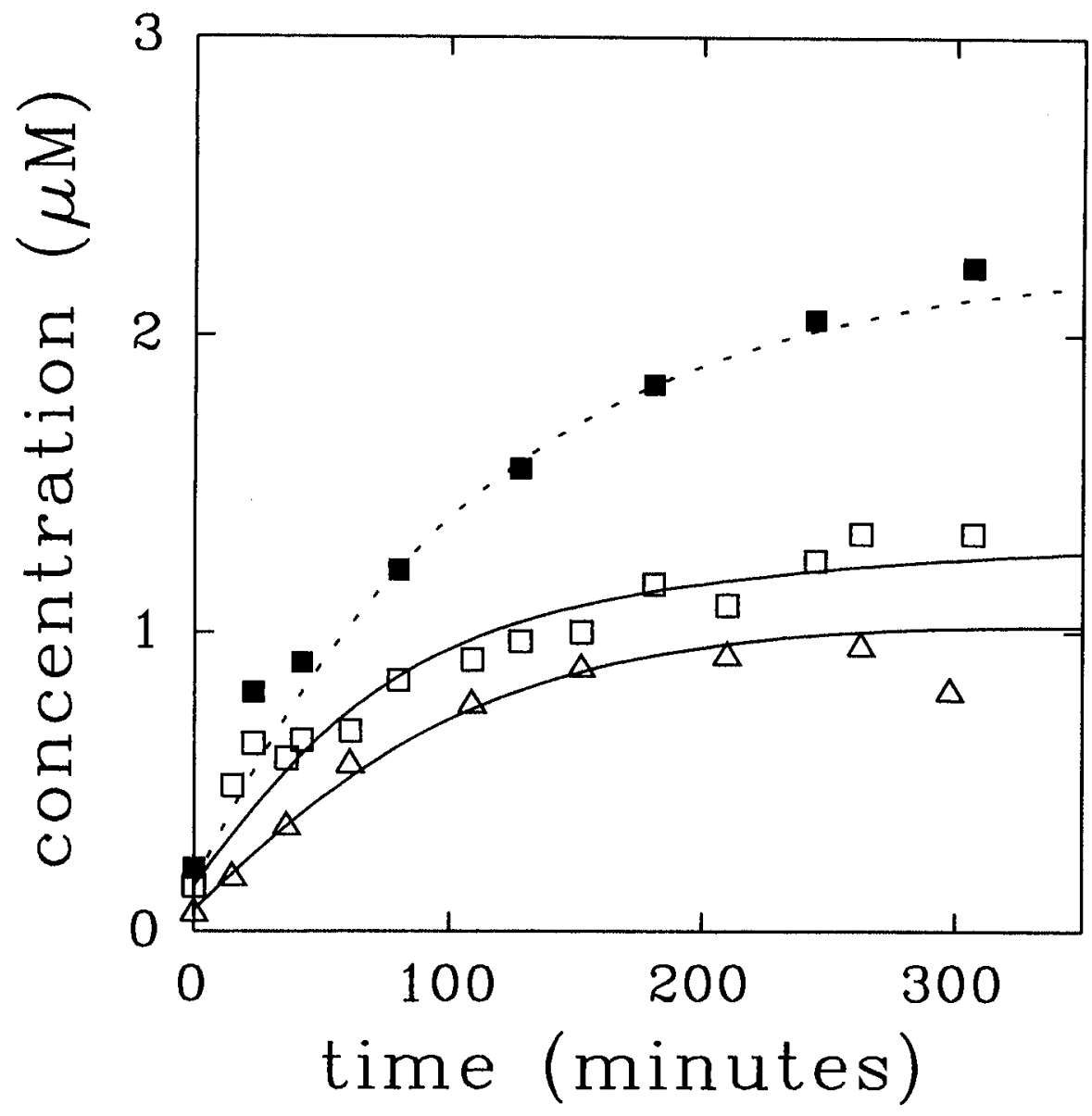

Figure 5.9. Total dissolved Fe (filled squares), Fe(II) (hollow squares) and hydrogen peroxide (triangles) in the aerated, irradiated lepidocrocite suspension at pH 5. Dashed lines represent the modeled iron dissolution rate; solid lines represent model fit of the $\mathrm{Fe}(I I)$ and hydrogen peroxide data (see text). 
become obvious as we compare model results to experimental data. The use of a model also helps us to compare the relative importance of competing processes and to understand how the behavior of the system may change under different conditions.

\subsubsection{Model set-up}

The components of this model include:

-- Photo-reductive dissolution of lepidocrocite in the presence of oxygen.

We assumed that all of the iron entering the solution from the surface was initially present as $\mathrm{Fe}$ (II) and that removal of dissolved $\mathrm{Fe}$ (II) and $\mathrm{Fe}$ (III) back to the surface was insignificant. The rate of $\mathrm{Fe}$ (II) input into the solution that we used in the model, then, was given by the rate of formation of total dissolved iron at each $\mathrm{pH}$. This rate was not linear at both $\mathrm{pH} 3$ and $\mathrm{pH} 5$, and an exponential fit was used to reproduce the observed rate (shown as the dashed lines in Figures 5.8 and 5.9).

-- Oxidation of $\mathrm{Fe}(\mathrm{II})$ by hydrogen peroxide

We used the kinetic parameters determined in chapter 4 for the rate of oxidation of $\mathrm{Fe}(\mathrm{II})$ by hydrogen peroxide in the presence of fulvic acid. The subsequent reaction of the $\mathrm{OH}$. radical produced by this reaction with fulvic acid, resulting in oxidized organic matter and $\mathrm{HO}_{2} / \mathrm{O}_{2}^{-}$, was also included (see chapter 4).

\section{-- Dark reduction of Fe(III) by fulvic acid}

Kinetic parameters for this process were determined in chapter 4 . The kinetics of $\mathrm{Fe}$ (III) reduction could be described by an initial fast reduction followed by slower processes. The rates of the slower processes were found to be independent of iron-to-ligand ratio over a wide range of iron concentrations. However, at $\mathrm{pH} \mathrm{3}$, the proportion of $\mathrm{Fe}(\mathrm{III})$ reduced by an initial, fast reaction (represented by the parameter 
$\mathrm{k}_{16} /\left(\mathrm{k}_{15}+\mathrm{k}_{16}\right)$ in chapter 4$)$ is somewhat dependent on the concentration of $\mathrm{Fe}$ (II) present in the system. At $\mathrm{pH} \mathrm{5,} \mathrm{the} \mathrm{variation} \mathrm{observed} \mathrm{in} \mathrm{the}$ value of this parameter at different iron-to-ligand ratios was insignificant. In the model shown here, we did not attempt to account for a change in $\mathrm{k}_{16} /\left(\mathrm{k}_{15}+\mathrm{k}_{16}\right)$ with increasing $\mathrm{Fe}(\mathrm{II})$ concentrations and estimated the reduction kinetics using the value of $\mathrm{k}_{16} /\left(\mathrm{k}_{15}+\mathrm{k}_{16}\right)$ valid for a total iron concentration of $5 \mu \mathrm{M}$ at $\mathrm{pH} 3$. A median value of $\mathrm{k}_{16} /\left(\mathrm{k}_{15}+\mathrm{k}_{16}\right)$ was used at $\mathrm{pH} 5$.

--Photochemical formation of $\mathrm{HO}_{2} / \mathrm{O}_{2}{ }^{-}$

We assumed that $\mathrm{HO}_{2} / \mathrm{O}_{2}^{-}$was formed photochemically at the same rate throughout the experiment and that all of the $\mathrm{HO}_{2} / \mathrm{O}_{2}^{-}$formed reacted with $\mathrm{Fe}$ (II) to form $\mathrm{Fe}$ (III) and hydrogen peroxide, as shown in equation (14). The observed leveling off of hydrogen peroxide concentration with time was presumed to be only a result of the destruction of hydrogen peroxide by accumulating concentrations of $\mathrm{Fe}(\mathrm{II})$. The photochemical formation rate of $\mathrm{HO}_{2} / \mathrm{O}_{2}^{-}$by SRFA measured in the absence of added iron is not directly comparable to the rate in these experiments, because the light conditions are different in the lepidocrocite suspension, and because $\mathrm{Fe}$ (II) changes the stochiometry of hydrogen peroxide formation (see above). The rate of $\mathrm{HO}_{2} / \mathrm{O}_{2}^{-}$formation was therefore an independent fitting parameter at both $\mathrm{pH}$ values.

--Photochemical reduction of dissolved Fe(III) complexes

In chapter 4 , we found that it was necessary to assume the presence of two types of $\mathrm{Fe}$ (III) complexes with different dissociation rates in order to explain the decrease in $\mathrm{Fe}$ (III) reduction rate observed over time. For simplicity, the Fe(III) in both of these types of complexes was assumed here to be reduced by light at the same rate. The apparent (lightdependent) first-order rate constant of this reaction was the second independent fitting parameter used to fit the data in Figures 5.8 and 5.9. 
The values of the two fitting parameters (the rate of photochemical $\mathrm{HO}_{2} / \mathrm{O}_{2}^{-}$production and the rate of photochemical reduction of $\mathrm{Fe}(\mathrm{III})$ organo complexes) were determined separately for the two $\mathrm{pH}$ values using the kinetic fitting routine described in the methods chapter.

\subsubsection{Model results}

The model accurately accounts for the behavior of Fe(II) and hydrogen peroxide at both pH values (solid lines in Figures 5.8 and 5.9).

Table 5.1 lists the values of the fitting parameters and the calculated amount of $\mathrm{Fe}$ reduced and oxidized after 300 minutes of irradiation by the various processes listed above. This calculation demonstrates that $\mathrm{Fe}(\mathrm{II})$ and $\mathrm{Fe}$ (III) are cycled back and forth rapidly and that the redox cycling of $\mathrm{Fe}$ is not dominated by only one or two reactions. Both the light and dark reduction by fulvic acid play significant roles, and both hydrogen peroxide and $\mathrm{HO}_{2} / \mathrm{O}_{2}^{-}$are important oxidants.

The apparent rate constant for Fe(III) photo-reduction in the presence of fulvic acid was found to be $2.8 \times 10^{-4} \mathrm{~s}^{-1}$ at $\mathrm{pH} 3$ and $3.5 \times 10^{-4} \mathrm{~s}^{-1}$ at $\mathrm{pH} 5$. Because of some uncertainty in dark Fe(III) reduction rates (especially at pH 3) and the actual efficiency of reaction (14) (here assumed to be the only source of hydrogen peroxide in our system), these numbers can only be considered an estimate. The fact that roughly the same rate was found at $\mathrm{pH} 3$ as at $\mathrm{pH} 5$ gives us added confidence in this model's validity, since the rate of photochemical iron reduction by ligand-to-metal charge transfer should be $\mathrm{pH}$-independent as long as the same Fe complex is present at both pH values (Zuo and Hoigné, 1992; Waite and Morel, $1984 b$, etc.).

A slightly higher reduction rate constant $\left(6 \times 10^{-4} \mathrm{~s}^{-1}\right)$ was used in the model of Fe redox reactions in the absence of an iron oxide phase (Figure 5.7) at $\mathrm{pH}$ 3. This is reasonable, since in the lepidocrocite suspension less 
light is available for absorption by the dissolved Fe(III)-SRFA complex (see section 3.4 in chapter 3). The half-life of the Fe(III)-SRFA complex (approximately 10 minutes at midlatitude solar noon) in the lepidocrocitefree system is comparable to those estimated by Faust and Zepp(1993) for $\mathrm{Fe}(\mathrm{III})$ complexes with malonate and citrate, 5 minutes and 0.9 minutes in sunlit surface waters at midday, respectively. For comparison, the half-life of $\mathrm{Fe}$ (III)-aquo complexes under these light conditions is approximately 9 minutes at pH 3 but 460 minutes at pH 5 (King et al., 1993).

The rate of $\mathrm{HO}_{2} / \mathrm{O}_{2}^{-}$production $\left(1.40 \times 10^{-10} \mathrm{M} \mathrm{s}^{-1}\right.$ at $\mathrm{pH} 3$ and $1.41 \times 10^{-10} \mathrm{M} \mathrm{s}^{-1}$ at $\mathrm{pH} \mathrm{5)}$ in the lepidocrocite suspensions is comparable to that calculated from the rate of formation of hydrogen peroxide in the absence of added iron $\left(1.34 \times 10^{-10} \mathrm{M} \mathrm{s}^{-1}\right.$ at $\mathrm{pH} 3$ and $1.39 \times 10^{-10} \mathrm{M} \mathrm{s}^{-1}$ at $\mathrm{pH} 5$, from linear least squares fits of the data in Figure 5.6). We assume that 2 moles of $\mathrm{HO}_{2} / \mathrm{O}_{2}^{-}$are needed for each mole of hydrogen peroxide formed in the absence of added iron. However, a direct comparison of these rates is not possible because of the different light conditions in the two systems and because small $(<0.1 \mu \mathrm{M})$ concentrations of $\mathrm{Fe}(\mathrm{II})$ in the experiments containing no added iron may still be enough to disrupt the assumed 2:1 stochimetry. In any case, comparison of these rates indicates that it is unlikely that significant amounts of additional $\mathrm{HO}_{2} / \mathrm{O}_{2}^{-}$result from reduction of oxygen by the primary photoproducts of ligand-tometal charge transfer reactions, either on the iron oxide surface or in solution. If $\mathrm{HO}_{2} / \mathrm{O}_{2}^{-}$is formed at the surface of the iron oxide, it may undergo further reactions there instead of being released into the solution. The organic radical intermediates formed in reaction (2) may also react with $\mathrm{Fe}$ (III) or with each other instead of reducing oxygen.

Sinks of hydrogen peroxide other than its reaction with dissolved $\mathrm{Fe}(\mathrm{II})$, such as reactions on the photo-excited lepidocrocite surface (Pehkonen et al., 1993), or reoxidation of surface $\mathrm{Fe}(\mathrm{II})$ by hydrogen peroxide 
(Sulzberger and Laubscher, submitted), also do not appear to be a significant factor in this experimental system.

\subsection{Conclusions of chapters 4 and 5}

Figure 5.10 depicts a summary of all the Fe(III) reduction and $\mathrm{Fe}(\mathrm{II})$ oxidation processes occurring in irradiated systems containing fulvic acid and iron oxides. It is apparent that the question of the net effect of light and fulvic acid on iron redox states is a complicated one to answer. Fulvic acid reduces $\mathrm{Fe}(\mathrm{III})$, but also accelerates the oxidation rate of $\mathrm{Fe}(\mathrm{II})$. Under the influence of light, more Fe(III) is reduced while at the same time $\mathrm{Fe}$ (II) oxidants are produced. In natural waters, then, both light-dependent acceleration of Fe(III) reduction (Collienne, 1983; McKnight et al., 1988; Sulzberger et al., 1990) and Fe(II) oxidation (Barry et al., 1994) may be observed.

While the net effect of these processes on steady-state iron redox states is not clear, the net effect on the organic matter is unambiguous: both iron and light have an accelerating effect on the oxidation of fulvic acid by oxygen. Fulvic acid is oxidized in the presence of light by an unknown photo-oxidative process which reduces oxygen to $\mathrm{HO}_{2} / \mathrm{O}_{2}{ }^{-}$. In the presence of iron, $\mathrm{Fe}$ (III)-fulvate complexes in solution or on the surface of an iron oxide can act as chromophores for additional photo-oxidation of fulvic acid. What happens after the initial electron transfer step of this process (reaction 2) is unclear, although our results suggest that stochiometric amounts of oxygen are not reduced to $\mathrm{HO}_{2} / \mathrm{O}_{2}^{-}$by the resulting organic intermediate radical.

Dark reactions of $\mathrm{Fe}(\mathrm{II})$ and $\mathrm{Fe}(\mathrm{III})$ also play a role in fulvic acid oxidation. Fe(III) acts as an electron acceptor in a dark reaction with fulvic acid. The reaction of $\mathrm{Fe}(\mathrm{II})$ with hydrogen peroxide yields $\mathrm{OH}$ radicals, which oxidize organic material. The intermediate organic 
Table 5.1. Model fitting parameters and results of calculations. Results are shown as $\mu M$ of $F e$ reduced or oxidized by various processes after 300 minutes of irradiation of a lepidocrocite suspension containing 10 $m g / l$ SRFA.

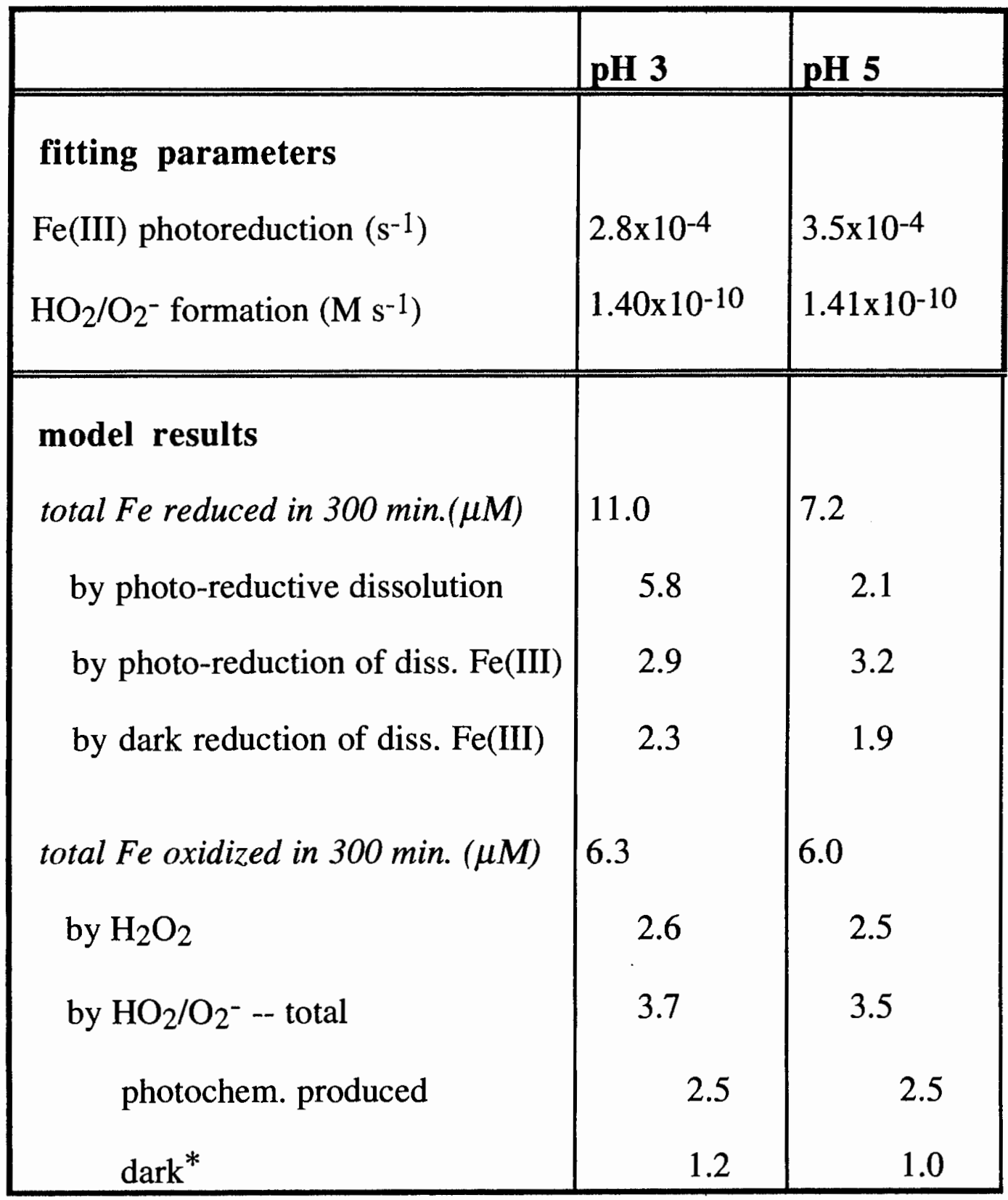

* Refers to $\mathrm{HO}_{2} / \mathrm{O}_{2}$ - formed as a result of oxidation of fulvic acid by $\mathrm{OH} \cdot$ (see chapter 4$)$. 
Figure 5.10. Summary of iron redox and surface reactions in aerated solutions containing $\gamma-\mathrm{FeOOH}$ and SRFA. The numbers in italics indicate the amount of iron (in $\mu M$ ) oxidized or reduced by each of the depicted processes after 300 minutes of illumination in the experiments shown in Figures 5.2 and 5.3 (results of model calculations). Numbers on the first line (in boldface) represent the experiment at $\mathrm{pH} 3$, numbers on the second line (not boldface) the experiment at $\mathrm{pH}$ 5. The rate of photo-reduction of surface Fe(III) was assumed to be equal to the rate of photo-reductive dissolution in de-aerated solutions (in which no re-oxidation of $F e(I I)$ at the surface should have occurred). The amount of surface $F e(I I)$ that re-oxidized instead of detaching was calculated as the difference in the amount of dissolved Fe formed in the de-aerated and aerated solutions. 


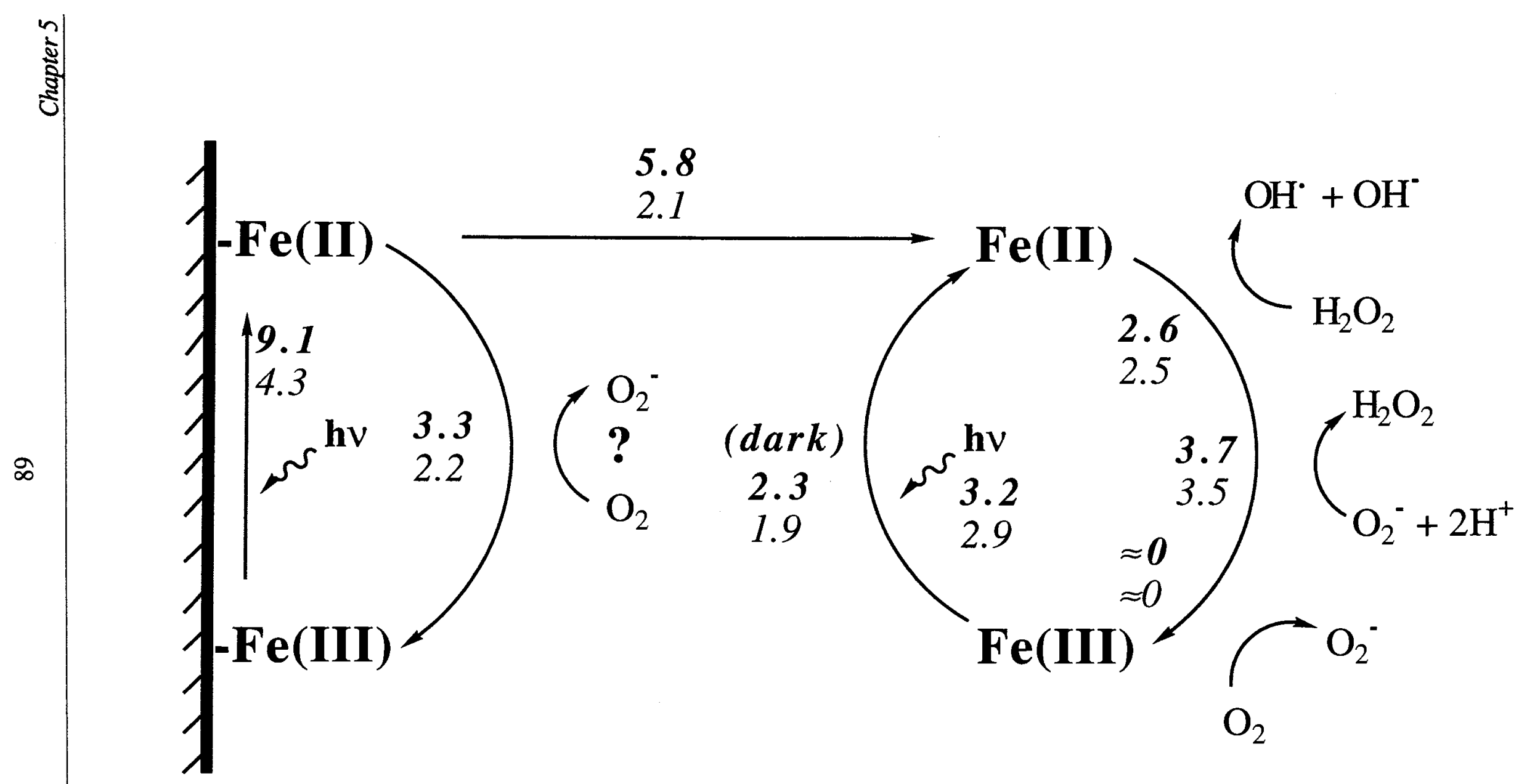


radical products resulting from the reaction of $\mathrm{OH}$. with fulvic acid reduce oxygen to $\mathrm{HO}_{2} / \mathrm{O}_{2}^{-}$. The oxygen consumption in the Fe-catalyzed oxidation of dissolved organic matter observed by Miles and Brezonik (1981) can therefore be the result of reactions other than the direct reaction of $\mathrm{Fe}(\mathrm{II})$ with $\mathrm{O}_{2}$. An interesting question which remains to be answered is whether oxidation of humic substances in the presence of iron leads to different products than oxidation in the absence of iron. Sunda and Kieber (1994) observed the formation of low molecular weight organic compounds, such as pyruvate, acetone, acetaldehyde, and formaldehyde, during the dark oxidation of humic substances by manganese oxides. Mopper et al. (1991) showed that pyruvate, acetaldehyde, and formaldehyde, as well as other low molecular weight organic compounds and $\mathrm{CO}$, are products of the photo-oxidation of marine humic substances. Miles and Brezonik (1981) measured the production of significant amounts of $\mathrm{CO}_{2}$ when lake water containing iron and humic substances was irradiated. These studies suggest that the oxidation of humic substances, no matter by what route, results in their degradation to smaller compounds. However, if the organic radicals formed by ligand-to-metal charge transfer reactions do not reduce either $\mathrm{Fe}$ (III) or oxygen, as our study suggests, they may react with each other, leading to further polymerization of the dissolved organic matter. 


\section{Chapter 6: Iron redox cycling by Superoxide in Seawater}

\subsection{Introduction}

We have seen in chapters 4 and 5 that dissolved organic matter affects iron photo-redox cycling in a number of ways. Photo-induced ligand-tometal charge transfer reactions of Fe(III)-organic complexes in solution or on the surface of iron oxides are important sources of Fe(II). Major sinks of $\mathrm{Fe}(\mathrm{II})$ are oxidation by $\mathrm{H}_{2} \mathrm{O}_{2}$ and $\mathrm{HO}_{2} / \mathrm{O}_{2}{ }^{-}$, both products of the reaction of photo-excited fulvic acid with oxygen. Our model system of Suwannee River Fulvic Acid and lepidocrocite is probably a good representation of an acidic lake or river containing iron oxide particles and dissolved organic matter of terrestrial origin. Dissolved organic matter is also a ubiquitous constituent of open ocean seawater. Although marine humic substances have somewhat different structures than organic matter of terrestrial origin, their metal-binding properties and photochemistry are usually believed to be similar (Morel and Hering, 1993). Should we therefore expect that our model system is also an accurate representation of iron redox cycling in seawater? This is unlikely, because there are some important differences between our model system and seawater.

Photoreductive dissolution of particulate $\mathrm{Fe}(\mathrm{III})$ is probably not a significant source of dissolved Fe(II) in seawater for two reasons. First, adsorption of humic substances to iron oxide surfaces decreases substantially with increasing $\mathrm{pH}$ (Tipping, 1981). A smaller concentration of surface-bound ligand means that the rate of production of surface $\mathrm{Fe}(\mathrm{II})$ by ligand-to-metal charge transfer reactions will be slower than at acidic $\mathrm{pH}$ values. Furthermore, surface Fe(II) probably detaches more slowly at high $\mathrm{pH}$ (Sulzberger and Laubscher, submitted), 
and may oxidize more quickly, so that a high proportion of the iron reduced at the surface will be re-oxidized there instead of dissolving.

For ligand-to-metal charge transfer reactions of dissolved Fe(III)-organic complexes to take place, these complexes must first form. It is not known whether humic substances are able to form complexes with $\mathrm{Fe}(\mathrm{III})$ at seawater $\mathrm{pH}$, and at the low concentrations of both Fe(III) and DOC found in seawater. Figure 2.3 suggests that this is unlikely unless stronger Fe(III)-binding sites than carboxylate functional groups are present on these molecules. It is possible that other, more specific, ligands than humic substances form complexes with $\mathrm{Fe}$ (III) in seawater. Whether these could undergo similar photochemical reactions is unknown.

Because of the expected slow rate of Fe(II) formation and the fast rate of $\mathrm{Fe}$ (II) oxidation in seawater, one would expect the steady-state concentration of $\mathrm{Fe}(\mathrm{II})$ in sunlit seawater to be very small. However, evidence has been presented that a considerable portion of the dissolved iron in seawater can be present as Fe(II) (Hong and Kester, 1986; O'Sullivan et al., 1991; Johnson et al., 1994). It is generally assumed that this $\mathrm{Fe}(\mathrm{II})$ is formed by biological processes or ligand-to-metal charge transfer reactions of unknown Fe(III)-organic complexes. However, an alternative explanation is also possible. While $\mathrm{HO}_{2} / \mathrm{O}_{2}{ }^{-}$is an oxidant of $\mathrm{Fe}$ (II) in the acidic systems studied in the previous chapters, in the absence of complexation and at seawater $\mathrm{pH}$, it could be an important reductant of $\mathrm{Fe}(\mathrm{III})$. In this chapter, we examine the role of $\mathrm{HO}_{2} / \mathrm{O}_{2}^{-}$in the redox cycling of iron in seawater.

\subsection{Background}

Like the fulvic acid examined in previous chapters, the organic chromophores present in seawater can reduce oxygen to $\mathrm{HO}_{2} / \mathrm{O}_{2}$ - in the 
presence of sunlight (Cooper et al., 1989). The bimolecular dismutation of superoxide has been postulated as the main source of hydrogen peroxide in the open ocean (Petasne and Zika, 1987):

$\mathrm{HO}_{2}+\mathrm{O}_{2}^{-} \rightarrow \mathrm{H}_{2} \mathrm{O}_{2}+\mathrm{O}_{2}+\mathrm{OH}^{-}$

However, reaction (1) is slow in seawater (effective $\mathrm{k}_{\text {dismut }}=3 \times 10^{4}$ $\mathrm{M}^{-1} \mathrm{~s}^{-1}$; Zafiriou, 1990) because the ratio of $\mathrm{HO}_{2}$ to $\mathrm{O}_{2}^{-}$is very low at $\mathrm{pH} 8$ (for this reason $\mathrm{HO}_{2} / \mathrm{O}_{2}^{-}$in seawater is simply referred to as "superoxide" or $\mathrm{O}_{2}^{-}$in this chapter). Under seawater conditions, reactions with trace concentrations of transition metals $(\mathrm{Me})$, such as iron, could be the dominant mechanism of superoxide dismutation:

$$
\begin{aligned}
& \mathrm{O}_{2}^{-}+\mathrm{Me}^{\mathrm{n}+1} \rightarrow \mathrm{O}_{2}+\mathrm{Me}^{\mathrm{n}+} \\
& \mathrm{O}_{2}^{-}+\mathrm{Me}^{\mathrm{n}+} \rightarrow \mathrm{H}_{2} \mathrm{O}_{2}+\mathrm{Me}^{\mathrm{n}+1}+2 \mathrm{OH}^{-}
\end{aligned}
$$

A simple calculation (Table 6.1) illustrates that the above reactions are as fast as or faster than all other known abiotic iron redox reactions in sunlit open-ocean water. Because the reduction of dissolved iron by superoxide is faster than its oxidation, this process could lead to significant concentrations of $\mathrm{Fe}(\mathrm{II})$. (Corresponding reactions of $\mathrm{Fe}(\mathrm{II})$ and $\mathrm{Fe}(\mathrm{III})$ with hydroperoxyl radical $\left(\mathrm{HO}_{2}\right)$ (reactions $2 \mathrm{~b}$ and $3 \mathrm{~b}$, not shown) are also possible, but insignificant at seawater $\mathrm{pH}$.)

Two questions must be answered to verify the effect of superoxide on the fraction of reduced iron $(\% \mathrm{Fe}[\mathrm{II}])$ in seawater: (1) Are the published rate constants (Rush and Bielski, 1985) for reactions 2 and 3, which were determined at lower ionic strengths and in the absence of chloride, valid for seawater? (2) Are steady-state superoxide concentrations $\left(\left[\mathrm{O}_{2}^{-}\right]_{\mathrm{ss}}\right)$ 
a Second-order rate constants determined at temperatures between 293-298 K (evaluated under seawater conditions for $\mathrm{O}_{2}, \mathrm{H}_{2} \mathrm{O}_{2}$ and $h \mathrm{v}$ ).

$b$ For species $X, t] / 2=\ln 2 /\left(k_{X} *[X]\right)$

$c$ Millero et al. (1987)

$d$ Moffett and Zika (1987b), Millero and Sotolongo (1989)

e Mopper and Zhou (1990)

$f$ Christensen and Sehested (1981)

$g$ Morel and Hering (1993)

$h$ Thornton and Laurence (1973)

$i$ See Table 6.2 and text for details of the assumptions used in the estimation of $\left[\mathrm{O}_{2}^{-}\right]_{s s}$.

$j$ Estimated $\left[\mathrm{O}_{2}^{-}\right]_{s s}$ in the presence of $0.1 \mathrm{nM}$ dissolved $\mathrm{Fe}$.

${ }^{k}$ Estimated $\left[\mathrm{O}_{2}{ }^{-}\right]_{s s}$ in the presence of $0.1 \mathrm{nM}$ dissolved $\mathrm{Fe}$ and $0.5 \mathrm{nM}$ dissolved $\mathrm{Cu}$.

$l$ Rush and Bielski (1985)

$m$ Rate constants for photoreduction of dissolved and colloidal Fe(III) were calculated as follows:

Dissolved $\mathrm{Fe}(I I I)$ : From the $\mathrm{pH}$-dependence of the reduction rate of $\mathrm{Fe}(\mathrm{III})$ in chloride solutions,

King et al. (1993) concluded that $\mathrm{FeOH}^{2+}$ is the dominant photoreactive inorganic $\mathrm{Fe}(\mathrm{III})$ complex in seawater. At $\mathrm{pH} 8, \alpha_{\mathrm{FeOH}}{ }^{2+} \approx 10^{-5}$ and therefore the first-order rate constant for photoreduction of dissolved $\mathrm{Fe}(\mathrm{III})$ is approximately equal to:

$k=10^{-5} \times 0.15 \mathrm{~min}^{-1}=2 \times 10^{-6} \mathrm{~min}^{-1}$.

Colloidal Fe(III): Wells and Mayer (1991) observed an increase in the oxine extractability of colloidal iron oxyhydroxides in a sample of open-ocean water upon exposure to sunlight, which they attributed to photoreductive dissolution followed by reoxidation and precipitation. From their data (Figure 5 in above reference) we estimate the first-order rate constant of photoreduction of colloidal $F e(I I I)$ to be:

$k=\frac{\left(1.3 \mathrm{nM} \mathrm{min}^{-1} \mathrm{Fe}(\mathrm{II})\right)}{(5,000 \mathrm{nM} \text { total } \mathrm{Fe})}=3 \times 10^{-4} \mathrm{~min}^{-1}$. 
Table 6.1: Estimated half-lives of $F e(I I)$ and $F e(I I I)$ in sunlit surface seawater with respect to different redox reactions.

\begin{tabular}{|c|c|c|c|}
\hline Reactant & $\operatorname{conc}(\mathrm{M})$ & $k\left(M^{-1} \mathbf{s}^{-1}\right)^{\mathbf{a}}$ & $t_{1 / 2(\min )^{b}}$ \\
\hline \multicolumn{4}{|c|}{$\mathrm{Fe}(I I)$ oxidation: } \\
\hline $\mathrm{O}_{2}$ & $2 \times 10^{-4} c$ & $10 c$ & 5 \\
\hline $\mathrm{H}_{2} \mathrm{O}_{2}$ & $5 \times 10^{-8} d$ & $5 \times 10^{4} d$ & 5 \\
\hline $\mathrm{OH}^{\bullet}$ & $1 \times 10^{-17} e$ & $3 \times 10^{8} f$ & $>10^{6}$ \\
\hline \multirow{3}{*}{$\begin{array}{l}\mathrm{Br}_{2}^{-} \\
\mathrm{O}_{2}^{-i}\end{array}$} & $1 \times 10^{-14} g$ & $4 \times 10^{6} h$ & $>10^{5}$ \\
\hline & $1 \times 10^{-9} j$ & & 1 \\
\hline & $8 \times 10^{-11} k$ & $1 \times 10^{7} l$ & 14 \\
\hline \multicolumn{4}{|c|}{ Fe(III) reduction } \\
\hline \multirow{3}{*}{$\begin{array}{l}\text { hv } m \\
\mathrm{O}_{2}^{-i}\end{array}$} & NA & NA & $>10^{4}$ \\
\hline & $1 \times 10^{-9} j$ & & 0.06 \\
\hline & $8 \times 10^{-11} k$ & $1.5 \times 10^{8} l$ & 1 \\
\hline
\end{tabular}


really high enough in sunlit open-ocean surface waters to significantly affect Fe chemistry?

\subsection{Results}

To examine the effect of chloride on the rates of $\mathrm{Fe}$ reactions with $\mathrm{HO}_{2} / \mathrm{O}_{2}{ }^{-}$, we performed a series of experiments using the $\gamma$-irradiation of water as a well-defined (non-photochemical) source of $\mathrm{HO}_{2} / \mathrm{O}_{2}^{-}$radicals. In the presence of the high $\mathrm{HO}_{2} / \mathrm{O}_{2}^{-}$fluxes generated in the $\gamma$-irradiation system, the fraction of reduced iron (\% Fe(II)) at steady state is a function of the relative rates of the reactions of $\mathrm{Fe}$ (II) and $\mathrm{Fe}$ (III) with $\mathrm{O}_{2}{ }^{-}$and $\mathrm{HO}_{2}$ and is therefore strongly dependent on the $\mathrm{pH}$ (Figure 6.1). At low $\mathrm{pH}$ values, most of the iron is present as $\mathrm{Fe}$ (III) because the reaction of $\mathrm{HO}_{2}$ with $\mathrm{Fe}(\mathrm{II})$ is much faster than the reaction of $\mathrm{HO}_{2}$ with $\mathrm{Fe}$ (III). At higher $\mathrm{pH}$, the $\% \mathrm{Fe}(\mathrm{II})$ increases because $\mathrm{O}_{2}^{-}$reacts more quickly with $\mathrm{Fe}(\mathrm{III})$ than with $\mathrm{Fe}$ (II).

The expected \% Fe(II) can be calculated using the published rate constants for these reactions (Rush and Bielski, 1985; Sedlak and Hoigné, 1993):

$\% \mathrm{Fe}(\mathrm{II})=100 \frac{\mathrm{Fe}(\mathrm{II})}{\mathrm{Fe}_{\mathrm{tot}}}=100 \frac{\frac{\mathrm{k}_{2 \mathrm{~b}}\left[\mathrm{H}^{+}\right]}{10^{-4.8}}+\mathrm{k}_{2 \mathrm{a}}}{\left(\mathrm{k}_{2 \mathrm{~b}}+\mathrm{k}_{3 \mathrm{~b}}\right) \frac{\left[\mathrm{H}^{+}\right]}{10^{-4.8}}+\left(\mathrm{k}_{2 \mathrm{a}}+\mathrm{k}_{3 \mathrm{a}}\right)}$

At $\mathrm{pH}$ values greater than 5 , the reactions with $\mathrm{HO}_{2}$ become insignificant and the $\% \mathrm{Fe}(\mathrm{II})$ reaches a maximum value given by:

$\% \mathrm{Fe}(\mathrm{II})=100 \frac{\mathrm{k}_{2 \mathrm{a}}}{\mathrm{k}_{2 \mathrm{a}}+\mathrm{k}_{3 \mathrm{a}}}$

As depicted in Figure 6.1, our data in the absence of chloride agree well with predictions made using equation (4). In the presence of $0.7 \mathrm{M}$ chloride (Figure 6.2), slightly different results were obtained due to a 
combination of ionic strength effects and changes in reactivity of iron through complexation by chloride. The observation that the percentage of $\mathrm{Fe}$ (II) reached a maximum value of approximately $75 \%$ can be used to estimate the effective rate constants of reactions $2 \mathrm{a}$ and $3 \mathrm{a}$ under these conditions $\left(\mathrm{k}_{2 \mathrm{a}}{ }^{\prime}\right.$ and $\left.\mathrm{k}_{3 \mathrm{a}}{ }^{\prime}\right)$. Assuming that $\mathrm{k}_{3 \mathrm{a}}{ }^{\prime}$ equals $\mathrm{k}_{3 \mathrm{a}}\left(1.5 \times 10^{8}\right.$ $\mathrm{M}^{-1} \mathrm{~s}^{-1}$ ), we calculate an upper limit of $\mathrm{k}_{2 \mathrm{a}}$ of $3 \times 10^{7} \mathrm{M}^{-1} \mathrm{~s}^{-1}$. Assuming instead that $\mathrm{k}_{2 \mathrm{a}}{ }^{\prime}$ is equal to $\mathrm{k}_{2 \mathrm{a}}\left(1 \times 10^{7} \mathrm{M}^{-1} \mathrm{~s}^{-1}\right)$, we calculate a lower limit of $\mathrm{k}_{3 \mathrm{a}}$ of $5 \times 10^{7} \mathrm{M}^{-1} \mathrm{~s}^{-1}$.

The decrease in the \% Fe(II) observed in both experiments (Figures 6.1 and 6.2) at $\mathrm{pH}$ values greater than 6 occurred because at the iron concentrations used in our experiments, oversaturation of the solutions with respect to amorphous $\mathrm{Fe}(\mathrm{OH})_{3}$ resulted in the formation of colloidal $\mathrm{Fe}$, which apparently does not react with $\mathrm{O}_{2}{ }^{-}$at significant rates. The dashed line was calculated for a total iron concentration of $300 \mathrm{nM}$ using equation (4) above, solubility limitations for amorphous iron hydroxide (Westall et al., 1976) and the assumption that reduction of colloidal $\mathrm{Fe}(\mathrm{III})$ by $\mathrm{O}_{2}^{-}$was negligible. In agreement with this hypothesis, the decrease in $\% \mathrm{Fe}(\mathrm{II})$ occurred at higher $\mathrm{pH}$ values when lower total iron concentrations were used ( symbols in Figure 6.2).

In sunlit open-ocean water, $\mathrm{O}_{2}^{-}$concentrations will be much lower than those in the $\gamma$-irradiation system, so that the oxidation of $\mathrm{Fe}$ (II) by hydrogen peroxide and oxygen must also be considered in a calculation of the $\% \mathrm{Fe}(\mathrm{II})$. If reduction by $\mathrm{O}_{2}^{-}$is the only source of reduced iron, the expected $\% \mathrm{Fe}(\mathrm{II})$ is given by:

$$
\% \mathrm{Fe}(\mathrm{II})=\frac{100 \mathrm{k}_{2 \mathrm{a}}\left[\mathrm{O}_{2}^{-}\right]_{\mathrm{ss}}}{\mathrm{k}_{2 \mathrm{a}}\left[\mathrm{O}_{2}^{-}\right]_{\mathrm{ss}}+\mathrm{k}_{3 \mathrm{a}}\left[\mathrm{O}_{2}^{-}\right]_{\mathrm{ss}}+\mathrm{k}_{\mathrm{O}_{2}}\left[\mathrm{O}_{2}\right]+\mathrm{k}_{\mathrm{H} 2 \mathrm{O}_{2}\left[\mathrm{H}_{2} \mathrm{O}_{2}\right]}}
$$

where $\mathrm{k}_{\mathrm{O} 2}$ and $\mathrm{k}_{\mathrm{H} 2 \mathrm{O} 2}$ represent the rate constants for the reactions of $\mathrm{Fe}$ (II) with $\mathrm{O}_{2}$ and $\mathrm{H}_{2} \mathrm{O}_{2}$ respectively. Using the estimates of $\mathrm{k}_{2} \mathrm{a}^{\prime}$ and 


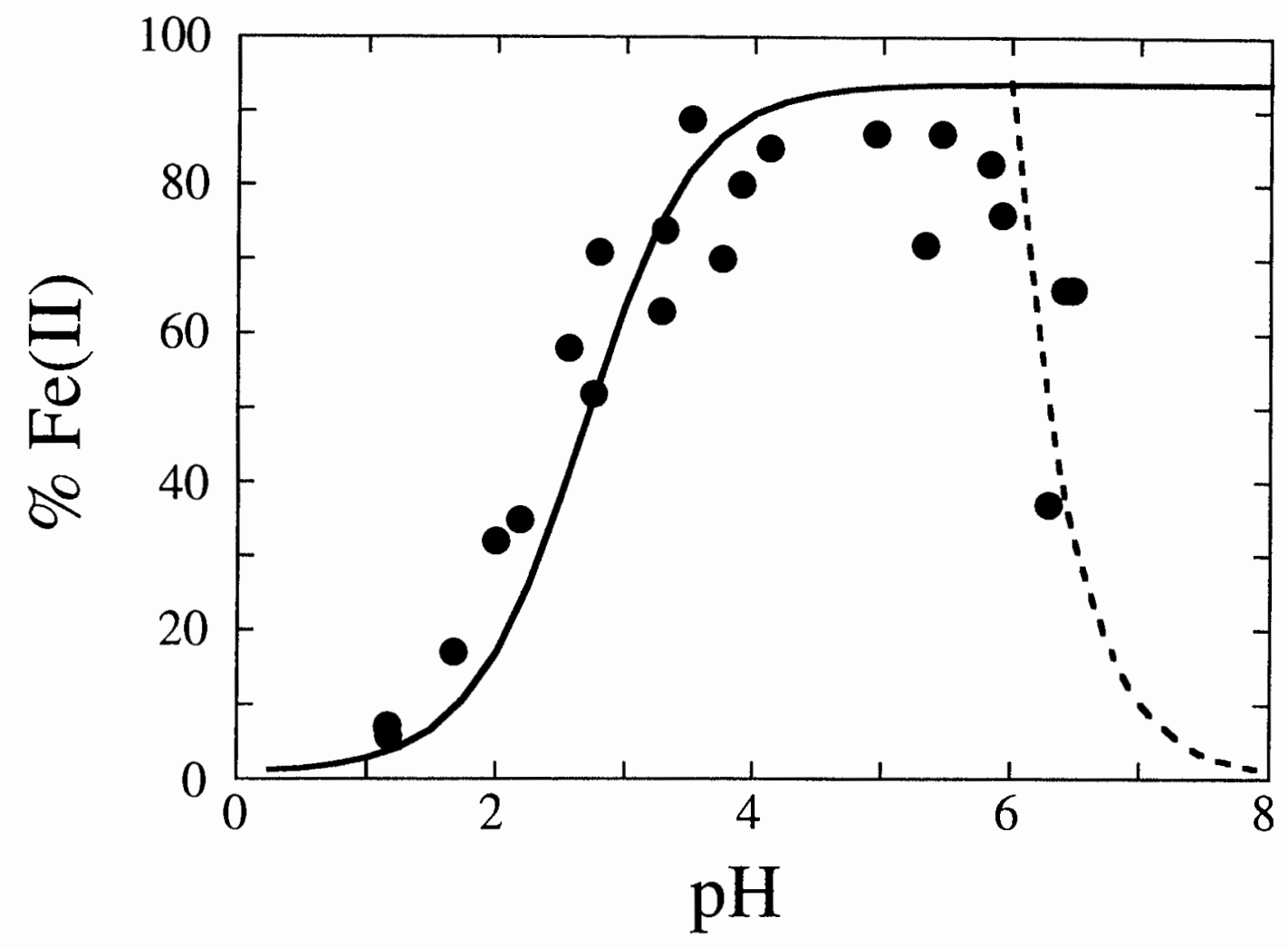

Figure 6.1. \% Fe(II) measured as a function of $\mathrm{pH}$ in the presence of radiolytically-produced superoxide radical after steady-state was achieved. Iron was initially added to the solutions as $\mathrm{Fe}(\mathrm{II})(\bullet=300 \mathrm{nM})$. The solid line was calculated using the published rate constants for reactions $2 a$ and $3 a$ and the corresponding reactions of iron with hydroperoxyl radical (equation 4 in text). The dashed line was calculated for a total iron concentration of $300 \mathrm{nM}$ using the same equation and solubility limitations for amorphous iron hydroxide. 


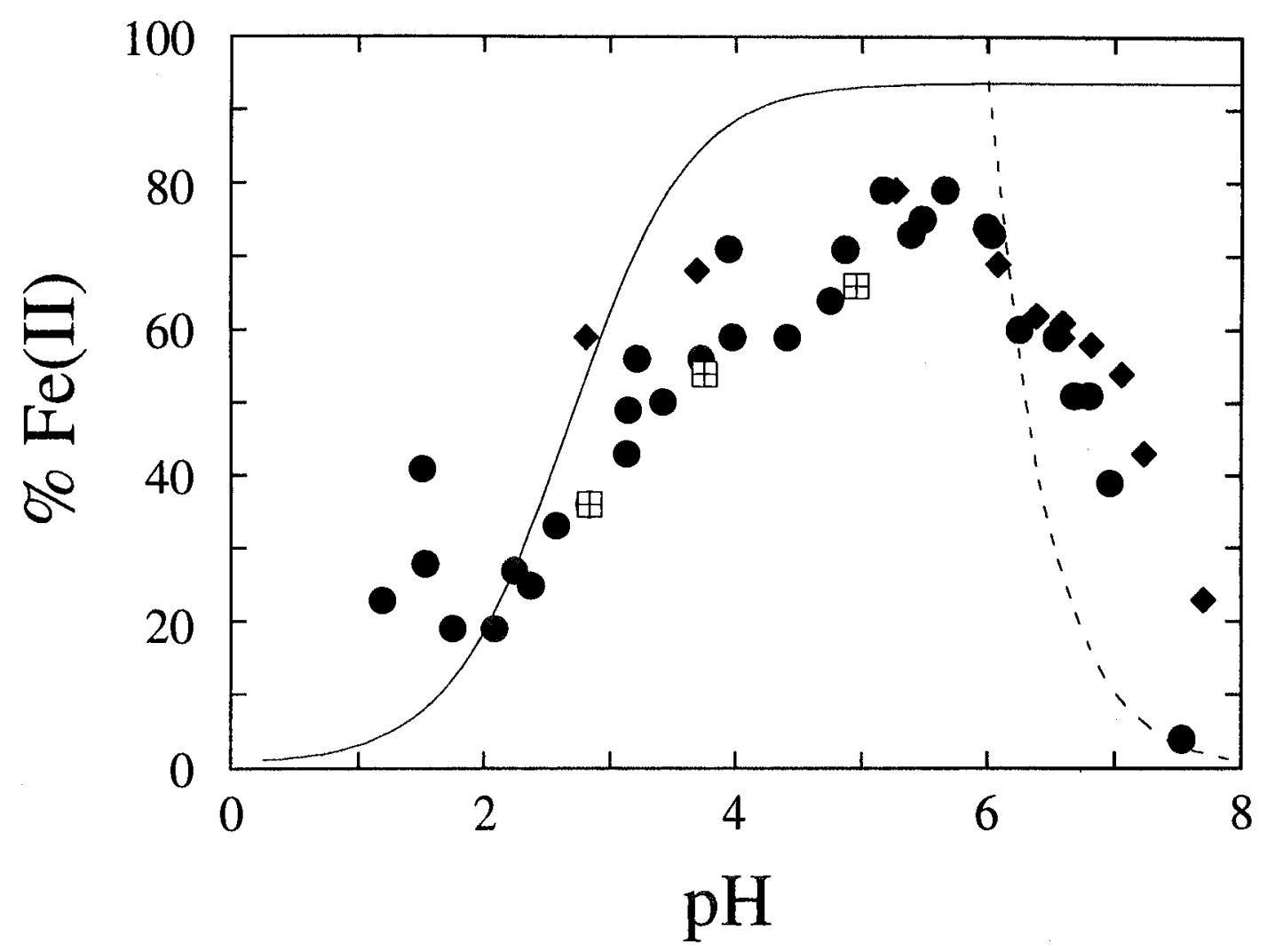

Figure 6.2. \% Fe(II) measured as a function of $\mathrm{pH}$ in the presence of radiolytically-produced superoxide radical after steady-state was achieved. Iron was initially added to the solutions as either $\mathrm{Fe}(\mathrm{II})$ $(\bullet=300 \mathrm{nM} ;=50 \mathrm{nM})$ or $\mathrm{Fe}(\mathrm{III})(\mathrm{⿴囗十}=300 \mathrm{nM})$. Conditions depicted in Figures 6.1 and 6.2 were identical except that in Figure 6.2 the solutions contained $0.7 \mathrm{M}$ chloride. 
$\mathrm{k}_{3} \mathrm{a}^{\prime}$ derived above, we predict that iron reduction by $\mathrm{O}_{2}^{-}$results in significant concentrations of $\mathrm{Fe}(\mathrm{II})$ in sunlit surface seawater $\left(\left[\mathrm{O}_{2}\right]=\right.$ $0.21 \mathrm{mM},\left[\mathrm{H}_{2} \mathrm{O}_{2}\right]=50 \mathrm{nM}$ ) whenever $\left[\mathrm{O}_{2}^{-}\right]_{\mathrm{ss}}$ exceeds $10^{-11} \mathrm{M}$ (Figure $6.3)$.

We can estimate $\left[\mathrm{O}_{2}^{-}\right]_{\mathrm{ss}}$ by dividing its rate of formation by its rate of loss:

$\left[\mathrm{O}_{2}^{-}\right]_{\mathrm{ss}}=\frac{\left(\mathrm{O}_{2}^{-} \text {flux }\right)}{\left(2 \mathrm{k}_{\mathrm{dismut}}\left[\mathrm{O}_{2}^{-}\right]+\Sigma \mathrm{k}_{\mathrm{x}}[\mathrm{Me}]_{\mathrm{x}}\right)}$

where $[\mathrm{Me}]_{\mathrm{X}}$ represents the concentration of each form of each metal that undergoes redox reactions with $\mathrm{O}_{2}^{-}$, and $\mathrm{k}_{\mathrm{x}}$ represents the second-order rate constant for reactions between $\mathrm{O}_{2}^{-}$and that form of Me. Ignoring the effect of trace-metal-catalyzed dismutation leads to an estimated $\left[\mathrm{O}_{2}^{-}\right]_{\mathrm{Ss}}$ of $7 \times 10^{-9} \mathrm{M}$ in oligotrophic surface seawater (Table 6.2). The inclusion of dissolved iron $(0.1 \mathrm{nM})$ in the calculation lowers our estimate of $\left[\mathrm{O}_{2}^{-}\right]_{\mathrm{Ss}}$ to $0.4-2 \times 10^{-9} \mathrm{M}$.

To determine the effect of copper reactions on $\left[\mathrm{O}_{2}^{-}\right]_{\mathrm{ss}}$, we used continuous radiolysis and an experimental design similar to that described for the iron experiments to evaluate the redox cycling of $\mathrm{Cu}(\mathrm{II} / \mathrm{I})$ in the presence of several representative copper ligands. In the presence of $0.7 \mathrm{M}$ chloride, the maximum $\% \mathrm{Cu}(\mathrm{I})$ measured at steady state reached a value of $37 \pm 3 \%$, which agreed well with predictions made by using published rate constants (Piechowski et al., 1993) for the reactions of $\mathrm{Cu}(\mathrm{I})$ and $\mathrm{Cu}(\mathrm{II})$ with $\mathrm{HO}_{2}$ and $\mathrm{O}_{2}^{-}$. Thus, we conclude that the reactivity of $\mathrm{Cu}(\mathrm{I})$-chloride complexes and $\mathrm{Cu}(\mathrm{II})-\mathrm{CO}_{3}$ complexes was not significantly different from that of the aquo complexes of $\mathrm{Cu}(\mathrm{I})$ and $\mathrm{Cu}(\mathrm{II})$. When organic compounds capable of forming complexes with $\mathrm{Cu}$ (II) were added to the solutions, the $\% \mathrm{Cu}(\mathrm{I})$ decreased (Table 6.3) to 


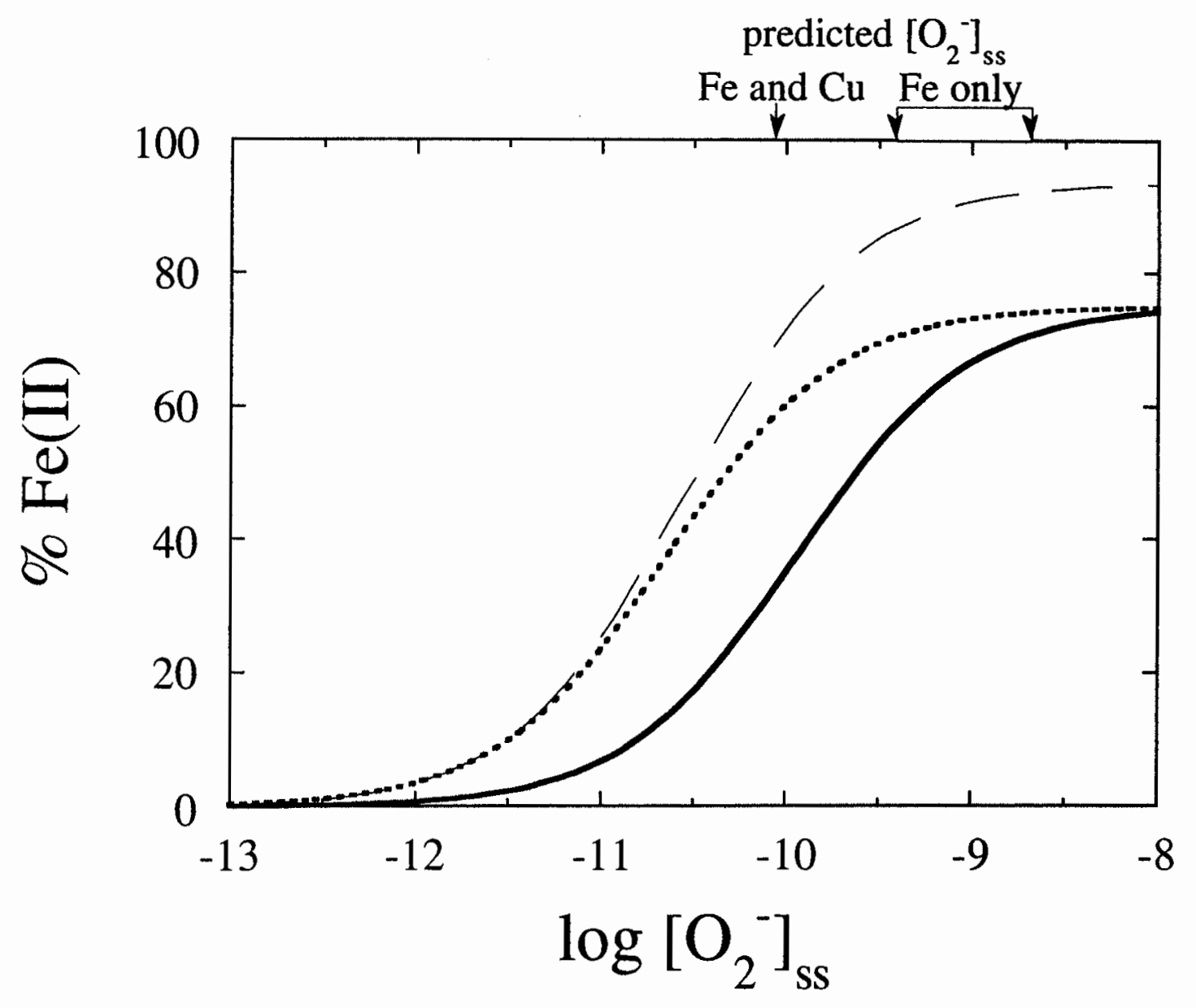

Figure 6.3. Estimated $\% \mathrm{Fe}(\mathrm{II})$ as a function of $\left[\mathrm{O}_{2}^{-}\right]_{s s}$ in the presence of $0.21 \mathrm{mM} \mathrm{O}_{2}$ and $50 \mathrm{nM} \mathrm{H}_{2} \mathrm{O}_{2}$. The dashed line was calculated for these conditions using the rate constants listed in Table 6.1 and equation (6) in the text. The other lines represent the results of calculations using the same rate constants for oxidation of $\mathrm{Fe}(\mathrm{II})$ by oxygen and hydrogen peroxide as above, and estimates of rate constants for reactions of iron with superoxide in $0.7 \mathrm{M} \mathrm{NaCl}$ as described in the text (solid line: $k_{2 a^{\prime}}=1 \times 10^{7} \mathrm{M}^{-1} \mathrm{~s}^{-1}, k_{3 a^{\prime}}=3 \times 10^{7} \mathrm{M}^{-1} \mathrm{~s}^{-1}$; dotted line: $k_{2 a^{\prime}}=5 \times 10^{7}$ $M^{-1} s^{-1}, k_{3 a^{\prime}}=1.5 \times 10^{8} \mathrm{M}^{-1} \mathrm{~s}^{-1}$ ). 
Table 6.2. Estimated $\left[\mathrm{O}_{2}^{-}\right]_{s s}$ in sunlit surface seawater in the presence of different superoxide sinks.

\begin{tabular}{|c|c|c|c|}
\hline Superoxide sinks & Reactant & $\mathbf{k}\left(\mathbf{M}^{-1} \mathbf{s}^{-1}\right)$ & {$\left[\mathbf{O}_{2}^{-}\right]_{\text {ss }}(\mathbf{M})^{\mathbf{a}}$} \\
\hline $\mathrm{O}_{2}-/ \mathrm{HO}_{2}$ & $\mathrm{O}_{2}^{-} / \mathrm{HO}_{2}$ & $3 \times 10^{4}$ & $7 \times 10^{-9}$ \\
\hline $\mathrm{Fe}, \mathrm{O}_{2}^{-} / \mathrm{HO}_{2}$ & $\mathrm{Fe}(\mathrm{II})$ & $1-5 \times 10^{7}$ & \\
$\left([\mathrm{Fe}]_{\mathrm{tot}}=0.1 \mathrm{nM}\right)$ & $\mathrm{Fe}(\mathrm{III})$ & $0.3-1.5 \times 10^{8}$ & $0.4-2 \times 10^{-9} \mathrm{~b}$ \\
\hline $\mathrm{Cu}, \mathrm{Fe}, \mathrm{O}_{2}^{-} / \mathrm{HO}_{2}$ & $\mathrm{Cu}(\mathrm{II})-\mathrm{org} \cdot{ }^{\mathrm{c}}$ & $1.6 \times 10^{7 \mathrm{c}}$ & $8 \times 10^{-11}$ \\
$\left([\mathrm{Cu}]_{\mathrm{tot}}=0.5 \mathrm{nM}\right)$ & $\mathrm{Cu}(\mathrm{I})-\mathrm{Cl}_{2}^{-}$ & $9 \times 10^{9}$ & \\
\hline
\end{tabular}

notes:

a Calculations were made with equation (7) from the text with a superoxide formation rate of $3 \times 10^{-12} \mathrm{M} \mathrm{s}^{-1}$. Measurements of superoxide flux by NO scavenging range from $2 \times 10^{-12} \mathrm{Ms}^{-1}$ in oligotrophic surface seawater to $1 \times 10^{-10} \mathrm{M} \mathrm{s}^{-1}$ in productive water (Micinski et al., 1993). Superoxide fluxes derived from multiplying hydrogen peroxide formation rates by two range from $3 \times 10^{-12} \mathrm{M} \mathrm{s}^{-1}$ to $3 \times 10^{-10} \mathrm{M} \mathrm{s}^{-1}$ in oligotrophic and productive waters, respectively (Moore et al., 1993).

$b$ Estimates are based upon the effective rate constants described in the text.

$c$ We assume $\mathrm{Cu}(\mathrm{II})$-organic complexes are as reactive as $\mathrm{Cu}(\mathrm{ArgH})_{2}{ }^{2+}$ (see Table 6.3). 
Table 6.3: The effect of complexation on relative rate constants for superoxide reactions with several different forms of $\mathrm{Cu}(\mathrm{I})$ and $\mathrm{Cu}(\mathrm{II})$.

\begin{tabular}{|c|c|}
\hline Cu-species & $\mathbf{k}_{\text {rel }}$ \\
\hline \multicolumn{2}{|l|}{$\mathrm{Cu}(\mathrm{I})$ species } \\
\hline $\mathrm{Cu}^{+}$ & 1 \\
\hline $\mathrm{CuCl}_{2}^{-}$ & $\approx 1 a$ \\
\hline \multicolumn{2}{|l|}{$\mathrm{Cu}(I I)$ species } \\
\hline $\mathrm{Cu}^{2+}$ & 1 \\
\hline $\mathrm{CuCO}_{3}$ & $\approx 1 a$ \\
\hline $\mathrm{Cu}(\mathrm{ArgH})_{2}{ }^{2+}$ & $0.002 a, b$ \\
\hline $\mathrm{CuArg}_{2} \mathrm{H}^{+}$ & $0.0001 b$ \\
\hline $\mathrm{Cu}\left(\mathrm{C}_{2} \mathrm{O}_{4}\right)_{2}{ }^{2-}$ & $0.2 a$ \\
\hline
\end{tabular}

notes:

a Rate constants relative to reactions with uncomplexed $\mathrm{Cu}(\mathrm{I})$ and $\mathrm{Cu}(\mathrm{II})$ determined in continuous radiolysis experiments in which \% $\mathrm{Cu}(\mathrm{I})$ was measured after steady-state was achieved. Absolute rate constants for reactions of $\mathrm{O}_{2}^{-}$with $\mathrm{Cu}^{+}$and $\mathrm{Cu}^{2+}$ are $9.4 \times 10^{9} \mathrm{M}^{-1} \mathrm{~s}^{-1}$ and $8 \times 10^{9} \mathrm{M}^{-1} \mathrm{~S}^{-1}$, respectively (Piechowski et al., 1993). For $\mathrm{HO}_{2}$ reactions, the rate constants for $\mathrm{Cu}^{+}$and $\mathrm{Cu}^{2+}$ are $1 \times 10^{9} \mathrm{M}^{-1} \mathrm{~s}^{-1}$ and $5 \times 10^{7} \mathrm{M}^{-1} \mathrm{~s}^{-1}$, respectively (Bielski et al., 1985).

b Cabelli et al. (1987). 
near or below our detection limit (i.e. $<5 \%$ of $[\mathrm{Cu}]_{\text {tot }}$ ). This is because the $\mathrm{Cu}(\mathrm{II})$-organo complexes react more slowly with $\mathrm{O}_{2}^{-}$than the inorganic complexes, as indicated for example by pulse radiolysis data (Cabelli et al., 1987) for $\mathrm{Cu}(\mathrm{II})$-arginine complexes.

Using the assumption that $\mathrm{Cu}(\mathrm{II})$ is present in seawater mainly as less reactive organic complexes (Moffett and Zika, 1987a) and that $\mathrm{Cu}(\mathrm{I})$ is present mainly as $\mathrm{Cu}(\mathrm{I}) \mathrm{Cl}_{2}^{-}$(Sharma and Millero, 1988) we estimate $\left[\mathrm{O}_{2}^{-}\right]_{\mathrm{ss}}$ in oligotrophic surface waters to be $8 \times 10^{-11} \mathrm{M}\left([\mathrm{Cu}]_{\text {tot }}=0.5 \mathrm{nM}\right.$ and $\left.[\mathrm{Fe}]_{\text {tot }}=0.1 \mathrm{nM}\right)$.

The rate constants for the reactions of other transition metals (i.e., Mn, Co, V) with superoxide under seawater conditions have not yet been determined, but available data (Bielski et al., 1985) suggest that unless these reactions are unexpectedly fast in seawater, they will have little effect on $\left[\mathrm{O}_{2}^{-}\right]_{\mathrm{Ss}}$ if iron and copper are also present. Comparison of our estimated $\left[\mathrm{O}_{2}^{-}\right]_{\mathrm{ss}}$ with Figure 6.3 indicates that $\mathrm{Fe}(\mathrm{II})$ will account for between 30 and $75 \%$ of the dissolved iron in sunlit surface seawater, independent of the initial oxidation state of the iron in the source material.

As a more direct test of our hypothesis that the low flux of superoxide in sunlit surface waters can result in the formation of significant concentrations of $\mathrm{Fe}$ (II) we conducted a series of experiments in a sample of seawater (acidified to $\mathrm{pH} 7.3$ to eliminate iron solubility problems) to which $5 \mathrm{nM}$ iron had been added (Figures 6.4 and 6.5). The \% $\mathrm{Fe}$ (II) reached a constant value of approximately $60 \%$ after 20 minutes of illumination, which is close to our predicted maximum value of $75 \%$. This value was observed regardless of whether iron was initially added as $\mathrm{Fe}[\mathrm{II}]$ ( symbols) or Fe[III] ( $由$ symbols) (Figure 6.4). The decrease in measured $\% \mathrm{Fe}(\mathrm{II})$ after 40 minutes of illumination in both experiments 
was due to oxidation of $\mathrm{Fe}(\mathrm{II})$ within the flow system, by $\mathrm{H}_{2} \mathrm{O}_{2}$ accumulated during the course of illumination. Although the $\mathrm{H}_{2} \mathrm{O}_{2}$ concentrations were not high enough to affect $\% \mathrm{Fe}(\mathrm{II})$ at the $\mathrm{O}_{2}^{-}$levels present in the illuminated samples, some oxidation of $\mathrm{Fe}$ (II) could have occurred during the 1.5 minutes in which the sample travelled through the unilluminated tubing of the flow system prior to analysis. The experiments were performed at $5^{\circ} \mathrm{C}$ to minimize this effect.

No measurable dark oxidation was observed when we added $\mathrm{Fe}$ (II) to solutions which had been pre-illuminated for 20 minutes (o symbols in Figure 6.4) confirming that the observed light-induced oxidation of $\mathrm{Fe}$ (II) was the result of reaction with a short-lived transient, such as superoxide, rather than the result of reactions with a more stable photoproduct, such as hydrogen peroxide. The addition of as much as $10 \mathrm{nM}$ of $\mathrm{Cu}(\mathrm{II})$ or $10 \mathrm{nM}$ of $\mathrm{Mn}(\mathrm{II})$ had little effect on either the kinetics of $\mathrm{Fe}$ (III) reduction or the steady-state \% $\mathrm{Fe}$ (II) (Figure 6.5), indicating that the $\mathrm{Cu}$ (II)-organic complexes were relatively unreactive with superoxide and that $\mathrm{Mn}$ reactions with superoxide were also slow.

\subsection{Discussion}

Our experiments demonstrate that reactions of dissolved iron with photoproduced superoxide radical can play a major role in the redox cycling of iron in sunlit surface waters. (Colloidal Fe(III) oxyhydroxides did not react with superoxide radical at appreciable rates.) In sunlit seawater containing oxygen and hydrogen peroxide, substantial steadystate concentrations of $\mathrm{Fe}$ (II) can be maintained by this process. Our results also suggest that iron oxidation states in seawater can be affected by the speciation of other trace metals. For example, photochemical ligand-to-metal charge transfer reactions of $\mathrm{Cu}(\mathrm{II})$-organo complexes could result in the production of $\mathrm{Cu}(\mathrm{I}) \mathrm{Cl}_{2}{ }^{-}$(Moffett and Zika, 1987a). 


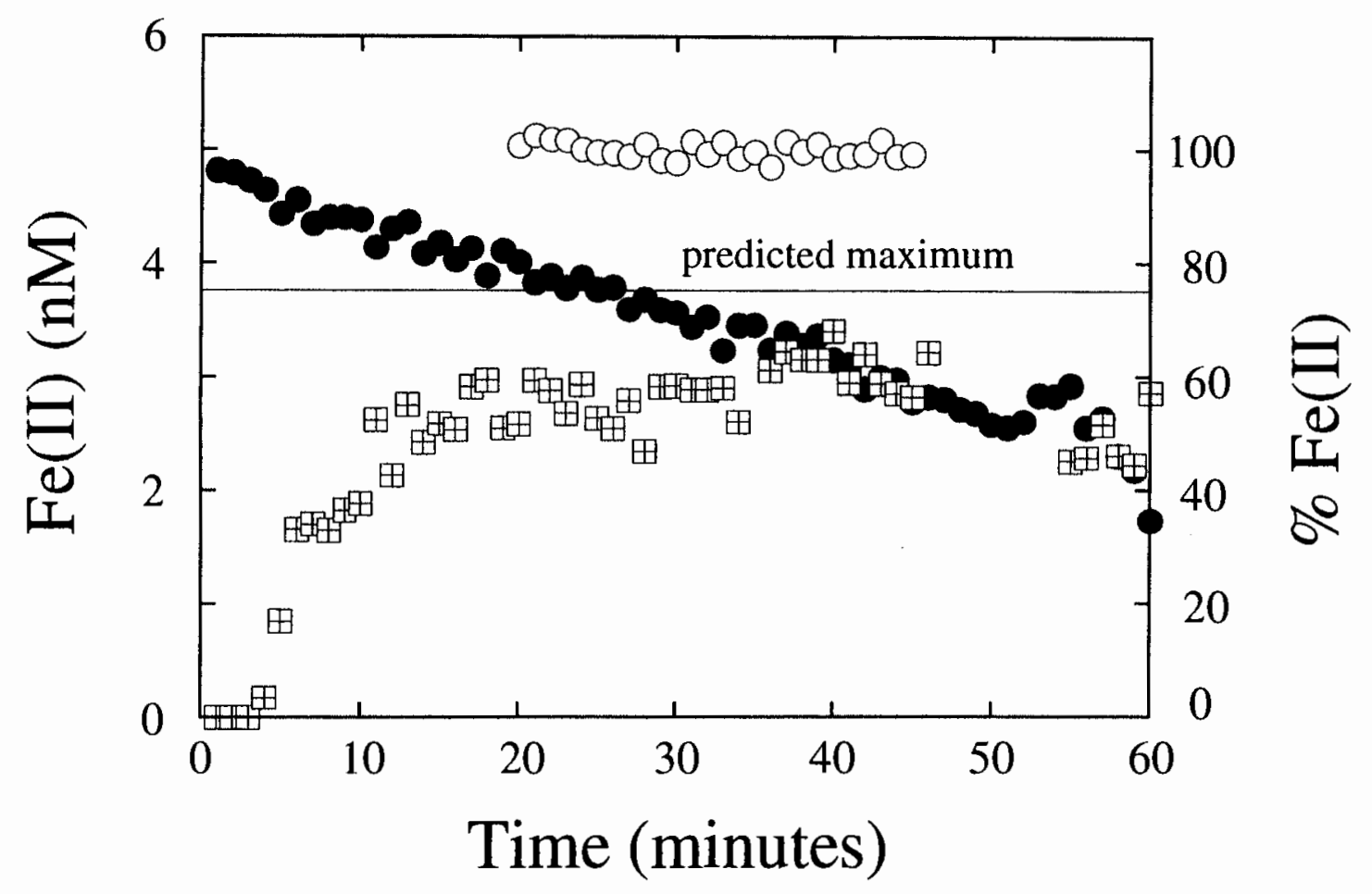

Figure 6.4. Concentrations of $\mathrm{Fe}(\mathrm{II})$ measured as a function of time during the exposure of a sample of seawater $\left(\mathrm{pH} 7.3,5^{\circ} \mathrm{C}\right)$ to simulated sunlight. The same steady-state $\mathrm{Fe}(\mathrm{II})$ concentration was observed regardless of whether the $5 \mathrm{nM}$ of iron was initially added as $\mathrm{Fe}(\mathrm{II})(\bullet)$ or $\mathrm{Fe}(I I I)$ ( $)$. In a seawater sample which was pre-illuminated for 20 minutes prior to the addition of $5 \mathrm{nM} \mathrm{Fe}(I I)$, no $\mathrm{Fe}(I I)$ oxidation in the dark was observed (o symbols). 


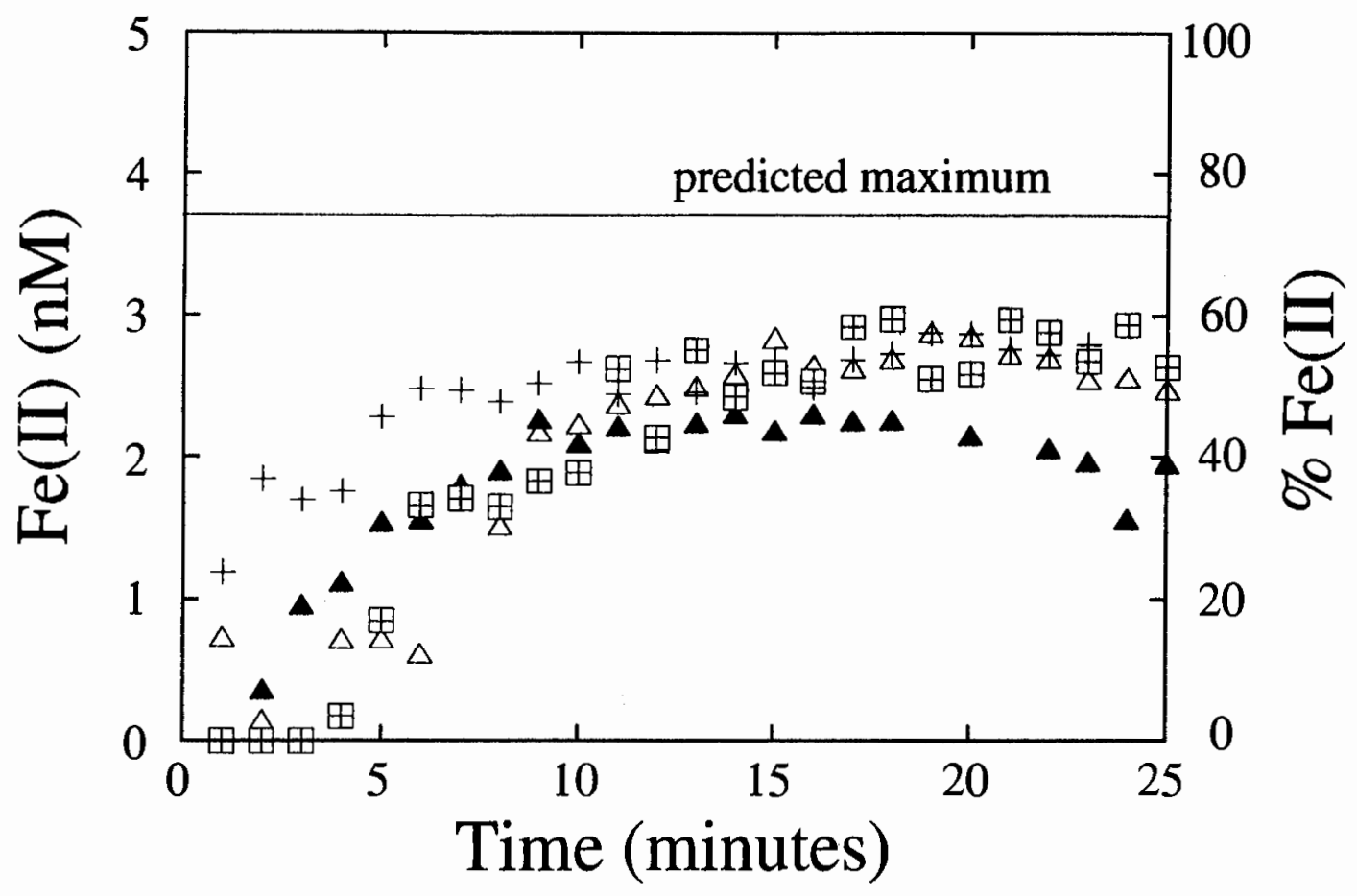

Figure 6.5. Concentrations of $F e(I I)$ measured as a function of time

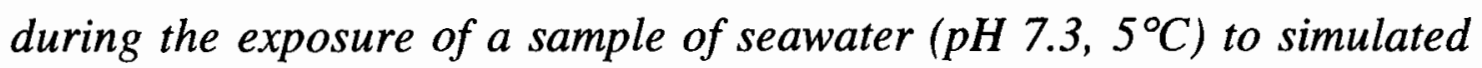
sunlight. This figure illustrates the effect of adding either copper $(\Delta=1 \mathrm{nM} ; \Delta=10 \mathrm{nM})$ or manganese $(+=10 \mathrm{nM})$ to seawater solutions along with $5 \mathrm{nM} \mathrm{Fe}(\mathrm{III})$. 田 symbols represent a solution containing no added metals besides Fe. 
The rapid reaction of $\mathrm{Cu}(\mathrm{I}) \mathrm{Cl}_{2}^{-}$with superoxide could then decrease $\left[\mathrm{O}_{2}^{-}\right]_{\mathrm{Ss}}$, leading to lower concentrations of $\mathrm{Fe}(\mathrm{II})$.

It has recently been suggested that dissolved iron may be present as Fe(III)-organic complexes in seawater (Rue and Bruland, 1994; Gledhill and van den Berg, 1994). At present, the structure and identity of the organic ligand are unknown, but previous experiments (Sedlak and Hoigné, 1993; Bielski et al., 1985) indicate that Fe(III)-organic complexes are generally less reactive with $\mathrm{O}_{2}^{-}$than inorganic $\mathrm{Fe}$ (III) complexes. In the case of organic complexation of $\mathrm{Fe}$ (III) in seawater, direct ligand-tometal charge transfer may play a more important role in the reduction of $\mathrm{Fe}$ (III), but superoxide should still be the dominant oxidant of $\mathrm{Fe}$ (II). 


\section{References}

Aiken, G.R., Brown, P.A., Noyes, T.I. and Pinckney, D.J., 1989. Molecular size and weight of fulvic and humic acids from the Suwannee River. In: Averett, R.C., Leenheer, J.A., McKnight, D.M. and Thorn, K.A. (Editors), Humic Substances in the Suwannee River, Georgia: Interactions, Properties, and Proposed Structures. U.S. Geological Survey Open File Report 87-557, Denver, CO, pp 163-178.

Bader, H., Sturzenegger, V. and Hoigné, J., 1988. Photometric method for the determination of low concentrations of hydrogen peroxide by the peroxidase catalyzed oxidation of $\mathrm{N}, \mathrm{N}$-diethy-p-phenylenediamine (DPD). Wat. Res., 22: 1109-1115.

Balzani, V., and Carassiti, V., 1970. Photochemistry of Coordination Compounds. Academic Press, London.

Barry, R.C., Schnoor, J.L., Sulzberger, B., Sigg, L. and Stumm, W., 1994. Iron oxidation kinetics in an acidic alpine lake. Wat. Res., 28: 323-333.

Behra, P. and Sigg, L., 1990. Evidence for redox cycling of iron in atmospheric water droplets. Nature, 357: 667-670.

Bielski, B.H.J., Cabelli, D.E., Arudi, R.L. and Ross, A.B., 1985. Reactivity of $\mathrm{O}_{2}^{-/} / \mathrm{HO}_{2}$ radicals in aqueous solution. J. Phys. Chem. Ref. Data, 14: 1041-1100.

Blough, N.V. and Zafiriou, O.C., 1985. Reaction of superoxide with nitric oxide to form peroxonitrite in alkaline aqueous solution. Inorg. Chem., 24: 3502-3504.

Blough, N.V. and Zepp, R.G., in press. Reactive oxygen species (ROS) in natural waters. In: Foote, C.S. and Valentine, J.S. (Editors), Reactive oxygen species in chemistry. Chapman and Hall.

Braun, W., Herron, J.T. and Kahaner, D.K., 1988. Acuchem: a computer program for modeling complex chemical reaction systems. Int. J. Chem. Kinetics, 20: 51-62. 
Cabelli, D.E., Bielski, B.H.J. and Holcman, J., 1987. Interaction between copper(II)-arginine complexes and $\mathrm{HO}_{2} / \mathrm{O}_{2}-$ radicals, a pulse radiolysis study. J. Am. Chem. Soc., 109: 3665-3669.

Choppin, G.R. and Clark, S.B., 1991. The kinetic interaction of metal ions with humic acids. Marine Chem., 36: 27-38.

Christensen, H. and Sehested, K., 1981. Pulse radiolysis at high temperatures and high pressures. Radiat. Phys. Chem., 18: 723-31.

Collienne, R.H., 1983. Photoreduction of iron in the epilimnion of acidic lakes. Limnol. Oceanogr. 28: 83-100.

Cooper, W.J. and Zika, R.G., 1983. Photochemical formation of hydrogen peroxide in surface and ground waters exposed to sunlight. Science, 220: 711-712.

Cooper, W.J., Zika, R.G., Petasne, R.G. and Plane, J.M.C., 1988. Photochemical formation of $\mathrm{H}_{2} \mathrm{O}_{2}$ in natural waters exposed to sunlight. Environ. Sci. Technol., 22: 1156-1160.

Cooper, W.J. and Lean, D.R.S., 1989. Hydrogen peroxide concentration in a northern lake: photochemical formation and diel variability. Environ. Sci. Technol. 23: 1425-1428.

Cooper, W.J., Zika, R.G., Petasne, R.G., and Fischer, A.M., 1989. Sunlight-induced photochemistry of humic substances in natural waters: major reactive species. In: Suffett, I.H. and MacCarthy, P. (Editors), Aquatic Humic Substances: Influence on Fate and Treatment of Pollutants. American Chemical Society, Washington, D.C., pp. 333-362.

Cunningham, K.M., Goldberg, M.C. and Weiner, E.R., 1988a. The aqueous photolysis of ethylene glycol adsorbed on goethite. Photochem. Photobiol., 41: 409-416.

Cunningham, K.M., Goldberg, M.C. and Weiner, E.R., 1988b. Mechanisms for aqueous photolysis of adsorbed benzoate, oxalate, and succinate on iron oxyhydroxide (goethite) surfaces. Environ. Sci. Technol., 22: 1090-1097. 
Davies, S.H.R. and Morgan, J.J., 1989. Manganese(II) oxidation kinetics on metal oxide surfaces. J. Coll. Interface Sci., 129: 63-77.

Davison, W., Heany, S.I., Talling, J.F. and Rigg, E., 1980. Seasonal transformations and movements of iron in a productive lake with deepwater anoxia. Schweiz. Z. Hydrol., 42: 196-224.

Deng, Y. and Stumm, W., 1994. Reactivity of aquatic iron(III) oxyhydroxides -- implications for redox cycling of iron in natural waters. Appl. Geochem., 9: 23-36.

Dorfman, L.M., Taub, I.A. and Bühler, R.E., 1962. Pulse radiolysis studies. I. Transient spectra and reaction-rate constants in irradiated aqueous solutions of benzene. J. Chem. Phys., 36: 3051-3061.

Dos Santos Afonso, M. and Stumm, W., 1992. Reductive dissolution of iron(III) (hydr)oxides by hydrogen sulfide. Langmuir, 8: 1671-1675.

Duce, R.A., 1986. The impact of atmospheric nitrogen, phosphorus and iron species on marine biological productivity. In: P. Buat-Menard (Editor), The role of air-sea exchange in geochemical cycling. Reidel, pp. 497-529.

Dzombak, D.A. and Morel, F.M.M., 1990. Surface complexation modeling: hydrous ferric oxide. Wiley, New York.

Erel, Y., Pehkonen, S.O. and Hoffmann, M.R., 1993. Redox chemistry of iron in fog and stratus clouds. J. Geophys. Res., 98: 423-434.

Faust, B.C. and Hoigné, J., 1990. Photolysis of Fe(III)-hydroxy complexes as sources of $\mathrm{OH}$ radicals in clouds, fog and rain. Atmos. Environ., 24A: 79-89.

Faust, B.C. and Zepp, R.G., 1993. Photochemistry of aqueous iron(III)polycarboxylate complexes: roles in the chemistry of atmospheric and surface waters. Environ. Sci. Technol., 27: 2517-2522. 
Fischer, W.R., 1988. Microbiological reactions of iron in soils. In: Stucki, J.W., Goodman, B.A. and Schwertmann, U. (Editors), Iron in Soils and Clay Minerals. D Reidel Publishing Company, Dordrecht, pp. 715-748.

Francko, D.A. and Heath, R.T., 1982. UV-sensitive complex phosphorus: association with dissolved humic material and iron in a bog lake. Limnol. Oceanogr. 27: 564-569.

Gledhill, M. and van den Berg, C.M.G., 1994. Determination of complexation of iron(III) with natural organic ligands in seawater using cathodic stripping voltammetry. Mar. Chem., in press.

Goldberg, M.C., Cunningham, K.M. and Weiner, E.R., 1993. Aquatic photolysis: photolytic redox reactions between goethite and adsorbed organic acids in aqueous solutions. J. Photochem. Photobiol. A: Chem., 73: $105-120$.

Hatchard, C.G., and Parker, A.C., 1956. A new sensitive chemical actinometer. II. Potassium ferrioxalate as a standard chemical actinometer. Proc. Roy. Soc. Lon. Ser. A, 235: 518-536.

Hering, J., and Stumm, W., 1990. Oxidative and reductive dissolution of minerals. In: Hochella, M.F. and White, A.F. (Editors), Reviews in Mineralogy 23: Mineral-Water Interface Geochemistry, Mineralogical Society of America, pp. 427-465.

Hering, J., and Stumm, W., 1991. Fluorescence spectroscopic evidence for surface complex formation at the mineral-water interface: elucidation of the mechanism of ligand-promoted dissolution. Langmuir 7: 15671570 .

Hoigné, J., 1975. Aqueous radiation chemistry in relation to waste treatment: an introductory overview. In: Radiation for a Clean Environment. International Atomic Energy Agency, Vienna, pp. 219232. 
Hoigné, J., Faust, B.C., Haag, W.R., Scully, F.E. and Zepp, R.G., 1989. Aquatic humic substances as sources and sinks of photochemically produced transient reactants. In: Suffett, I.H. and MacCarthy, P. (Editors), Aquatic Humic Substances: Influence on Fate and Treatment of Pollutants. American Chemical Society, Washington, D.C., pp. 363-381.

Hong, H. and Kester, D.R., 1986. Redox state of iron in the offshore waters of Peru. Limnol. oceanogr. 31: 512-524.

Johnson, K.S., Coale, K.H., Elrod, V.A., and Tindale, N.W., 1994. Iron photochemistry in waters from the equatorial Pacific. Mar. Chem., in press.

Jones, G.J. and Morel, F.M.M., 1988. Plasmalemma redox activity in the diatom Thallassiosira. Plant Physiol. 87: 143-147.

Kari, F.G., 1994. Umweltverhalten von Ethylendiamintetraaceetat (EDTA) unter spezieller Berücksichtigung des photochemischen Abbaus. $\mathrm{Ph}$. D. Dissertation no. 10698, Eidgenössische Technische Hochschule, Zürich, Switzerland.

King, D.W., Aldrich, R.A. and Charnecki, S.E., 1993. Photochemical redox cycling of iron in $\mathrm{NaCl}$ solutions. Mar. Chem., 44: 105-120.

King, D.W., Lounsbury, H.A. and Millero, F.J., 1994. Rates and mechanism of $\mathrm{Fe}(\mathrm{II})$ oxidation at nanomolar total iron concentrations. Environ. Sci. Technol., in press.

Klopf, L.L. and Nieman, T.A., 1983. Effect of iron(II), cobalt(II), copper(II) and manganese(II) on the chemiluminescence of luminol in the absence of hydrogen peroxide. Anal. Chem. 55: 1080-1083.

Langford, C.H., Kay, R., Quance, G.W. and Khan, T.R., 1977. Kinetic analysis applied to iron in a natural water model containing ions, organic complexes, colloids, and particles. Anal. Letters, 10:1249-1260.

Leenheer, J.A., 1981. Comprehensive approach to preparative isolation and fractionation of dissolved organic carbon from natural waters and wastewaters. Environ. Sci. Technol., 15: 578-587. 
Leifer, A., 1988. The kinetics of environmental aquatic photochemistry: theory and practice. American Chemical Society, Washington, D.C.

Liang, L., McNabb, J.A., Paulk, J.M., Gu, B. and McCarthy, J.F., 1993. Kinetics of iron(II) oxygenation at low partial pressure of oxygen in the presence of natural organic matter. Environ. Sci. Technol., 27: 18641872.

Martin, J.H. et al., 1994. Testing the iron hypothesis in ecosystems of the equatorial Pacific Ocean. Nature, 371: 123-130.

McKnight, D.M., Kimball, B.A. and Bencala, K.E., 1988. Iron photoreduction and oxidation in an acidic mountain stream. Science, 240: 637-640.

Micinski, E., Ball, L.A. and Zafiriou, O.C., 1993. Photochemical oxygen activation: superoxide radical detection and production rates in the Eastern Carribean. J. Geophys. Res., 98(C2): 2299-2306.

Miles, C.J. and Brezonik, P.L., 1981. Oxygen consumption in humiccolored waters by a photochemical ferrous-ferric catalytic cycle. Environ. Sci. Technol., 15: 1089-1095.

Millero, F.J., Sotolongo, S. and Izaguirre, M., 1987. The kinetics of oxidation of $\mathrm{Fe}(\mathrm{II})$ in seawater. Geochim. Cosmochim. Acta, 51: 793801.

Millero, F.J. and Izaguirre, M., 1989. Effect of ionic strength and ionic interactions on the oxidation of Fe(II). J. Solution Chem., 18: 585-599.

Millero, F.J., and Sotolongo, S., 1989. The oxidation of Fe(II) with $\mathrm{H}_{2} \mathrm{O}_{2}$ in seawater. Geochim. Cosmochim. Acta, 53: 1867-1873.

Millero, F.J., Sotolongo, S., Stade, D.J., and Vega, C.A., 1991. Effect of ionic interactions on the oxidation of $\mathrm{Fe}(\mathrm{II})$ with $\mathrm{H}_{2} \mathrm{O}_{2}$ in aqueous solutions. J. Solution Chem., 20: 1079-1092. 
Moffett, J.W. and Zika, R.G., 1987a. Photochemistry of copper complexes in sea water. In: R.G. Zika and W.J. Cooper (Editors), Photochemistry of Environmental Aquatic Systems. ACS Symposium Series, Washington, D.C., pp. 116-130.

Moffett, J.W. and Zika, R.G., 1987b. Reaction kinetics of hydrogen peroxide with copper and iron in seawater. Environ. Sci. Technol., 21: 804-810.

Moore, C.A., Farmer, C.T. and Zika, R.G., 1993. Influence of the Orinoco River on hydrogen peroxide distribution and production rates in the Eastern Carribean. J. Geophys. Res., 98(C2): 2289-2298.

Mopper, K. and Zhou, X., 1990. Hydroxyl radical photoproduction in the sea and its potential impact on marine processes. Science, 250: 661664.

Mopper, K., Zhou, X., Kieber, R.J. et al., 1991. Photochemical degradation of dissolved organic carbon and its impact on the oceanic carbon cycle. Nature, 353: 60-62.

Morel, F.M.M. and Hering, J.G., 1993 Principles and Applications of Aquatic Chemistry. Wiley, New York.

Moss, M.L. and Mellon, M.G., 1942. Colorimetric determination of iron with 2,2'-Bipyridyl and with 2,2,'2"-Terpyridyl. Industrial and Engineering Chem. (Anal. Ed.) 14: 862-865.

Mulazzani, Q.G., D'Angelantonio, M., Venturi, M., Hoffman, M.Z. and Rodgers, M.A., 1986. Interaction of formate and oxalate ions with radiation-generated radicals in aqueous solution. Methylviologen as a mechanistic probe. J. Phys. Chem. 90: 5347-5352.

O'Sullivan, D.W., Hanson, A.K., Miller, W.L. and Kester, D.R., 1991. Measurement of $\mathrm{Fe}(\mathrm{II})$ in surface water of the equatorial Pacific. Limnol. Oceanogr., 36: 1727-1741.

O'Sullivan, D.W., Hanson, A.K. and Kester, D.R., 1994. Stopped flow luminol chemiluminescence determination of $\mathrm{Fe}(\mathrm{II})$ and reducible iron in seawater at subnanomolar levels. Marine Chem., submitted. 
Palenik, B., Zafiriou, O.C. and Morel, F.M.M., 1987. Hydrogen peroxide production by a marine phytoplankter. Limnol. Oceanogr. 32: $1365-1369$.

Pehkonen, S.O., Siefert, R., Erel, Y., Webb, S. and Hoffmann, M.R., 1993. Photoreduction of iron oxyhydroxides in the presence of important atmospheric compounds. Environ. Sci. Technol., 27: 20562062.

Petasne, R.G. and Zika, R.G., 1987. Fate of superoxide in coastal seawater. Nature, 325: 516-518.

Piechowski, M. von, Nauser, T., Hoigné, J. and Bühler, R., 1993. O2decay catalyzed by $\mathrm{Cu}^{2+}$ and $\mathrm{Cu}^{+}$ions in aqueous solutions: a pulse radiolysis study for atmospheric chemistry. Ber. Bunsenges. Phys. Chem., 6: 762-771.

Powell, P.E., Cline, G.R., Reid, C.P.P. and Szanizlo, P.J., 1980. Occurrence of hydroxamate siderophore iron chelators in soils. Nature, 287: 833 .

Price, N.M. and Maldonado, M.T:, 1994. Iron acquisition ny marine diatoms consuming different nitrogen substrates. Abstract presented at Workshop on Iron Speciation and its Availability to Phytoplankton in Seawater, Bermuda Biological Station, May 1-5, 1994.

Rich, H.W., and Morel, F.M.M., 1990. Availability of well-defined iron colloids to the marine diatom Thalassiosira weissflogii. Limnol. oceanogr. 35: 652-662.

Rue, E.L. and Bruland, K.W., 1994. Complexation of iron(III) by natural organic ligands in central North Pacific as determined by competitive equilibration/adsorptive cathodic stripping voltammetry. Abstract presented at Workshop on Iron Speciation and its Availability to Phytoplankton in Seawater, Bermuda Biological Station, May 1-5, 1994.

Rueter, J.G., 1988. Iron stimulation of photosynthesis and nitrogen fixation in Anabaena 7120 and Trichodesmium (Cyanophyceae). J. Phycol., 23: 452-457. 
Rush, J.D. and Bielski, B.H.J., 1985. Pulse radiolysis studies of the reactions of $\mathrm{HO}_{2} / \mathrm{O}_{2}$ - with ferric ions and its implication on the occurence of the Haber-Weiss reaction. J. Phys. Chem., 89: 5062-5066.

Rush, J.D., Maskos, Z. and Koppenol, W.H.,1990. Distinction between hydroxyl radical and ferryl species. Methods Enzymol. 186: 148-156.

Schindler, P.W. and Stumm, W., 1987. The surface chemistry of oxides, hydroxides, and oxide minerals. In: Stumm, W. (editor), Aquatic Surface Chemistry, John Wiley and Sons, New York, pp. 83-110.

Schneider, W. and Schwyn, B., 1987. The hydrolysis of iron in synthetic, biological, and aquatic media. In: W. Stumm (Editor), Aquatic surface chemistry, Wiley, New York, pp. 167-194.

Schnitzer, M. and Khan, S.U., 1972. Humic substances in the environment. Marcel Dekker, New York.

Schwarzenbach, R.P., Stierli, R., Lanz, K. and Zeyer, J., 1990. Quinone and iron porphyrin mediated reduction of nitroaromatic components in homogeneous aqueous solution. Environ. Sci. Technol., 24: 1566-1574.

Schwertmann, U. and Cornell, R.M., 1991. Iron oxides in the laboratory: preparation and characterization. VCH Publishers, Inc., New York.

Sedlak, D.L. and Hoigné, J., 1993. The role of copper and oxalate in the redox cycling of iron in atmospheric waters. Atmos. Environ., 27A: 2173-2185.

Sedlak, D.L. and Hoigné, J., 1994. The oxidation of S(IV) in atmospheric waters by photooxidants and iron in the presence of copper. Environ. Sci. Tech., in press.

Seitz, W.R. and Hercules, D.M., 1972. Determination of trace amounts of iron(II) using chemiluminescence analysis. Anal. Chem., 44: 21432149. 
Sharma, V.K., and Millero, F.J., 1988. Oxidation of copper(I) in seawater. Environ. Sci. Technol., 22: 768-771.

Sholkovitz, E.R., 1976. Flocculation of dissolved organic and inorganic matter during the mixing of river watr and seawater. Geochim. Cosmochim. Acta, 40: 831-845.

Siffert, C. and Sulzberger, B., 1991. Light-induced dissolution of hematite in the presence of oxalate: a case study. Langmuir, 7: 16271634.

Sigg, L. and Stumm, W., 1980. The interaction of anions and weak acids with the hydrous goethite surface. Colloids and Surfaces, 2: 101-110.

Sigg, L., 1985. Metal transfer mechanisms in lakes; the role of settling particles. In Stumm, W. (Editor), Chemical Processes in Lakes. Wiley Interscience, New York.

Sigleo, A.C., Cunningham, K.M., Goldberg, M.C. and Kimball, B.A., 1988. Hydroxyl radical formation in St. Kevin Gulch, an iron-rich stream in Colorado. In: G.E. Mallard and Ragone, S.E. (Editors), U.S. Geological Survey Toxic Substances Hydrology Program -- Proceedings of the Technical Meeting, Phoenix, Arizona, September 26-30, 1988. U.S. Geological Survey Water-Resources Investigations Report 88-4220, Denver, CO, pp.125-129.

Skogerboe, R.K. and Wilson, S.A., 1981. Reduction of ionic species by fulvic acid. Anal. Chem., 53:228-232.

Skoog and West, 1969. Fundamentals of Analytical Chemistry 2nd ed. Holt International, London.

Staehelin, J. Ozonzerfall in Wasser: Kinetik der Initiierung durch $\mathrm{OH}^{-}-$ Ionen und $\mathrm{H}_{2} \mathrm{O}_{2}$ sowie der Folgereaktionen der $\mathrm{OH} \cdot$-und $\cdot \mathrm{O}_{2}$--Radikale. $\mathrm{Ph}$. D. Dissertation no. 7342, Eidgenössische Technische Hochschule, Zürich, Switzerland.

Stookey, L.L., 1970. Ferrozine - a new spectrophotometric reagent for iron. Anal. Chem., 42: 779-781.

Stumm, W., 1992. Chemistry of the solid-water interface: processesat the mineral-water and particle-water interface in natural systems. Wiley, New York. 
Sturzenegger, V.T., 1989. Wasserstoffperoxid in Oberflächengewässern: Photochemische Produktion und Abbau. Ph. D. Dissertation no. 9004, Eidgenössische Technische Hochschule, Zürich, Switzerland.

Sulzberger, B., Schnoor, J., Giovanoli, R., Hering, J.G. and Zobrist, J., 1990. Biogeochemistry of iron in an acidic lake. Aquatic Sci., 52: 5674.

Sulzberger, B. and Laubscher, H.U., 1995. Photochemical reductive dissolution of lepidocrocite: the effect of pH. In: Huang, C.P., O'Melia, C.R. , and Morgan, J.J. (Editors), Aquatic Chemistry: Interfacial and Interspecies Processes, Advanced in Chemistry Series No. 244, American Chemical Society, Washington, DC., in press.

Sulzberger, B. and Laubscher, H.U., 1995. Reactivity of various types of iron(III) (hydr)oxides towards light-induced reductive dissolution. Mar. Chem., submitted.

Sunda, W.G. and Kieber, D.J., 1994. Oxidation of humic substances by manganese oxides yields low-molecular-weight organic substrates. Nature, 367: 62-64.

Szilàgyi, M., 1971. Reduction of $\mathrm{Fe}^{3+}$ ion by humic acid preparations. Soil Science, 111: 233-235.

Szymczak, R. and Waite, T.D., 1988. Generation and decay of hydrogen peroxide in estuarine waters. Aust. J. Mar. Freshwater Res., 39: 289299.

Tamura, H., Goto, K. and Nagayama, M., 1976. The effect of ferric hydroxide on the oxygenation of ferrous ions in neutral solutions. Corrosion Sci., 16: 197-207.

Theis, T.L. and Singer, P., 1974. Complexation of iron(II) by organic matter and its effect on iron(II) oxygenation. Environ. Sci. Technol., 8: 569-573.

Thornton, A.T. and Laurence, G.S., 1973. Kinetics of oxidation of transition-metal ions by halogen radical anions. Part I. The oxidation of iron(II) by dibromide and dichloride ions generated by flash photolysis. J. Chem. Soc. Dalton Trans., pp. 804-813.

Tipping, E., 1981. The adsoprtion of aquatic humic substances by iron oxides. Geochim. Cosmochim. Acta, 45: 191-199. 
Turner, D.R., Whitfield, M. and Dickson, A.G., 1981. The equilibrium speciation of dissolved components in freshwater and seawater at $25^{\circ} \mathrm{C}$ and 1 atm pressure. Geochim. Cosmochim. Acta, 45: 855-881.

Waite, T.D. and Morel, F.M.M., 1984a. Coulometric study of the redox dynamics of iron in seawater. Anal. Chem., 56: 787-792.

Waite, T.D. and Morel, F.M.M., 1984b. Photoreductive dissolution of colloidal iron oxide: effect of citrate. J. Coll. Interface Sci., 102:121137.

Waite, T.D. and Morel, F.M.M., 1984c. Photoreductive dissolution of colloidal iron oxides in natural waters. Environ. Sci. Technol., 18: 860868.

Waite, T.D., 1990. Photo-redox processes at the mineral-water interface. In: Hochella, M.F. and White, A.F. (Editors), Reviews in Mineralogy 23: Mineral-Water Interface Geochemistry, Mineralogical Society of America, pp. 559-603.

Wehrli, B., 1990. Redox reactions of metal ions at mineral surfaces. In: W. Stumm (Editor), Aquatic Chemical Kinetics. Wiley, New York, pp. 311-336.

Weinstein-Lloyd, J. and Schwartz, S.E., 1991. Low-intensity radilysis study of free-radical reactions in cloudwater: $\mathrm{H}_{2} \mathrm{O}_{2}$ production and destruction. Environ. Sci. Technol., 25: 791-800.

Wells, M.L. and Mayer, L.M., 1991. The photoconversion of colloidal iron oxyhydroxides in seawater. Deep-Sea Res., 38: 1379-1395.

Westall, J.C., Zachary, J.L. and Morel, F.M.M., 1976. Mineql: a computer program for the calculation of chemical equilibrium composition of aqueous systems. R. M. Parsons Laboratory Technical Note No. 18. Massachusetts Institute of Technology, Cambridge, USA.

Wieland, W., Wehrli, B. and Stumm, W., 1988. The coordination chemistry of weathering: III. A generalization of the dissolution rates of minerals. Geochim. Cosmochim. Acta, 52: 1969-1981.

Wu, J. and Luther, G.W., 1994. Size-fractionated iron concentrations in the water column of the northwest Atlantic Ocean. Limnol. Oceanogr., 39: 1119-1129. 
Zafiriou, O.C., 1990. Chemistry of superoxide ion-radical $\left(\mathrm{O}_{2}^{-}\right)$in seawater. I. $\mathrm{pK}^{*}$ asw $(\mathrm{HOO})$ and uncatalyzed dismutation kinetics studied by pulse radiolysis. Mar. Chem., 30: 31-43.

Zepp, R.G., Faust, B.C. and Hoigné, J., 1992. Hydroxyl radical formation in aqueous reactions (pH 3-8) of iron(II) with hydrogen peroxide: the photo-Fenton reaction. Environ. Sci. Technol., 26: 313319.

Zhu, X., Prospero, J.M., Savoie, D.L., Millero, F.J., Zika, R.G. and Saltzmann, E.S., 1993. Photoreduction of iron(III) in marine mineral aerosol solutions. J. Geophys. Res., 98: 9039-9046.

Zhuang, G., Yi, Z., Duce, R.A. and Brown, P.R., 1992. Link between iron and sulfur suggested by the detection of $\mathrm{Fe}(\mathrm{II})$ in remote marine aerosols. Nature, 355: 537-539.

Zuo, Y. and Hoigné, J., 1992. Formation of hydrogen peroxide and depletion of oxalic acid in atmospheric water by photolysis of iron(III)oxalato complexes. Environ. Sci. Technol., 26: 1014-1022. 


\section{Curriculum vitae}

Born in Gehrden, Germany

1973-1977 Grundschule Gehrden, Germany

1977-1979 Ferry Elementary School, Grosse Pointe Woods, Michigan, USA

1979-1981 Ft. Couch Middle School, Upper St. Clair, Pennsylvania, USA

1981-1984 Upper St. Clair High School, Pennsylvania, USA

1984-1986 Massachusetts Institute of Technology, Cambridge, Massachusetts, USA

1986-1987 Universität Konstanz, Germany

1987-1990 Massachusetts Institute of Technology

1989 Completion of Bachelor of Science

Department of Chemistry, MIT

1990 Completion of Master of Science

Department of Civil and Environmental Engineering, MIT

Master's Thesis: An electrostatic model of the metal-binding properties of humic substances

1990-1994 Dissertation at the Swiss Federal Institute for Environmental Science and Technology (EAWAG), Dübendorf, Switzerland 